\title{
Extração de informações de narrativas clínicas
}

\author{
Michel Oleynik \\ DisSERTAÇÃO APRESENTADA \\ $\mathrm{AO}$ \\ Instituto De Matemática e Estatística \\ DA \\ UNIVERSIDADE DE SÃo PAUlo \\ PARA \\ OBTENÇÃO DO TÍTULO \\ $\mathrm{DE}$ \\ Mestre em CiÊNCIAS
}

Programa: Ciência da Computação

Orientador: Prof. Dr. Marcelo Finger

Durante o desenvolvimento deste trabalho o autor recebeu auxílio financeiro do CNPq.

São Paulo, novembro de 2013 


\section{Extração de informações de narrativas clínicas}

Esta versão da dissertação contém as correções e alterações sugeridas pela Comissão Julgadora durante a defesa da versão original do trabalho, realizada em 02/10/2013. Uma cópia da versão original está disponível no

Instituto de Matemática e Estatística da Universidade de São Paulo.

Comissão Julgadora:

- Prof. Dr. Marcelo Finger (orientador) - IME-USP

- Prof. Dr. Alair Pereira do Lago - IME-USP

- Prof. Dr. Stefan Paul Schulz - IMISD 


\section{Agradecimentos}

A realização dessa pesquisa não teria sido possível sem a contribuição direta e indireta de várias pessoas, a quem dedico aqui meus agradecimentos.

Em primeiro lugar, agradeço ao meu orientador Marcelo Finger pelas lições aprendidas durante essa caminhada. Aos colegas do IME-USP, Carlos Eduardo Dantas de Menezes, Wesley Seidel Carvalho e William Daniel Colen de Moura Silva, pelas diversas conversas profissionais e pessoais.

Do mesmo modo, agradeço aos colegas do CIPE, Aline Santos Damascena, Diogo Ferreira da Costa Patrão, Fabio Filocomo, Fábio Rampazzo Mathias, Felipe Massicano, Guilherme de Oliveira Martins Bastos, Leandro Lima, Luiz Paulo Camargo, Marcelo Sagayama, Renan Valieris Bueno de Almeida, Renato David Puga e Ricardo Moura Sekeff Budaruiche, por manterem um ambiente de trabalho tão agradável e produtivo.

Em especial, agradeço ao Diogo Patrão por abrir tantas portas.

Agradeço ao CNPq pelo financiamento da pesquisa. Ao A.C. Camargo Cancer Center e à Universidade de São Paulo pela disponibilidade de dados e infraestrutura para processá-los.

Ao Emiro Khury e à Elisabete Furtado Brognolo Khury pela casa e coração sempre abertos. À Silvia Maria Santos Alarcón, pela energia sempre presente.

À Thisby Alarcón Khury, pela paciência, apoio e carinho em tantos momentos. Obrigado por ser como você é.

Agradeço aos meus pais, Maria Ester Helpa Oleynik e João Oleynik, por todo o apoio e amor incondicional em todos esses anos de vida. Ao meu irmão, Leonardo Oleynik, por acreditar nessa caminhada.

A Deus, por estar sempre perto. 


\section{Resumo}

OLEYNIK, Michel. Extração de informações de narrativas clínicas. 2013. 58 p. Dissertação (Mestrado) - Instituto de Matemática e Estatística, Universidade de São Paulo, São Paulo, 2013.

Narrativas clínicas são normalmente escritas em linguagem natural devido a seu poder descritivo e facilidade de comunicação entre os especialistas. Processar esses dados para fins de descoberta de conhecimento e coleta de estatísticas exige técnicas de extração de informações, com alguns resultados já apresentados na literatura para o domínio jornalístico, mas ainda raras no domínio médico. O presente trabalho visa desenvolver um classificador de laudos de anatomia patológica que seja capaz de inferir a topografia e a morfologia de um câncer na Classificação Internacional de Doenças para Oncologia (CID-O). Dados fornecidos pelo A.C. Camargo Cancer Center em São Paulo foram utilizados para treinamento e validação. Técnicas de processamento de linguagem natural (PLN) aliadas a classificadores bayesianos foram exploradas na busca de qualidade da recuperação da informação, avaliada por meio da medida- $F_{2}$. Valores acima de $74 \%$ para o grupo topográfico e de $61 \%$ para o grupo morfológico são relatados, com pequena contribuição das técnicas de PLN e suavização. Os resultados corroboram trabalhos similares e demonstram a necessidade de retreinamento das ferramentas de PLN no domínio médico.

Palavras-chave: classificação de texto, processamento de linguagem natural, laudos de anatomia patológica. 


\section{Abstract}

OLEYNIK, Michel. Clinical reports information retrieval. 2013. 58 p. Dissertação (Mestrado) - Instituto de Matemática e Estatística, Universidade de São Paulo, São Paulo, 2013.

Clinical reports are usually written in natural language due to its descriptive power and ease of communication among specialists. Processing data for knowledge discovery and statistical analysis requires information retrieval techniques, already established for newswire texts, but still rare in the medical subdomain. The present work aims at developing an automated classifier of pathology reports, which should be able to infer the topography and the morphology classes of a cancer using codes of the International Classification of Diseases for Oncology (ICD-O). Data provided by the A.C. Camargo Cancer Center located in Sao Paulo was used for training and validation. Techniques of natural language processing (NLP) and Bayes classifiers were used in search for information retrieval quality, evaluated by $F_{2}$-score. Measures upper than $74 \%$ in the topographic group and $61 \%$ in the morphologic group are reported, with small contribution from NLP or smoothing techniques. The results agree with similar studies and show that a retraining of NLP tools in the medical domain is necessary.

Keywords: text classification, natural language processing, pathology reports. 


\section{Sumário}

$\begin{array}{ll}\text { Lista de Abreviaturas } & \text { ix }\end{array}$

Lista de Figuras

Lista de Tabelas $\quad$ xiii

1 Introdução $\quad 1$

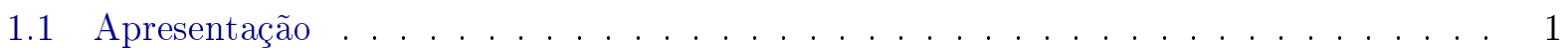

1.2 Motivação . . . . . . . . . . . . . . . . . . . . . 2

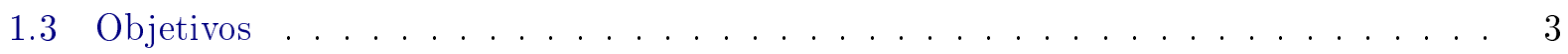

1.3 .1 Objetivo Geral . . . . . . . . . . . . . . . . 3

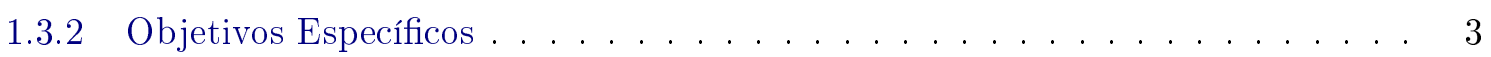

1.4 Organização do Trabalho . . . . . . . . . . . . . . . . . . 3

1.5 Aspectos Legais . . . . . . . . . . . . . . . . . . . . . . . . . 4

2 Fundamentação Teórica $\quad 5$

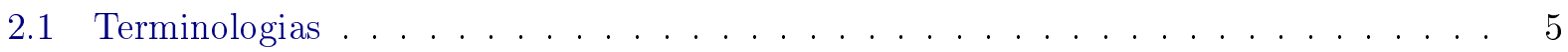

2.1 .1 Classificação Internacional de Doenças . . . . . . . . . . . . . . . . . 5

2.1.2 Classificação Internacional de Doenças para Oncologia . . . . . . . . . . . . 6

2.2 Classificadores . . . . . . . . . . . . . . . . . . 8

2.2 .1 Baseado em Regras . . . . . . . . . . . . . . . . . . . 8

2.2.2 Aprendizagem Automática . . . . . . . . . . . . . . . . . . 9

2.2 .3 Classificador Bayesiano . . . . . . . . . . . . . . . . . . . . 10

2.3 Processamento de Linguagem Natural . . . . . . . . . . . . . . . . . . . . . . . . . . . . . . . . . . . . . . . . . . .

2.3 .1 Morfologia . . . . . . . . . . . . . . . . . . 13

2.3 .2 Lexicografia . . . . . . . . . . . . . . . . . . . . . . . . . . . . . . . . . . . 15

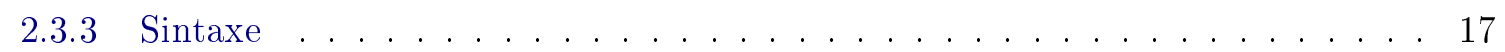

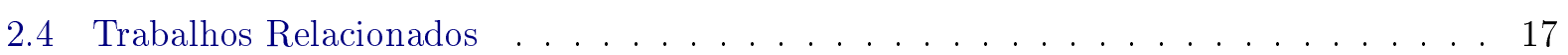

3 Materiais e Métodos $\quad 21$

3.1 Caracterização do Domínio . . . . . . . . . . . . . . . . . . . 21

3.1 .1 Laudos de Anatomia Patológica . . . . . . . . . . . . . . . . . . 22

3.1 .2 Registro Hospitalar de Câncer . . . . . . . . . . . . . . . . . . 23

3.2 Medidas de Avaliação . . . . . . . . . . . . . . . . . . . . 23

3.2.1 Acurácia, Precisão e Cobertura ～. . . . . . . . . . . . . . . 23

3.2 .2 Medida-F . . . . . . . . . . . . . . . 25 
3.2 .3 Validação Cruzada . . . . . . . . . . . . . . . . . . . . . 25

3.2 .4 Média micro e macro . . . . . . . . . . . . . . . . . . . 26

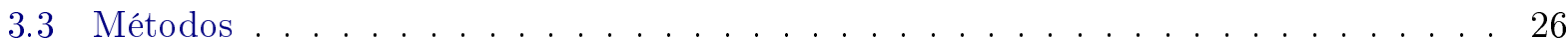

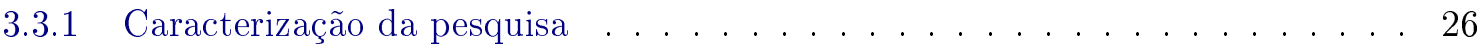

3.3 .2 Procedimentos . . . . . . . . . . . . . . . . . . . 26

3.4 Aspectos Tecnológicos . . . . . . . . . . . . . . . . . . . . . 27

4 Resultados $\quad 29$

4.1 Análise dos Dados . . . . . . . . . . . . . . . . . . . . . 29

4.1 .1 Distribuição dos dados . . . . . . . . . . . . . . . . . . . . . 29

4.2 Classificador basal . . . . . . . . . . . . . . . . . . . . . . 30

4.2 .1 Limite inferior . . . . . . . . . . . . . . . . . . . 30

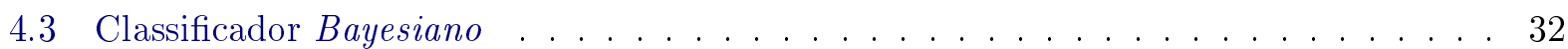

4.3 .1 Resultados iniciais . . . . . . . . . . . . . . . . . . . 32

4.3.2 Tamanho da base de treinamento . . . . . . . . . . . . . . . . . 33

4.3 .3 Tamanho do vocabulário . . . . . . . . . . . . . . . . . 36

4.3.4 Número mínimo de laudos por paciente . . . . . . . . . . . . . . . . 37

4.3.5 Poder discriminante dos tokens . . . . . . . . . . . . . . . . 38

4.3.6 Eficiência por classe . . . . . . . . . . . . . . . . . . . . 39

4.3 .7 Resultados finais . . . . . . . . . . . . . . . . . . . . 40

4.4 Técnicas de Suavização . . . . . . . . . . . . . . . . . . . . . . . 41

4.4 .1 Suavização de Laplace . . . . . . . . . . . . . . . . . . . . . . . . . . . 41

$4.4 .2 \quad A d d-\alpha \ldots \ldots \ldots \ldots \ldots \ldots \ldots \ldots \ldots$

4.4 .3 Good-Turing . . . . . . . . . . . . . . . . . . 41

4.4 .4 Resultados finais . . . . . . . . . . . . . . . . . . . . . . 42

4.5 Processamento de Linguagem Natural _ . . . . . . . . . . . . . . . . . . . . 42

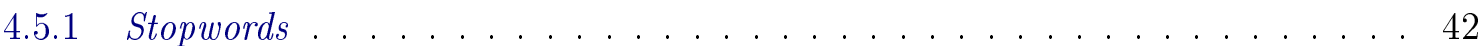

4.5.2 Detecção de sentenças e itemização . . . . . . . . . . . . . . . . . . 44

4.5.3 Detecção de radicais . . . . . . . . . . . . . . . . . . . . . . 44

4.5 .4 Deteç̧ão de segmentos . . . . . . . . . . . . . . . . . . . 46

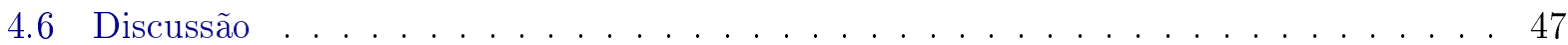

5 Conclusões $\quad 49$

5.1 Considerações Finais . . . . . . . . . . . . . . . . . . . . . . . . 49

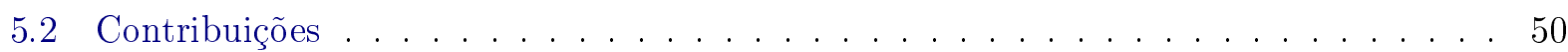

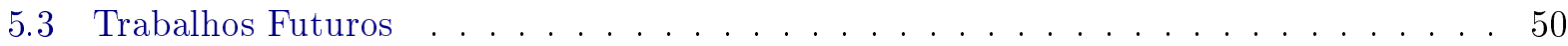

A Classificação Internacional de Doenças para Oncologia 53

Referências Bibliográficas $\quad 55$

$\begin{array}{ll}\text { Índice Remissivo } & 59\end{array}$ 


\section{Lista de Abreviaturas}

$\begin{array}{ll}\text { AP } & \text { Anatomia patológica } \\ \text { CFM } & \text { Conselho Federal de Medicina } \\ \text { CID } & \text { Classificação Internacional de Doenças } \\ \text { CID-O } & \text { Classificação Internacional de Doenças para Oncologia } \\ \text { CIPE } & \text { Centro Internacional de Pesquisa e Ensino } \\ \text { CoGrOO } & \text { Corretor Gramatical para o OpenOffice } \\ \text { CTI } & \text { Centro de Tratamento Intensivo } \\ \text { DCE } & \text { Digital Clinics } \\ \text { FOSP } & \text { Fundação Oncocentro de São Paulo } \\ \text { INCA } & \text { Instituto de Câncer } \\ \text { MNB } & \text { Multinomial Naive Bayes } \\ \text { NLM } & \text { United States National Library of Medicine } \\ \text { OMS } & \text { Organização Mundial da Saúde } \\ \text { ONU } & \text { Organização das Nações Unidas } \\ \text { PEP } & \text { Prontuário Eletrônico do Paciente } \\ \text { PLN } & \text { Processamento de Linguagem Natural (Natural Language Processing) } \\ \text { POP } & \text { Procedimento Operacional Padrão } \\ \text { RGH } & \text { Registro Hospitalar } \\ \text { RI } & \text { Recuperação de Informação } \\ \text { RHC } & \text { Registro Hospitalar de Câncer } \\ \text { SIGH } & \text { Sistema Integrado de Gestão Hospitalar } \\ \text { SNOMED CT } & \text { Systematized Nomenclature of Medicine - Clinical Terms } \\ \text { SUS } & \text { Sistema Único de Saúde } \\ \text { UMLS } & \text { Unified Medical Language System }\end{array}$




\section{Lista de Figuras}

2.1 Estrutura do código de topografia na CID-O (Percy et al., 2000) . . . . . . . . . 7

2.2 Estrutura do código de morfologia na CID-O (Percy et al., 2000) . . . . . . . . . 7

3.1 Dimensões aproximadas das amostras de estudo (em milhares de pacientes). . . . . . 21

3.2 Exemplo de laudo de anatomia patológica. . . . . . . . . . . . . . . . . . . . 22

3.3 Interface de usuário do sistema RHC . . . . . . . . . . . . . . . . . . . . . 24

4.1 Distribuição de pacientes por grupo de topografia. . . . . . . . . . . . . . . . 31

4.2 Avaliação do classificador de grupos de topografia em função do número de pacientes utilizado para treinamento. . . . . . . . . . . . . . . . 34

4.3 Avaliação do classificador de categorias de topografia em função do número de pacientes utilizado para treinamento. . . . . . . . . . . . . . . 35

4.4 Avaliação do classificador de grupo de topografias em função do número de palavras utilizadas para treinamento. . . . . . . . . . . . . . 36

4.5 Variação do tamanho da amostra e medida- $F_{2}$ em função do número mínimo de laudos por paciente. . . . . . . . . . . . . . . . 37

4.6 Mapa de calor do grupo topográfico . . . . . . . . . . . . . . . . . 38

4.7 Exemplo de texto antes e após processamento por detector de sentenças e itemização. 44

4.8 Exemplo de texto antes e após processamento por stemmer. . . . . . . . . . . . . . 45

4.9 Exemplo de texto antes e após processamento por detector de lemas. . . . . . . . . . 45

4.10 Exemplo de texto antes e após processamento por detector de segmentos. . . . . . . 46 


\section{Lista de Tabelas}

2.1 Conjunto de regras da primeira fase do Porter Stemmer (Porter, 1980). . . . . . . . 16

2.2 Lista de palavras mais frequentes no Banco de Português (Sardinha, 2004). . . . . 17

3.1 Exemplos de fenômenos linguísticos identificados na base de estudo. . . . . . . . . . . 23

3.2 Tabela de contingência. . . . . . . . . . . . . . . . . . . . . 24

4.1 Número de classes possíveis em diferentes configurações. . . . . . . . . . . . . . . . 30

4.2 Número de pacientes em diferentes configurações. . . . . . . . . . . . . . . . . 30

4.3 Classe sugerida por diferentes classificadores basais. . . . . . . . . . . . . . . . 31

4.4 Eficiência (em porcentual) de diferentes classificadores basais. . . . . . . . . . . . . 32

4.5 Eficiência (em porcentual) por micro-averaging de diferentes classificadores bayesianos. 33

4.6 Eficiência (em porcentual) por macro-averaging de diferentes classificadores bayesianos. 33

4.7 Lista de tokens com maior poder discriminante para grupo de topografia. . . . . . . 38

4.8 Matriz de confusão para grupo de topografia. . . . . . . . . . . . . . . . . 39

4.9 Eficiência (valor absoluto) por classe para grupo de topografia, ordenada pela medida-

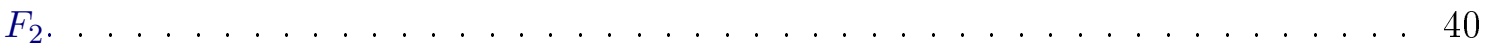

4.10 Eficiência (em porcentual) de diferentes classificadores bayesianos com o uso de suavização de Laplace. . . . . . . . . . . . . . . . . . . . . . . . 41 4

4.11 Eficiência (em porcentual) de diferentes classificadores bayesianos com o uso de su-

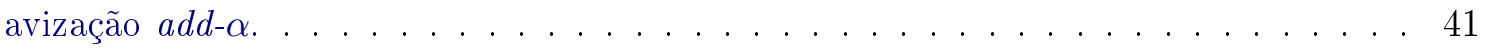

4.12 Eficiência (em porcentual) de diferentes classificadores bayesianos com o uso de suavização Good-Turing. . . . . . . . . . . . . . . . . . . . . . . . . . . 42

4.13 Comparação entre lista de palavras do Banco de Português (Sardinha, 2004) e do domínio em estudo. . . . . . . . . . . . . . . . . . . . . 43

4.14 Eficiência (em porcentual) de diferentes classificadores bayesianos com o uso de

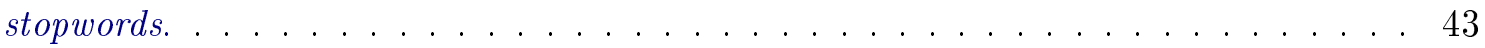

4.15 Eficiência (em porcentual) de diferentes classificadores bayesianos com o uso de detector de sentenças e itemizador. . . . . . . . . . . . . . . . . . . . 44

4.16 Eficiência (em porcentual) de diferentes classificadores bayesianos com o uso de stem-

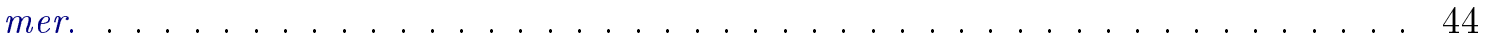

4.17 Eficiência (em porcentual) de diferentes classificadores bayesianos com o uso de lem-

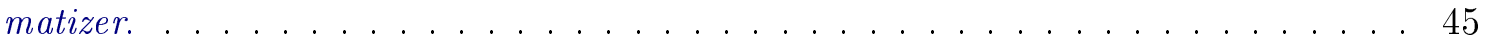

4.18 Eficiência (em porcentual) de diferentes classificadores bayesianos com o uso de detector de segmentos. . . . . . . . . . . . . . . . . . . 46

4.19 Lista de segmentos com maior poder discriminante para grupo de topografia. . . . . 46 
4.20 Resultados (em porcentual) encontrados para medida- $F_{2}$ em diferentes configurações. 47

A.1 Grupos de topografia na Classificação Internacional de Doenças para Oncologia. . . . 53

A.2 Grupos de morfologia na Classificação Internacional de Doenças para Oncologia. . 54 


\section{Capítulo 1}

\section{Introdução}

\subsection{Apresentação}

Frutos do trabalho conjunto entre medicina e computação, os laboratórios de Informática Médica espalharam-se por instituições de pesquisa e hospitais universitários. No Brasil, o A.C. Camargo Cancer Center, por meio de seu Centro Internacional de Pesquisa e Ensino (CIPE), é referência mundial em pesquisa oncogenética, com atuação diversificada entre as áreas de pesquisa clínica, bioinformática e informática médica.

Fundado em 1953 e com sede na cidade de São Paulo, o A.C. Camargo Cancer Center é um hospital oncológico, sem fins lucrativos. Reconhecido como referência no tratamento oncológico, o hospital mantém o primeiro banco de tumores do país, com mais de 30.000 amostras, e possui mais de mil trabalhos científicos publicados em revistas internacionais de grande impacto (Cuminale , 2011). Além disso, atende a uma média mensal de 2.500 pacientes, dos quais 1.500 estão em sua primeira consulta, e realiza cerca de 1.000 cirurgias nesse mesmo período (Filocomo, 2010).

Em 1996, o hospital iniciou a informatização de seus processos através da implantação do Sistema Integrado de Gestão Hospitalar (SIGH). Até 2007, as informações de atendimentos, agendamento e faturamento foram registradas nesse sistema. A partir de então, o hospital integrou o sistema $M V 2000 i$ em suas instalações, utilizado até hoje para gestão hospitalar e registro do prontuário eletrônico do paciente (PEP).

Um dos documentos armazenados através desses sistemas é o laudo de anatomia patológica (AP), redigido por um patologista no momento em que analisa as características macroscópicas e microscópicas de uma biópsia de material colhida de um paciente suspeito de câncer. No A.C. Camargo Cancer Center, os laudos criados entre 1998 a 2007 estão armazenados no sistema SIGH, que substituiu o sistema TOT-LAUD adotado entre 1992 e 1998, enquanto que os laudos posteriores a 2007 passaram a ser registrados no banco de dados Digital Clinics (DCE) do sistema MV $2000 i$.

Sujeito às exigências do governo de São Paulo, o A.C. Camargo Cancer Center - assim como todas as instituições de cunho oncológico do estado - mantém anualmente, desde o ano 2000, o Registro Hospitalar de Câncer (RHC), que contém informações de todos os casos de cânceres diagnosticados no ano anterior pela instituição, além do acompanhamento dos casos presentes em relatórios anteriores. Dentre as informações presentes no RHC, encontram-se dados de topografia e morfologia da Classificação Internacional de Doenças para Oncologia (CID-O) (Percy et al., 2000), além da Classificação para Tumores Malignos (TNM) (Sobin e Wittekind, 2004), também mantida pela Organização Mundial da Saúde. Esses dados estruturados são reunidos no estado pela Fundação 
Oncocentro de São Paulo (FOSP), que os encaminha ao Instituto Nacional de Câncer (INCA).

\subsection{Motivação}

É natural e importante que informação médica esteja disponível de forma não-estruturada em textos de diversas naturezas. Pacheco (2009) identificou que, nos hospitais da Aliança Saúde em Curitiba, o tempo médio investido no preenchimento da evolução clínica do paciente é de 2,3 minutos para pacientes sem passagem pelo Centro de Tratamento Intensivo (CTI) e de 6 minutos para pacientes do CTI. Por sua vez, os atendimentos ambulatoriais para pacientes do Sistema Único de Saúde (SUS) requerem cerca de 12 minutos de atenção profissional. Nesse cenário, é natural que o profissional de saúde busque registrar a maior quantidade possível de informações no menor intervalo de tempo, o que implica a utilização de uma linguagem o mais próxima possível de sua forma de raciocínio - isto é, a linguagem natural - e caracterizada por um uso intensivo de acrônimos, presença de erros ortográficos e utilização de sentenças curtas de baixa complexidade gramatical.

Algum tempo antes, Veras e Martins (1994) haviam analisado a documentação de uma amostra de hospitais do Rio de Janeiro e concluíram que a confiabilidade de diversos campos estruturados da Autorização para Internação Hospitalar (AIH) é insatisfatória. Os autores verificaram que a concordância entre profissionais de saúde sobre a codificação para Serviços Auxiliares de Diagnósticos e Terapia (SADT) atingiu 51,6\% para laudos de anatomia patológica, mas apenas $15,1 \%$ para dados de nebulização. Diante dessa realidade, é importante que informação textual não-estruturada esteja disponível como forma de assegurar a confiabilidade dos registros, haja vista que, nesse cenário, os dados contidos em laudos são mais confiáveis.

Aliada a essa realidade, está a exigência legislatória de se armazenar os dados clínicos dos pacientes por, ao menos, vinte anos, de acordo com a resolução 1.821/2007 do Conselho Federal de Medicina (CFM). Uma vez que o armazenamento físico dessas informações é inviável, muitas instituições utilizam o registro eletrônico. A informatização desses dados cria também a necessidade, fortalecida nos termos da resolução citada, de sua indexação e disponibilidade aos profissionais de saúde, que demandam a recuperação imediata e eficiente de informações de forma detalhada e consolidada.

Em algumas instituições de saúde, incluindo o A.C. Camargo Cancer Center, parte desse volume de informações é codificado periodicamente por uma equipe dedicada, de forma a viabilizar não só a qualidade da codificação, como também assegurar a eficiência do atendimento ao paciente. Entretanto, o intervalo entre a geração da informação e sua codificação pode ser de até um ano, caso do A.C. Camargo Cancer Center, o que reduz as possibilidades de análise estatística em menor prazo. Além disso, o trabalho de codificação é uma tarefa extenuante e sujeita a erros. Diante do prontuário do paciente, especialistas humanos devem ser capazes de inferir o código topográfico e morfológico na Classificação Internacional de Doenças para Oncologia (CID-O) dentre um conjunto relativamente grande de possibilidades equiprováveis.

Ainda, a realidade dos laudos de anatomia patológica predispõe sua análise automatizada, uma vez que são constituídos de texto semiestruturado - há separação nítida entre seções de microscopia, macroscopia e imunoistoquímica, por exemplo - e elaborados de acordo com padrões préestabelecidos — há modelos de texto com campos a serem substituídos —, em um ambiente que 
favorece uma redação apropriada por reduzir as pressões de tempo.

Motivado pela natureza interdisciplinar da pesquisa e pela necessidade de facilitar o trabalho do especialista, a presente dissertação visa aplicar técnicas de mapeamento para terminologias, baseadas em classificação textual e processamento da linguagem natural, em laudos de anatomia patológica, de modo a inferir a topografia e a morfologia de um câncer na Classificação Internacional para Doenças para Oncologia (CID-O). Dessa forma, espera-se prover ao profissional de saúde ferramentas capazes de obter dados aproximados de câncer em menor espaço de tempo e esforço, atualmente não disponíveis sob forma estruturada. Adicionalmente, busca-se facilitar o esforço de codificação ao introduzir uma camada de pré-processamento, responsável por ordenar listas de códigos de acordo com a probabilidade computacionalmente calculada de cada entrada.

\subsection{Objetivos}

\subsubsection{Objetivo Geral}

Obter automaticamente o conceito de um laudo de anatomia patológica na Classificação Internacional de Doenças para Oncologia (CID-O) para facilitar o trabalho de codificação e acelerar a disponibilidade de dados estruturados sobre câncer.

\subsubsection{Objetivos Específicos}

- Determinar o limite inferior para o desempenho do algoritmo de classificação, de modo a guiar os testes e avaliação.

- Treinar um classificador bayesiano multinomial, com o intuito de comparar seu desempenho perante variações de parâmetros.

- Aplicar técnicas de processamento de linguagem natural, de forma a aprimorar o espaço de características utilizado pelo classificador.

\subsection{Organização do Trabalho}

O trabalho está organizado como se segue. No Capítulo 2, é apresentada uma fundamentação teórica sobre terminologias na área da saúde (Seção 2.1), um estudo sobre classificadores baseados em regras e bayesianos (Seção 2.2), uma rápida revisão de processamento de linguagem natural (Seção 2.3), além de trabalhos correlatos referentes à extração de informações de documentos médicos (Seção 2.4).

Em seguida, o Capítulo 3 discorre sobre os materiais e métodos que foram avaliados no presente trabalho e os índices utilizados para comparação de resultados, apresentados em detalhes no Capítulo 4 seguinte.

Por fim, o Capítulo 5 encerra a atual dissertação ao apresentar as considerações finais, contribuições e os trabalhos futuros a serem desenvolvidos. 


\subsection{Aspectos Legais}

O presente trabalho foi desenvolvido em parceria com o A.C. Camargo Cancer Center (projeto 'dp654', aprovado pelo Comitê de Ética em Pesquisa em 13/07/2010 sob código 1418/10), com auxílio financeiro do Conselho Nacional de Desenvolvimento Científico e Tecnológico (projeto 133862/2010-0 aprovado sob o edital MCT/CNPq nº. 70/2009). 


\section{Capítulo 2}

\section{Fundamentação Teórica}

\section{$2.1 \quad$ Terminologias}

A necessidade de catalogar e identificar os principais casos de mortalidade no pós-segunda guerra determinou o surgimento das primeiras terminologias na área da saúde, encabeçadas pelas então recém-criadas Organização Mundial da Saúde (OMS) e Organização das Nações Unidas (ONU) (Percy et al., 2000). Quase 60 anos depois, os padrões internacionais de codificação de doenças são utilizados para os mais diversos fins, dos quais se destacam o faturamento de procedimentos hospitalares, o controle de epidemias e acompanhamento por entidades governamentais e os serviços de seguro e plano de saúde (Shortliffe e Cimino, 2006).

Entretanto, o uso de terminologias não se restringe a necessidades burocráticas, mas também permite a coleta unificada de estatísticas, passíveis de segmentação geográfica e temporal (WHO, 2004). Graus variados de detalhamento são fornecidos por diferentes padrões existentes, que atendem a necessidades distintas de profissionais de saúde. Um cardiologista, por exemplo, necessita de uma especificação distinta das doenças do coração se comparado a um neurologista, cujo maior interesse estaria nas diferentes estruturas que compõem o nosso cérebro. Atender a essas necessidades e, ao mesmo tempo, prover a capacidade de generalização necessária por pesquisadores de outras áreas é um desafio e o objetivo dos arquitetos de terminologias.

Entretanto, há significativa resistência dos profissionais da saúde em adotar padrões de terminologias, o que se traduz em má qualidade da codificação quando a adoção é imposta. Sobre o assunto, Shortliffe e Cimino (2006) afirmam que "enquanto médicos enxergarem o PEP [Prontuário Eletrônico do Paciente] como uma folha de papel em branco onde qualquer informação não-estruturada pode ser escrita, as informações que eles registram serão inadequadas para processamento dinâmico, pesquisa clínica e planejamento de saúde". Todavia, é nítido que a adoção de padrões e a codificação de documentos seja uma necessidade palpável.

Nesse contexto, o presente trabalho busca auxiliar a prática médica por meio de ferramentas computacionais que organizem a informação textual em uma classificação estruturada, mesmo que com eficiência limitada.

\subsubsection{Classificação Internacional de Doenças}

É razoável supor que a terminologia em saúde mais conhecida na atualidade seja a Classificação Internacional de Doenças (CID), mantida pela Organização Mundial da Saúde (OMS) e atualmente 
em sua décima edição (1992). Criada originalmente em 1893, é revisada a cada década desde então, com o objetivo declarado de "permitir a sistemática análise, interpretação e comparação de dados de mortalidade $^{1}$ e morbidade ${ }^{2}$ coletados em diferentes países ou áreas e em diferentes épocas" (WHO, 2004).

A CID é uma classificação hierárquica de quatro dígitos, dos quais três são considerados o mínimo necessário para reporte dos dados dos países à OMS e o quarto dígito provê um detalhamento adicional em até 10 subníveis. Sua décima edição utiliza um código alfanumérico cujo primeiro dígito é uma letra e, portanto, varia de A00.0 a Z99.9 (a letra U não é utilizada). Organizada em 21 capítulos, cada qual corresponde geralmente a uma letra e é subdivido em blocos homogêneos de condições médicas similares.

Uma família de classificações agrega valor para a CID em diferentes setores específicos, como psiquiatria, neurologia, dermatologia, pediatria e, também, oncologia.

\subsubsection{Classificação Internacional de Doenças para Oncologia}

A Classificação Internacional de Doenças para Oncologia (CID-O) é uma especialização da CID para os casos de câncer. Estruturada em dois eixos, é concebida para a codificação simultânea da topografia (localização) e morfologia (tipo histológico e comportamento) do tumor. Os códigos para topografia são originados do capítulo II (neoplasias) da CID-9 e mantêm a mesma estrutura em quatro caracteres da codificação original. Por sua vez, os códigos de morfologia são derivados do Manual de Nomenclatura de Tumores e Códigos (MOTNAC) da Sociedade Americana de Câncer (ACS), datado de 1951, e descrevem o tipo celular e atividade biológica do tumor por meio de uma estrutura de cinco dígitos (Percy et al., 2000).

Desde a primeira edição da CID-O, os códigos para morfologia foram incorporados na Nomenclatura Sistematizada de Medicina (SNOMED) e seguem, portanto, a mesma estrutura, o que não acontece para os códigos topográficos, que seguem uma organização totalmente diferente naquela ontologia. Não obstante ser incorporada pela mais extensa ontologia médica, a CID-O adicionou, em sua terceira edição, as classificações REAL (Revisão Europea-Americana de Linfomas) e FAB (Classificação Franco-Americana e Britânica de Leucemias), o que lhe garantiu uma maior cobertura dos casos de linfomas (Percy et al., 2000).

Utilizada desde 1976, a CID-O surge após a constatação de que somente o código topográfico presente na CID não seria suficiente para descrever detalhadamente casos de câncer, além de garantir maior especificidade topográfica para neoplasias não-malignas (Percy et al., 2000). Atualmente é utilizada em âmbito mundial com traduções em onze línguas e é referência na classificação dos casos de câncer.

A CID-O pressupõe a pré-coordenação, isto é, os conceitos são previamente definidos e não oriundos da conjunção de outros conceitos. Esse fato, em conjunto com a afirmação de Percy et al. (2000) de que a classificação manual é geralmente realizada com base no diagnóstico anatomopatológico, viabilizam a realização desse processo de forma automatizada, o exato foco do presente trabalho.

\footnotetext{
${ }^{1}$ Número de óbitos a cada grupo de habitantes em uma dada região em um período de tempo.

${ }^{2}$ Número de portadores de determinada doença em relação aos indivíduos sãos.
} 


\section{Estrutura da CID-O}

Os códigos de topografia seguem a estrutura exibida na Figura 2.1. São compostos por quatro dígitos que variam de $\mathrm{C} 00.0$ a C80.9, em que o ponto indica uma subdivisão da categoria de três dígitos. Já os códigos morfológicos, cuja estrutura é mostrada na Figura 2.2, são compostos por cinco caracteres variáveis de $8000 / 0$ a 9989/1. Os quatro primeiros indicam o tipo histológico do tumor e o caractere após a barra representa seu comportamento biológico: maligno, benigno, in situ ou incerto quanto a malignidade. Um sexto dígito é utilizado para definir a graduação histológica ou diferenciação da neoplasia.

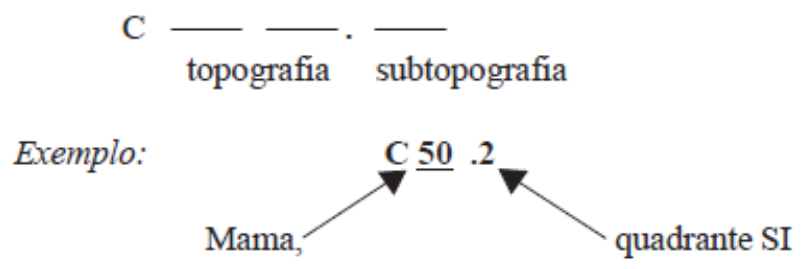

Figura 2.1: Estrutura do código de topografia na CID-O (Percy et al., 2000).

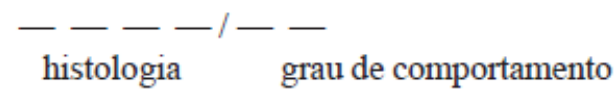

Exemplo: adenocarcinoma bem difereciado

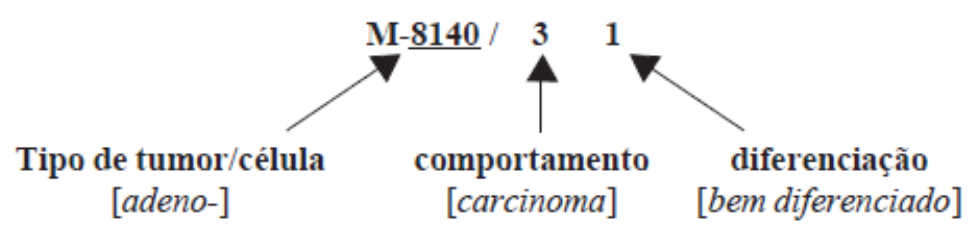

Figura 2.2: Estrutura do código de morfologia na CID-O (Percy et al., 2000).

O laudo de um paciente diagnosticado com câncer de mama, por exemplo, tipicamente recebe a classificação topográfica C50.9: mama, sem outras especificações caso a localização na mama (quadrante) não possa ser definida ou uma das subtopografias, como C50.4: quadrante superior externo da mama caso o tumor esteja localizado nesse quadrante em específico. Quanto à classificação morfológica, o tumor será classificado como M-8500/2: carcinoma intraductal não infiltrante, sem outras especificações caso seja do tipo in situ, isto é, as células tumorais não tenham atravessado a membrana basal, ou M-8500/3: carcinoma intraductal infiltrante, sem outras especificações, no caso de ele já possuir ramificações em outras estruturas vizinhas.

Considerando a dificuldade de licença de outras terminologias, bem como a adoção da Classificação Internacional de Doenças (CID) pelo governo brasileiro e a disponibilidade de dados com essa classificação no A.C. Camargo Cancer Center, o foco do presente trabalho será a especialização da CID para Oncologia, a CID-O. A utilização dessa terminologia reforça o trabalho desenvolvido pelos Registros Hospitalares de Câncer e facilita a recuperação da informação, uma vez que seu significado é facilmente compreendido pelos profissionais de saúde, muitas vezes já acostumados aos códigos utilizados. 


\subsection{Classificadores}

O problema de classificação de entidades, inerente à natureza humana, está presente em diversas áreas do conhecimento, incluindo a Medicina. Nesse domínio, é comum a necessidade de classificação de documentos em taxonomias e terminologias para fins de pesquisa ou remuneração. Em qualquer área, entretanto, tal problema pode ser automatizado de diferentes formas, sejam elas baseadas em regras manualmente criadas ou em mecanismos de aprendizagem automática.

Normalmente, a criação e manutenção de regras manualmente geradas é um processo extenuante, embora possa produzir resultados bastante satisfatórios, que até mesmo superam aqueles encontrados por meio de mecanismos automatizados (Manning et al., 2008). Uma alternativa bastante plausível consiste na construção de corpora etiquetados por especialistas de domínio, sobre os quais algoritmos de aprendizagem automático podem ser executados para a inferência de regras de classificação ou modelos probabilísticos.

De acordo com Manning et al. (2008), um classificador consiste em uma função $\gamma: \mathbb{X} \rightarrow \mathbb{C}$ que mapeia documentos em um espaço multidimensional $\mathbb{X}$ para um conjunto de classes $\mathbb{C}$. Esse processo é conhecido como aprendizado supervisionado, uma vez que as classes do conjunto de treinamento são definidas por humanos. O processo de aprendizagem automática consiste então em uma função $\Gamma(\mathbb{D})=\gamma$, que opera sobre um conjunto de treinamento $\mathbb{D}$ a fim de obter o classificador $\gamma$. Ainda, a classificação é dita one-of ("um-de", em tradução livre) por mapear uma única classe para cada documento.

\subsubsection{Baseado em Regras}

Classificadores baseados em regras constituem uma alternativa para métodos automatizados, geralmente de complexidade elevada. Segundo Manning et al. (2008), são interessantes nos casos em que (a) a base de exemplos é pequena, (b) especialistas de domínio com conhecimentos de informática (essencialmente lógica e expressões regulares) estão disponíveis e/ou (c) a manipulação fácil do classificador é desejada ou necessária.

Ainda segundo aqueles autores, essa classe de classificadores geralmente produz resultados melhores. Em estudos independentes e pioneiros, Jacobs e Rau (1990) e Hayes e Weinstein (1990) obtiveram resultados promissores com a aplicação de regras. Jacobs e Rau (1990) relatam precisão de $92 \%$ e cobertura de $88,5 \%^{3}$ com um classificador de artigos sobre aquisições de empresas no mercado financeiro. Já Hayes e Weinstein (1990) reportam precisão de $84 \%$ e cobertura de $94 \%$ na classificação de notícias em 674 diferentes categorias (economia, política, saúde, etc.) da Reuters.

Entretanto, o esforço necessário para criação e manutenção do conjunto de regras, geralmente baseadas em expressões regulares, não é desprezível. De acordo com Manning et al. (2008), são necessários dois dias de trabalho por classe a ser distinguida. Uma rápida estimativa indica que, para o caso da CID-O, isso implicaria em aproximadamente cinco meses de trabalho apenas para a distinção entre as categorias de três dígitos (70 diferentes classes) ou um esforço total de cerca de sete anos-pessoa para a classificação em todas as categorias de quatro dígitos (331 classes) e códigos morfológicos (895 classes). Ainda, o conteúdo dos documentos em cada classe varia com o tempo (Manning et al., 2008), o que exige um retrabalho constante para manutenção do sistema.

\footnotetext{
${ }^{3}$ A precisão é uma medida que expressa a fração relevante dos documentos recuperados, enquanto que a cobertura indica a fração recuperada dos documentos relevantes. Para uma descrição detalhada dos métodos de avaliação normalmente utilizados, vide Seção 3.2.
} 
Uma alternativa plausível consiste na utilização de uma camada de regras sobre resultados de um classificador automatizado. Essa estratégia é vantajosa por permitir a visualização fácil do mecanismo do classificador e a correção rápida de problemas sem, entretanto, comprometer a acurácia da ferramenta como um todo.

Haja vista que o objetivo do presente trabalho é o desenvolvimento de uma ferramenta automatizada para a classificação de laudos de anatomia patológica, mesmo que isso represente uma perda de eficiência máxima, um classificador baseado em regras não está presente no escopo da solução apresentada.

\subsubsection{Aprendizagem Automática}

Aprendizagem Automática ou Aprendizagem de Máquina (Machine Learning, no termo em inglês) é uma área da Inteligência Artificial que visa a construção de sistemas que otimizam uma função de classificação baseada em um conjunto de exemplos ou experiência passada (Alpaydin , 2004). A técnica se baseia na constatação de que massas de dados possuem, em geral, padrões ocultos que podem ser inferidos estatisticamente. A estratégia se resume, então, a encontrar um modelo matemático que represente os dados de entrada o mais verossímil possível.

Já se tornou clássica a divisão dessa área em aprendizado supervisionado e não-supervisionado. No primeiro, foco do presente trabalho, uma base de exemplos está marcada com a informação de saída, isto é, cada exemplo é um par $(x, f(x))$, com $x \in \mathbb{R}^{n}$. O objetivo torna-se, então, treinar um modelo sobre a base de exemplos para ser utilizado em novos casos, desconhecidos para o sistema, mas similares aos já existentes. No segundo caso, o aprendizado opera sobre um conjunto de exemplos que não possuem a informação de saída, ou seja, cada exemplo é apenas um ponto $x, x \in \mathbb{R}^{n}$. Aqui o objetivo é, portanto, localizar regularidades no conjunto de exemplos, tal como um agrupador (clusterizer).

Os dados de exemplos são normalmente divididos em dois conjuntos, um para treinamento e outro para teste ${ }^{4}$. O conjunto de treinamento corresponde à maioria do material disponível e é onde o algoritmo deve realizar seu aprendizado, enquanto que o material restante é utilizado para avaliação do algoritmo ${ }^{5}$.

Cada conjunto é constituído por exemplos de entrada, cada qual formado por valores de atributos (características) que definem o dado e um rótulo de classe, que especifica a saída correta para o exemplo. Na área de processamento de linguagem natural, é comum que o conjunto seja formado por uma coleção de sentenças, cada qual separada em tokens com seus respectivos rótulos. Os atributos utilizados são o conjunto de palavras existentes no vocabulário do domínio.

Técnicas de aprendizagem automática podem ser aplicadas em classificação textual. Um exemplo de classificação textual estatística, em que o critério de decisão é aprendido automaticamente a partir da base de treinamento usando um modelo estatístico, é o classificador bayesiano multinomial, a ser discutido a seguir.

\footnotetext{
${ }^{4}$ Para maior confiabilidade dos resultados, os experimentos com diversos algoritmos devem ser realizados em um par treinamento-teste isolado de um terceiro conjunto, a ser utilizado ao final para medir a qualidade do melhor algoritmo. Do contrário, a própria seleção do algoritmo pode ser influenciada pelos dados de teste (Duda et al., 2001; Manning et al., 2008; Russell e Norvig, 2010).

${ }^{5}$ Uma discussão detalhada sobre o assunto de validação dos resultados está presente na Seção 3.2.3 do Capítulo de Materiais e Métodos.
} 


\subsubsection{Classificador Bayesiano}

O Teorema de Bayes, assim nomeado após a publicação de "Ensaio para resolver um problema na Doutrina das Chances" por Thomas Bayes (Bayes e Price, 1763), inspirou diversos trabalhos posteriores, dentre os quais se incluem uma das primeiras referências a um classificador de textos bayesiano por Maron e Kuhns (1960) e a posterior formalização das redes bayesianas por Pearl (1985).

Segundo Manning et al. (2008), um classificador bayesiano (Naive Bayes em inglês) é aquele que decide a classe $c$ de um documento $d$ como a classe com a máxima probabilidade a posteriori $c_{\text {map }}$ de acordo com:

$$
\begin{gathered}
c_{\text {map }}=\arg \max _{c \in \mathbb{C}} \hat{P}(c \mid d) \\
c_{\text {map }}=\arg \max _{c \in \mathbb{C}} \frac{\hat{P}(d \mid c) \hat{P}(c)}{\hat{P}(d)}
\end{gathered}
$$

Aqui, escreve-se $\hat{P}$ ao invés de $P$ para indicar uma probabilidade estimada a partir do conjunto de treinamento, haja vista que a probabilidade verdadeira não é conhecida. A regra de Bayes é então aplicada e elimina-se o denominador $\hat{P}(d)$, comum a todas as classes.

$$
c_{\text {map }}=\arg \max _{c \in \mathbb{C}} \hat{P}(d \mid c) \hat{P}(c)
$$

Uma forma alternativa de representação consiste em expressar a classe decidida $c_{\text {map }}$ como aquela com a máxima densidade de probabilidade (conjunta) de o padrão representar simultaneamente a classe $c$ e o documento $d$ (Duda et al., 2001):

$$
c_{\text {map }}=\arg \max _{c \in \mathbb{C}} \hat{P}(c, d)
$$

Na Equação 2.3, a probabilidade a priori $\hat{P}(c)$ de uma classe é facilmente estimada a partir do conjunto de treinamento, como será detalhado mais a frente. Por sua vez, a estimativa da verossimilhança $\hat{P}(d \mid c)$ depende do modelo linguístico adotado. No modelo de Bayes, assume-se a independência posicional de tokens ${ }^{6}$ e a independência de palavras em um mesmo documento ${ }^{7}$. Com isso, a classe de um documento pode ser facilmente inferida por meio da Equação 2.5, em que $t_{k}$ corresponde ao token na posição $k$ do documento $d$ e $n_{d}$ é o número de tokens em $d$.

$$
c_{\text {map }}=\arg \max _{c \in \mathbb{C}} \hat{P}(c) \prod_{1 \leq k \leq n_{d}} \hat{P}\left(t_{k} \mid c\right)
$$

A probabilidade $\hat{P}(d \mid c)$ de geração de um documento $d$ a partir de uma classe $c$ torna-se, então, proporcional às probabilidades individuais $\hat{P}\left(t_{k} \mid c\right)$ de geração dos tokens presentes no documento. Para reduzir problemas de underflow devido a multiplicações sucessivas de probabilidades, comumente substitui-se o produtório de probabilidades pelo somatório de seus logaritmos, o que não afeta a definição de classe pelo fato de a função logarítmica ser monotônica. A escolha da classe

\footnotetext{
${ }^{6}$ Token, em computação, representa a ocorrência de um conjunto de caracteres com significado próprio, geralmente correspondente à ocorrência de uma palavra.

${ }^{7} \mathrm{~A}$ Seção 2.2.3 discute as hipóteses adotadas em detalhe e o impacto de sua aplicação no domínio em estudo.
} 
$c_{\text {map }}$ torna-se, então:

$$
c_{\text {map }}=\arg \max _{c \in \mathbb{C}}\left[\log \hat{P}(c)+\sum_{1 \leq k \leq n_{d}} \log \hat{P}\left(t_{k} \mid c\right)\right]
$$

Como afirmado anteriormente, o cálculo da probabilidade $\hat{P}(c)$ de uma classe pode ser facilmente realizado pela razão entre o número de tokens $N_{c}$ presentes em uma classe e o número total de tokens $N$ presentes no vocabulário (vide Equação 2.7). Todavia, a estimativa $\hat{P}(t \mid c)$, se fosse realizada de forma análoga, geraria probabilidades nulas para termos que não ocorrem na base de treinamento, o que induziria probabilidades também nulas para a classificação. Por conta disso, realiza-se normalmente um processo de suavização. A suavização de Laplace, por exemplo, apenas adiciona 1 em cada contagem (Manning et al., 2008), de forma com que $\hat{P}(t \mid c)$ possa ser definido como na Equação 2.8.

$$
\begin{gathered}
\hat{P}(c)=\frac{N_{c}}{N} \\
\hat{P}(t \mid c)=\frac{T_{c t}+1}{\sum_{t^{\prime} \in V}\left(T_{c t^{\prime}}+1\right)}
\end{gathered}
$$

Aqui, $T_{c t}$ corresponde ao número de tokens $t$ em documentos da classe $c$ e $V$ é o vocabulário do espaço de documentos.

\section{Outras suavizações}

Embora de fácil compreensão, a suavização de Laplace ou add-one induz comumente a erros elevados (Chen e Goodman, 1996). Uma generalização dessa técnica é conhecida como add- $\alpha$, em que um número $\alpha, 0<\alpha \leq 1$, é adicionado a cada contagem (vide Equação 2.9). Supõe-se, assim, uma distribuição uniforme a priori sobre os termos presentes no vocabulário, em que $\alpha$ denota a crença na uniformidade (Manning et al., 2008). Dada uma crença fraca, adota-se normalmente $\alpha=\frac{1}{2}$. Quando $\alpha=1$, obtém-se a suavização de Laplace.

$$
\hat{P}(t \mid c)=\frac{T_{c t}+\alpha}{\sum_{t^{\prime} \in V}\left(T_{c t^{\prime}}+\alpha\right)}
$$

Uma alternativa à suposição da distribuição uniforme consiste na suposição de uma distribuição binomial sobre as frequências dos termos do vocabulário, base da suavização conhecida como GoodTuring. De acordo com Manning e Schütze (1999), "esse método é viável para um número grande de observações de dados retirados de um vocabulário grande e funciona bem para n-gramas, apesar do fato de que palavras e n-gramas não seguem uma distribuição binomial". A ideia do método é realocar a massa de probabilidade dos termos que ocorrem $r+1$ vezes para os termos que ocorrem $r$ vezes e, em especial, a probabilidade dos termos que ocorrem uma única vez para aqueles nunca vistos na base de treinamento. Para isso, calcula-se uma frequência ajustada $r^{*}$ para cada termo encontrado na base de treinamento de acordo com:

$$
r^{*}=(r+1) \frac{n_{r+1}}{n_{r}}
$$

Em que $n_{r}$ é o número de termos encontrados exatamente $r$ vezes. Assim, pode-se escrever a 
probabilidade individual $\hat{P}_{G T}(t \mid c)$ de um token $t$ ser gerado por um documento $d$, ajustada por Good-Turing, como:

$$
\hat{P}_{G T}(t \mid c)=\frac{r^{*}}{N^{*}}
$$

Aqui, $N^{*}$ corresponde ao somatório ajustado das frequências individuais, ou seja:

$$
N^{*}=\sum_{r=0}^{\infty} r^{*} n_{r}=\sum_{r=1}^{\infty} r n_{r}
$$

É importante observar que a suavização de Good-Turing penaliza os termos mais frequentes do vocabulário, ao reduzir suas chances para garantir probabilidade não-nula aos termos desconhecidos. A Lei de Zipf auxilia a compreensão desse fenômeno. Segundo ela, a frequência $f$ de uma palavra está relacionada com sua posição $r$ em uma lista ordenada pela frequência decrescente das palavras em um corpus através da relação $f \propto \frac{1}{r}$, isto é, a frequência de uma palavra é inversamente proporcional à sua posição na lista de frequências. Dessa forma, é natural existirem muitos termos com baixa probabilidade e alguns poucos termos que são muito frequentes - exatamente aqueles que serão penalizados pela suavização de Good-Turing.

Em todo caso, técnicas de suavização devem ser sempre consideradas na resolução de um problema, não somente para solucionar o problema da semântica conjuntiva (em que a probabilidade de um documento pertencer a uma classe é diferente de zero somente se todos os seus termos existirem na base de treinamento), como também para reduzir a probabilidade de eventos conhecidos, ao mesmo tempo em que se incrementa a chance dos eventos ainda não vistos.

Sobre o assunto, Chen e Goodman (1996) afirmam que "em qualquer lugar em que dados esparsos sejam um problema, técnicas de suavização podem melhorar os resultados, e dados esparsos são quase sempre um problema em modelagem estatística. No caso extremo em que haja tantos dados de treinamento que todos os parâmetros possam ser acuradamente treinados sem suavização, pode-se quase sempre expandir o modelo, movendo-o para um modelo $n$-grama de ordem superior, por exemplo, para alcançar melhores resultados. Com mais parâmetros, dados esparsos tornam-se um problema novamente, mas, com suavização adequada, os modelos tornam-se usualmente mais acurados do que os modelos originais. Então, não importa quantos dados se possua, técnicas de suavização podem quase sempre melhorar os resultados, e com um esforço relativamente pequeno."

\section{Propriedades}

Embora não especificado explicitamente, os classificadores acima apresentados simplificam algumas características dos dados sobre os quais operam, cujas hipóteses, nem sempre verdadeiras, devem ser levadas em conta na escolha e avaliação do algoritmo. A primeira delas diz respeito à suposição de homogeneidade das distribuições de treinamento e teste, que deriva do fato de que classificadores lineares, tais como Naive Bayes, serem capazes de modelar as fronteiras de decisão apenas como hiperplanos lineares (Manning et al., 2008).

A segunda e a terceira suposições dos modelos apresentados dizem respeito, respectivamente, à independência de palavras e de posição. Os classificadores consideram, simultaneamente, que os atributos são independentes uns dos outros em uma mesma classe e que seu valor não depende de sua posição relativa no texto. Na prática, isso significa que uma sentença como Paciente 
diagnosticado com câncer de mama é classificada da mesma forma que a sentença (inválida do ponto de vista semântico, porém correta em sintaxe) Câncer de mama diagnosticado com paciente: ambas indicam a localização topográfica C50: mama na Classificação Internacional de Doenças para Oncologia. Além disso, a informação de que as palavras câncer e mama ocorrem juntas com frequência maior do que separadas também é desprezada.

Essas suposições, entretanto, não desqualificam os classificadores apresentados: de acordo com Manning et al. (2008), "Naive Bayes é ruim para estimar probabilidades, mas bom para tomar decisões". Tipicamente, a classe vencedora nesse modelo possui probabilidade muito maior do que as demais, cujo valor diverge bastante do real, porém é corretamente identificada como a classe mais provável.

\subsection{Processamento de Linguagem Natural}

Classificadores textuais estatísticos demandam muitas vezes um processamento mais refinado da informação linguística existente na base de treinamento. Técnicas de Processamento de Linguagem Natural (NLP, na sigla em inglês) são comumente utilizadas para enriquecer ou simplificar os dados de entrada, de modo a adicionar características úteis para a distinção entre classes ou reduzir a dimensionalidade do problema. Os estudos nessa área são fundamentais para o desenvolvimento de várias outras linhas de pesquisa e são comumente divididos em três ramos: morfologia, lexicografia e sintaxe.

\subsubsection{Morfologia}

A morfologia, termo que significa "o estudo das formas", consiste no estudo dos componentes que formam as palavras em uma linguagem ${ }^{8}$. Na área de processamento de linguagem natural, é a primeira etapa a ser realizada e geralmente compreende (a) a identificação dos tokens (itemização) e (b) a identificação das sentenças. Embora aparentemente trivial, essa tarefa mostra-se complexa mesmo em línguas ocidentais, cuja delimitação de termos e sentenças é facilitada pelo uso de caracteres específicos, como o espaço em branco e o ponto final ${ }^{9}$.

\section{Itemização}

A definição estrita de um item (token) na estrutura textual não é consenso mesmo entre linguistas (Manning e Schütze, 1999) e varia de acordo com o domínio de estudo e a finalidade do corpus. Kučera e Francis (1967) propõem uma abordagem prática e objetiva ao definirem token como "uma cadeia de caracteres alfanuméricos contíguos com espaço em ambos os lados; pode incluir hifens e apóstrofos, mas não outros sinais de pontuação".

Segundo Manning e Schütze (1999), diversos problemas estão presentes na etapa de itemização. O primeiro deles diz respeito ao fato de, na maioria das vezes, os sinais de pontuação serem grafados logo após a palavra que os antecede (sem um espaço em branco), mesmo representando tokens distintos.

\footnotetext{
${ }^{8}$ Não deve ser confundida com o eixo de morfologia da CID-O, que diz respeito ao comportamento de um tumor.

${ }^{9}$ Tal fenômeno não está presente na maioria dos idiomas de origem oriental, tal como o japonês e o chinês, nos quais a delimitação entre conceitos é definida pela semântica do contexto e, portanto, exige um processamento linguístico mais profundo.
} 
O segundo desafio diz respeito a um fenômeno linguístico conhecido como haplologia, em que um único caractere é visualmente representado na existência de dois ou mais caracteres idênticos, mas com semântica diferente. Exemplo clássico desse fenômeno consiste na supressão de um ponto (.) ao final de uma sentença que encerra com uma abreviação, como na frase Para escrever um bom artigo, deve-se tomar cuidado com a redação, ortografia, etc..

Uma segunda manifestação da haplologia ocorre com o uso de hifens, que podem ser utilizados na separação de dois tokens em um termo composto, como indicativo de quebra de linha ou ambos. Com relação a esse problema, ainda se adiciona o fato de que, em português, coexistem atualmente duas padronizações no uso de hifens, a mais antiga delas sem regras muito bem definidas para todos os casos de hifenização.

No domínio médico, aos desafios linguísticos acima supracitados adiciona-se o uso extensivo de acrônimos e abreviaturas, que dificultam as possibilidades de desambiguação através do uso de um léxico.

De acordo com Shortliffe e Cimino (2006), a solução para os desafios apresentados inclui tipicamente uma ou mais das seguintes alternativas: (a) uso de expressões regulares elaboradas e mantidas manualmente - um processo custoso, mas que garante qualidade para um domínio específico; (b) modelos de Markov treinados por meio de algoritmos de aprendizagem automática em corpora marcados; e/ou (c) algoritmo de Viterbi para determinação do caminho que maximiza as probabilidades obtidas na matriz de transição obtida em (b). Ainda, podem ser utilizadas técnicas de máxima entropia ou máquinas de estado para a solução desse problema.

\section{Detecção de sentenças}

A abordagem ingênua para realizar detecção de sentenças — uma sentença é definida como tal se, e somente se, é encerrada por um ponto (.) - é falha em ambos os lados da bidireção implícita na definição: a linguagem compreende sentenças aninhadas em outras e há marcas de ponto (.) que não definem uma sentença, como as que definem abreviaturas. Entretanto, essa definição simples é fundamentada pelo fato de que, segundo Riley (1989), 90\% dos pontos determinam fim de sentença. Por conta disso, um procedimento simples tal como o apresentado no Algoritmo 1 (Manning e Schütze, 1999) pode ser utilizado.

Abordagens contemporâneas utilizam árvores de classificação (Riley, 1989) com uma combinação linear das seguintes características: (a) existência de maiúscula e minúscula e tamanho da palavra antes e depois do sinal de ponto; e (b) probabilidade a priori de as palavras antecederem ou sucederem uma marca de ponto. Variações dessa metodologia foram avaliadas por Palmer e Hearst (1994, 1997), que obtiveram acurácia de $98 \%$ a $99 \%$ ao utilizar a classe gramatical das palavras. Com base em algoritmos de máxima entropia, Reynar e Ratnaparkhi (1997) relatam, por sua vez, uma taxa de sucesso de 99,25\% para detectar finais de sentença ${ }^{10}$.

Outras características também podem ser utilizadas para o treinamento de um algoritmo de aprendizagem automática, como o tamanho médio de uma sentença em número de palavras. Segundo Manning e Schütze (1999), sentenças pertencentes ao domínio jornalístico contém, em média, 23 palavras. No domínio médico, conforme apontado por Oleynik et al. (2010), a complexidade gramatical é menor e, por consequência, as sentenças apresentam tamanho reduzido (média de 21

\footnotetext{
${ }^{10} \mathrm{~A}$ variante dessa técnica implementada no âmbito do projeto OpenNLP (APACHE, 2011) será utilizada no presente trabalho.
} 


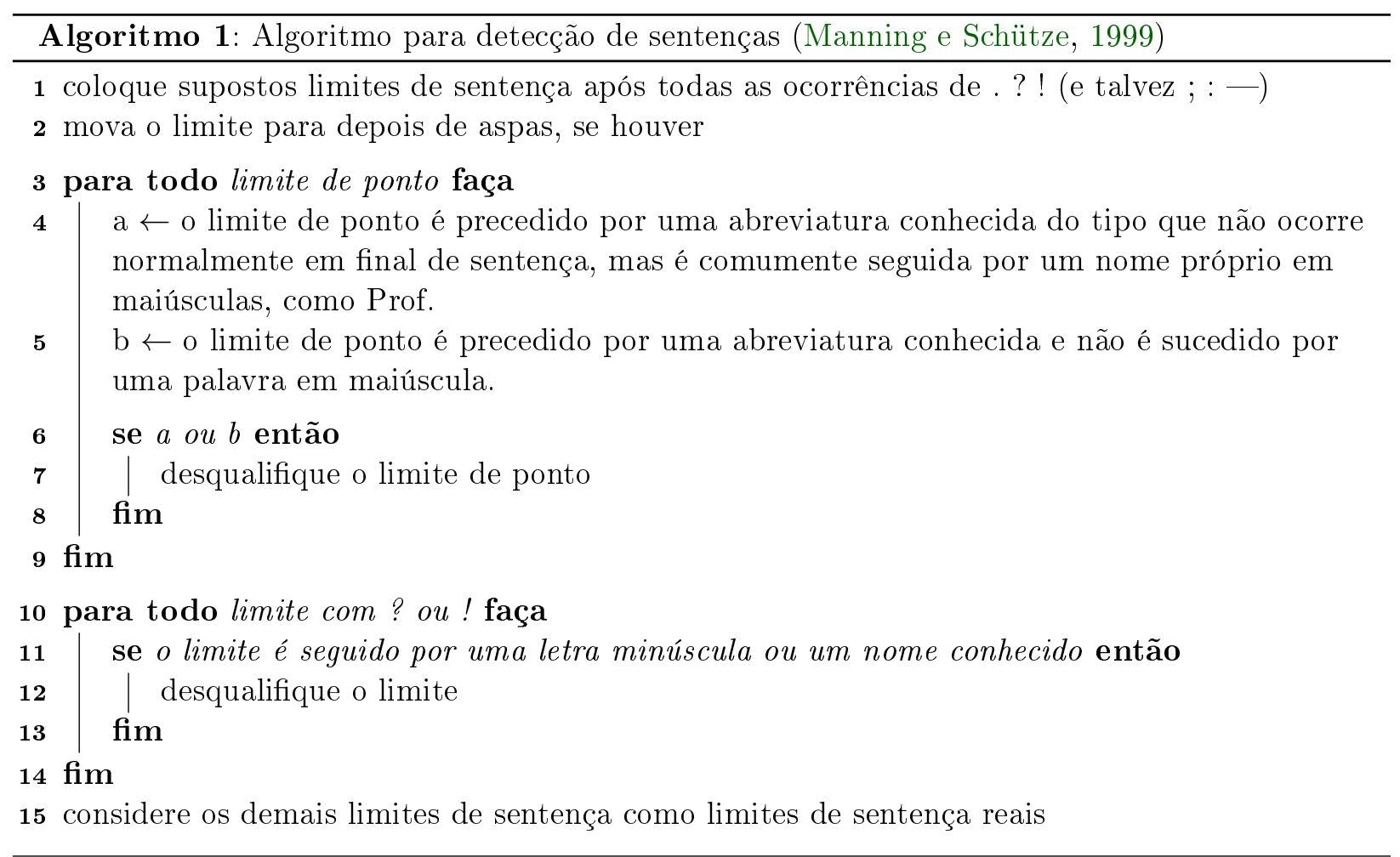

palavras), ao menos quando comparadas àquelas existentes no ramo jornalístico (média de 27 palavras nesse estudo).

\subsubsection{Lexicografia}

Paralela à morfologia, a lexicografia compreende o estudo do léxico, isto é, dos termos que compõem uma linguagem. Dois problemas básicos fazem-se presentes nessa área: (1) a identificação da forma canônica de cada token — presumida sua correta identificação em 2.3.1; e (2) a remoção de tokens não-interessantes ao processamento automatizado do texto.

\section{Stemmers e Lemmatizers}

No que tange ao processamento da linguagem natural, é interessante e comumente desejável o agrupamento de declinações verbais e de adjetivos, de modo com que formas similares como [sofreu, sofria, sofre] e [abdominal, abdômen, abdome] sejam interpretadas e apresentadas em seus respectivos grupos.

A estratégia mais simples e de rápido processamento para completar essa tarefa é conhecida como stemming e consiste em remover prefixos e sufixos, em uma espécie de "fatiamento" do termo original. Um conjunto de regras previamente determinado (como o presente na Tabela 2.1) e normalmente definido de forma manual é utilizado para identificar o radical (em inglês, stem) de cada palavra. Embora muito eficiente, tal estratégia está sujeita a diversos erros, já identificados por outros autores. Sobre o assunto, Manning et al. (2008) argumentam que técnicas agressivas de stemming podem degradar o desempenho [sic] de aplicações nelas baseadas. De modo análogo, Hull (1996); Salton (1989) afirmam que "extensivos resultados empíricos na comunidade de Recuperação de Informação têm mostrado que stemming não melhora o desempenho dos sistemas clássicos de RI quando o desempenho é avaliado como uma média sobre queries", o que talvez leve 
Manning e Schütze (1999) a concluírem que o método não tenha utilidade em sistemas de Recuperação de Informação não interativos, em que o usuário não contribui com informações. Todavia, cabe ressaltar que stemming reduz inegavelmente o tamanho do léxico, o que acelera a execução de aplicações e melhora o desempenho, aqui entendido somente no que tange à velocidade de processamento.

\begin{tabular}{l|l}
\hline Regra & Exemplo \\
\hline SSES $\rightarrow$ SS & caresses $\rightarrow$ caress \\
IES $\rightarrow$ I & ponies $\rightarrow$ poni \\
$\mathrm{SS} \rightarrow$ SS & caress $\rightarrow$ caress \\
$\mathrm{S} \rightarrow$ & cats $\rightarrow$ cat \\
\hline
\end{tabular}

Tabela 2.1: Conjunto de regras da primeira fase do Porter Stemmer (Porter, 1980). Nessa fase, a regra selecionada é aquela que se aplica ao maior sufixo possivel do termo de entrada, com o objetivo de eliminar corretamente o plural.

A alternativa ao uso de um stemmer consiste em uma ferramenta conhecida como lemmatizer, capaz de identificar o radical de uma palavra (por exemplo, "ir" para a forma declinada "foram") através de técnicas de análise mais sofisticadas, que incluem a desambiguação de significados. Sua utilização em sistemas de NLP e RI afeta a velocidade da aplicação e pode não gerar resultados melhores.

Algoritmos e ferramentas que realizam a função de stemmer e lemmatizer estão amplamente disponíveis na literatura. Em inglês, um dos algoritmos mais conhecidos é denominado Porter Stemmer, em referência ao seu autor, Martin Porter (Porter, 1980). O Porter Stemmer opera em cinco fases, em cada qual um conjunto de regras é aplicado sobre os termos resultantes da fase anterior. De acordo com Manning et al. (2008), são aplicadas na primeira fase as regras presentes na Tabela 2.1. Uma implementação dessa estratégia está disponível na ferramenta Snowball (Porter, 2011), mantida pelo autor original do algoritmo.

Em português, o corretor gramatical CoGrOO (CoGrOO, 2011) oferece uma tentativa de lema no módulo de etiquetagem morfossintática, enquanto que o Snowball oferece as mesmas funções de stemming adaptadas para o português.

\section{Stopwords}

Outra necessidade inerente ao processamento linguístico consiste na exclusão de palavras não interessantes ao léxico, denominadas em inglês stopwords, para acelerar o desempenho. Os termos a serem removidos são normalmente definidos em uma lista conhecida como stoplist e incluem as palavras mais comuns em um domínio ou idioma e que não permitem a diferenciação entre documentos que as contêm. Uma extensa lista de frequência das palavras do português foi compilada por Sardinha (2004) e em muito se assemelha à listagem produzida sobre o domínio de laudos de anatomia patológica em estudo, compilada em trabalhos iniciais. As dez primeiras ocorrências daquela lista estão reproduzidas na Tabela 2.2.

De acordo com Manning e Schütze (1999), a utilização de uma lista com apenas algumas palavras pode reduzir o tamanho do índice invertido pela metade, o que é explicado pela Lei de Zipf. 


\begin{tabular}{c|c|c}
\hline Posição & Palavra & Frequência \\
\hline 1 & de & 6.022 .939 \\
2 & $\mathrm{a}$ & 4.289 .463 \\
3 & o & 4.135 .372 \\
4 & e & 2.906 .593 \\
5 & que & 2.763 .756 \\
6 & do & 2.433 .919 \\
7 & da & 2.169 .947 \\
8 & em & 1.760 .984 \\
9 & para & 1.403 .295 \\
10 & no & 1.233 .337 \\
\hline
\end{tabular}

Tabela 2.2: Lista de palavras mais frequentes no Banco de Português (Sardinha, 2004).

\subsubsection{Sintaxe}

O estudo da sintaxe consiste em entender as relações entre diferentes palavras que contribuem para a formação de uma frase, de modo a realizar a sua análise sintática. A implementação de um parseador (ou parser, como é muito conhecido no original em inglês) capaz de realizar análise sintática é uma tarefa que exige o esforço conjunto de linguistas e cientistas da computação, haja vista sua execução ser computacionalmente complexa.

\section{Segmentadores}

Uma simplificação da análise sintática foi proposta por Abney (1991) e é conhecida como segmentador (chunking). Mais fácil de implementar, consiste em determinar em um texto as chamadas frases verbais e nominais - como piora da febre e câncer de mama -, que encapsulam em si um sentido completo. Essas composições podem estar presentes em um texto em vários níveis de aninhamento, que variam desde a união de dois ou mais termos - geralmente um verbo ou substantivo e outro substantivo, modificados ou não por um adjetivo e relacionados ou não por meio de uma preposição, como nos exemplos citados — até a análise sintática completa. Em sua versão mais simples, a técnica utiliza a saída de um etiquetador morfossintático (ferramenta responsável pela identificação da classe gramatical de uma palavra em uma sentença, conhecida em inglês como part-of-speech (POS) tagger) como entrada em um aplicador de regras, responsável por agrupar termos no mesmo nível sintático em um único chunk (Silva, 2013).

A identificação e extração dos segmentos pode ser interessante para uso como características em um classificador bayesiano (vide Capítulo 2.2.3). Essa abordagem é conhecida como sacola de segmentos (bag of chunks) e considera que, ao invés de palavras, segmentos são dispostos em uma "sacola", independentemente de sua posição original na sentença.

\subsection{Trabalhos Relacionados}

A literatura contemporânea no que tange a técnicas de extração de informações de documentos médicos é ampla e em constante expansão. Grande parte dos trabalhos visa extrair um conjunto de conceitos referenciados em um mesmo texto e mapeá-los para uma terminologia de domínio, como a SNOMED CT (em português, Nomenclatura Sistematizada de Medicina - Termos Clínicos) ou 
UMLS (Sistema de Linguagem Médica Unificado), de forma a facilitar e aprimorar a recuperação de documentos. Outros autores seguem a proposta da presente pesquisa e avaliam a qualidade da classificação de documentos médicos, em que cada unidade de trabalho é mapeada para um único conceito de uma terminologia ou ontologia, não necessariamente mencionado no texto. Uma breve descrição dos trabalhos similares realizados recentemente é agora apresentada.

Aronson (2001) descreve uma ferramenta conhecida como MetaMap para identificação de conceitos do UMLS Metathesaurus, em uso pela Biblioteca Nacional de Medicina dos Estados Unidos (NLM) para construção semiautomatizada de seu índice de artigos. O algoritmo opera em cinco etapas: (1) detecção de frases nominais por meio do parser SPECIALIST, presente na UMLS; (2) geração de variantes através do léxico SPECIALIST, também contido na UMLS; (3) recuperação de todos os conceitos da UMLS com ao menos um termo em comum com os sintagmas identificados anteriormente; (4) elaboração de um ranking dos conceitos recuperados em função da centralidade (envolvimento do termo principal), variação (média da distância inversa), cobertura (quantidade de termos do texto envoltos pelo conceito) e coesão (quantidade de termos do conceito); e (5) combinação dos conceitos entre si para identificação dos conceitos mais específicos. Avaliada somente em trabalhos paralelos, a ferramenta é citada pelo autor como responsável por uma melhora de $4 \%$ em um contexto de indexação e $14 \%$ como meio de expansão da consulta. Os principais problemas identificados são dois: idiossincrasia (presença de acrônimos, números e nomes químicos) e ambiguidade.

Friedman et al. (2004) realizaram uma avaliação sistemática da ferramenta denominada MedLEE para identificação de conceitos da UMLS em documentos médicos, inclusive com o reconhecimento de quantificadores e modificadores. O método de funcionamento da ferramenta pode ser descrito em três fases: (1) análise sintática; (2) agrupamento de palavras textualmente distantes; e (3) codificação baseada em mapa, em que o conceito mais específico é escolhido como aquele com o termo primário mais próximo e uma maior quantidade de modificadores. O mapa utilizado em (3) é previamente construído com base em um processo automatizado que envolve a seleção de conceitos da UMLS, sua preparação para adição de variantes, análise sintática e geração da tabela que mapeia conceitos MedLEE para UMLS. Os autores relatam resultados similares ou melhores do que aqueles encontrados por meio do uso de especialistas, com taxa de cobertura de $84 \%$ e precisão de $89 \%$, avaliadas em um conjunto de 150 sentenças. Dentre as fraquezas relatadas, encontra-se a não-tolerância de erros ortográficos.

Hripcsak et al. (1995) avaliaram o sistema MedLEE ${ }^{11}$ para detectar a presença ou ausência de seis condições médicas distintas em 200 documentos de admissão de radiografia de tórax. Em seu trabalho, termos presentes em um vocabulário são mapeados para conceitos e classificados semanticamente quanto a local, achado clínico, etc. Um analisador sintático combina então conceitos semânticos utilizando uma gramática. A distância média encontrada entre especialistas - medida como a discordância em número de condições clínicas por documento — foi de 0,24 (de um máximo de 6), reflexo da falta de consenso na classificação de alguns documentos. A distância média verificada para o processador baseado em NLP foi 0,26 , enquanto que a distância para um conjunto de pessoas leigas foi sempre maior do que 0,5. Segundo os autores, o processador automático é indistinguível dos especialistas e atinge $81 \%$ de cobertura e $98 \%$ de precisão.

\footnotetext{
${ }^{11}$ O sistema MedLEE também é base de inúmeros outros trabalhos (Friedman et al., 1994; Wilcox e Hripcsak, 2003, 1999). Entretanto, dado o pioneirismo e a importância dos trabalhos de Friedman et al. (2004) e Hripcsak et al. (1995), foram aqui escolhidos para uma descrição textual mais detalhada.
} 
Baseado nos resultados encontrados por Aronson (2001) e Friedman et al. (2004), Pacheco (2009) desenvolve um trabalho de mapeamento automático de sumários de alta para a SNOMED CT, denominado MorphoMap. Os dados foram fornecidos pelo Hospital de Clínicas de Porto Alegre (HCPA) e compreendem essencialmente atendimentos do setor de cardiologia. Por meio da utilização de técnicas de processamento de linguagem natural aliadas ao uso de uma máquina de abstração morfossemântica denominada Morphosaurus, o autor relata taxas de acurácia de 83,9\% quando avaliado sobre um padrão-ouro de 1000 documentos construído por especialistas. O sistema ainda inclui funções de correção ortográfica e resolução de acrônimos, bastante frequentes na linguagem médica.

Em um projeto independente, Bulegon (2011) relata taxas de $97,5 \%$ de precisão e $70 \%$ de cobertura na identificação de diagnóstico e classificação para CID-10 de 6000 registros de sumários de alta da mesma base de dados. O trabalho envolveu a elaboração manual de um conjunto de 32 regras responsáveis pela detecção de diagnósticos baseada em trigramas de etiquetas gramaticais, construídas sem técnicas de aprendizagem automática. O etiquetador morfológico utilizado é uma modificação da ferramenta CoGrOO (Silva, 2013) treinada para o domínio da medicina no âmbito do trabalho apresentado por Oleynik et al. (2010). O mapeamento dos conceitos identificados para a terminologia é realizado por meio da comparação de strings, embora um estudo exaustivo da qualidade do mapeamento não seja apresentado.

Mais recentemente, Jouhet et al. (2012) avaliaram o uso de classificadores Naive Bayes e máquinas de vetores de suporte (SVM) para a classificação de 5.121 laudos de anatomia patológica na CID-O e na categorização da Agência Internacional de Pesquisa em Câncer (IARC, na sigla em inglês). A representação textual é realizada por meio de descritores clássicos: frequência de termos $t f$, frequência de termos com frequência de documento inversa $t f$.idf e frequência de termos com frequência de classe inversa $t f . i c f$. Os pesquisadores relatam os melhores resultados com o uso de SVM e $t f . i c f:$ medida- $F_{1}$ de $96,7 \%$ para os eixos de topografia e morfologia na classificação da IARC, composta por 16 e 8 classes, respectivamente e, para a classificação de 26 topografias e 18 morfologias na CID-O, medidas- $F_{1}$ de $71,5 \%$ e 85,4\%, respectivamente. Os trabalhos futuros descritos envolvem a utilização de técnicas de processamento de linguagem natural para refinar as características utilizadas, classificação multietiqueta para casos de tumores múltiplos e a incorporação de outros documentos médicos, como laudos cirúrgicos, durante o treinamento.

O presente trabalho estende os resultados apresentados por Jouhet et al. (2012) ao incorporar as técnicas de processamento de linguagem natural descritas entre os pontos fracos da proposta. $\mathrm{O}$ uso de stopwords, deteç̧ão de sentenças, tokens, radicais e segmentos permite a redução da dimensionalidade do classificador, bem como a utilização de características dependentes entre si, como in e situ. Além disso, técnicas de aprendizagem automática superam a abordagem baseada em regras manuais proposta por Bulegon (2011), pois permitem expansão e atualização constante da tarefa de classificação. Por sua vez, a não-utilização de uma abordagem baseada em identificação de termos, como aquelas propostas por Aronson (2001); Friedman et al. (2004); Hripcsak et al. (1995); Pacheco (2009), simplifica o problema e garante-lhe maior versatilidade, ao assumir uma única classe alvo para cada documento e permitir que sua descrição textual não esteja mencionada em nenhum local da entrada. Finalmente, o trabalho destaca-se pela extensão do corpus adotado para análise, pois compreende cerca de 20.000 pacientes e 75.000 laudos. 


\section{Capítulo 3}

\section{Materiais e Métodos}

\subsection{Caracterização do Domínio}

As bases de estudo do presente trabalho e suas representatividades em número de pacientes são apresentadas no diagrama de Venn visível na Figura 3.1. As intersecções entre as bases de dados correspondem a pacientes que possuem registro simultaneamente no Registro Hospitalar de Câncer (RHC) e em sistemas de laudos de anatomia patológica. Na figura, é possível verificar que cerca de $28 \%(16 / 57)$ dos pacientes com laudos de anatomia patológica registrados no sistema DCE (mais recente) possuem correspondência com entradas do RHC. Um número similar de pacientes com laudos no sistema SIGH (mais antigo) possuem entradas correspondentes no sistema RHC.

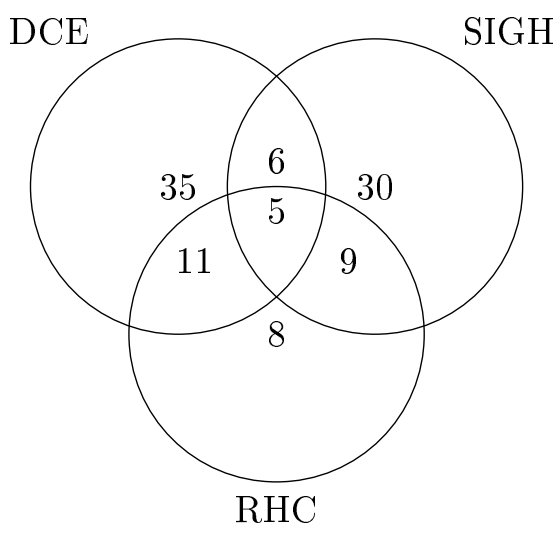

Figura 3.1: Dimensões aproximadas das amostras de estudo (em milhares de pacientes).

As intersecções entre os sistemas, realizada por meio do RGH (Registro Hospitalar) do paciente, constituem a massa de dados preliminar da presente pesquisa, uma vez que mapeiam um conjunto de laudos textuais de um paciente para um ou mais registros no RHC, em que informações codificadas de topografia e morfologia na Classificação Internacional de Doenças para Oncologia (CID-O) estão presentes.

Para garantir o escopo do problema proposto, foram removidos pacientes metastáticos ${ }^{1}$ e pacientes com mais de um registro no RHC, exceto se todos os registros indicam a mesma classe alvo no nível de granularidade desejado. Pelo mesmo motivo, os diferentes laudos de um mesmo paciente foram unificados em um mesmo texto. Com o intuito de reduzir a dimensionalidade do problema,

\footnotetext{
${ }^{1}$ Pacientes metastáticos apresentam $\mathrm{M}=1$ na classificação TNM (Sobin e Wittekind, 2004).
} 
foi avaliada também a capacidade de identificação somente do grupo topográfico e morfológico a que pertence um laudo.

Convém relembrar que, embora o mapeamento entre texto e classe esteja disponível, ele é realizado com periodicidade anual e manualmente. Acelerar a disponibilidade dessas informações de forma estruturada e reduzir o esforço dos especialistas é o objetivo do presente trabalho.

\subsubsection{Laudos de Anatomia Patológica}

Os laudos de anatomia patológica do A.C. Camargo Cancer Center seguem os procedimentos operacionais padrão do departamento estabelecidos em A.C. Camargo (2012). Embora os sistemas DCE e SIGH não ofereçam possibilidade de estruturação das informações registradas, foram estabelecidos no manual modelos padronizados de texto a serem utilizados na rotina diagnóstica. Os modelos oferecem algum nível de estrutura aos dados, embora nem sempre haja consistência nos termos utilizados para descrição de informações similares, como a topografia e morfologia. Um trecho de laudo real pode ser visualizado na Figura 3.2.

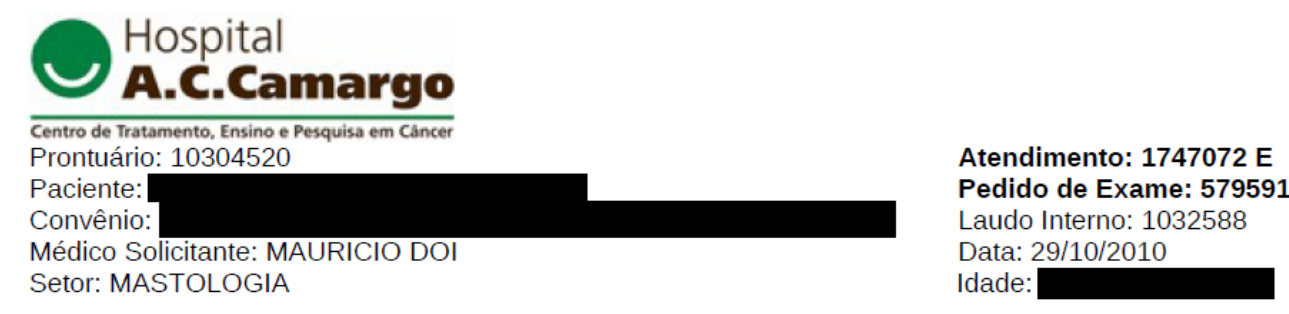

EXAME ANATOMOPATOLÓGICO

REVISÃO DE LÂMINAS

Recebemos para revisão 01 bloco e 01 lâmina identificados como M10-20990, provenientes do Serviço de Anatomia Patológica de Santos, acompanhados do respectivo laudo anátomopatológico. Aqui, foram identificados como A-1032588.

. Biópsia de mama direita:

* Carcinoma ductal invasivo

* Grau nuclear: 2

* Grau I de SBR

* Mitoses: 0-1/10 CGA

* Desmoplasia peritumoral: Intensa

* Infiltrado linfocitário peritumoral: Discreto

* Invasão vascular linfática: Não detectada

* Invasão vascular sanguínea: Não detectada

* Invasão perineural: Não detectada

* Necrose: Ausente

Nota: Foi solicitada a realização de estudo imunoistoquímico para complementação diagnóstica.

Figura 3.2: Exemplo de laudo de anatomia patológica.

Entre os textos presentes na base de estudo, diversos fenômenos linguísticos podem ser identificados, conforme exemplificado na Tabela 3.1. Tais fenômenos dificultam o processamento automatizado e, embora técnicas de PLN já sejam capazes de endereçar alguns problemas, muitos ainda 
permanecem em aberto na literatura. O reconhecimento desses fenômenos é etapa essencial para a completa compreensão do problema em estudo, mas não será o foco da atual pesquisa.

\begin{tabular}{c|l}
\hline Fenômeno & Exemplo \\
\hline Numerais & "Aqui, foram identificados como A-1034582." \\
Acrônimos & "Carcinoma de mama sem amplificação do gene HER-2/neu pesqui- \\
& sada através de FISH." \\
Ausência de ponto final & "O espécime foi totalmente submetido a exame histológico - 2F/1C" \\
Excesso de maiúsculas & "MATERIAL RECEBIDO: LINFONODO CERVICAL POSTERIOR \\
& ESQUERDO:" \\
Negação & "Negativo para malignidade compatível com hiperplasia mesotelial." \\
Codificação de domínio & "MATERIAL RECEBIDO: BIÓPSIA DE MAMA DIREITA - 6 HO- \\
& RAS: [posicionamento angular da lesão na mama]" \\
\hline
\end{tabular}

Tabela 3.1: Exemplos de fenômenos linguísticos identificados na base de estudo.

\subsubsection{Registro Hospitalar de Câncer}

O Registro Hospitalar de Câncer (RHC) do A.C. Camargo Cancer Center, bem como o de outras instituições no estado de São Paulo, contém informações estruturadas sobre casos confirmados de tumores malignos. Na base em estudo, estão presentes dados de pacientes com prontuário aberto na instituição e diagnosticados no ano anterior ao de sua publicação, bem como informações de seguimento dos pacientes incluídos em anos anteriores. Esse critério, embora simples, exclui casos diagnosticados em outras instituições e pacientes com diagnóstico em ano posterior ao de sua primeira visita na instituição.

Dentre as informações relevantes para a presente pesquisa, são codificadas a topografia (localização primária) e tipo histológico (morfologia) do tumor, como visível na interface de usuário do sistema RHC presente na Figura 3.3.

\subsection{Medidas de Avaliação}

É sabido que trabalhos de aprendizagem automática, incluindo classificação automatizada de documentos e recuperação de informação, devem ser avaliados consistentemente no intuito de garantir a comparabilidade dos resultados. Nesse sentido, é comum fazer uso de medidas conhecidas de qualidade, das quais se destacam a acurácia (exatidão), precisão, cobertura e medida-F. Nessa seção serão descritos os métodos de avaliação utilizados no presente trabalho.

\subsubsection{Acurácia, Precisão e Cobertura}

A medida trivial de qualidade de qualquer experimento é a acurácia (do inglês accuracy), também conhecida como exatidão. A acurácia exibe a razão entre o número de acertos e o total como uma porcentagem, tal qual expressa na Equação 3.1.

$$
A=\frac{\text { acertos }}{\text { total de documentos }}
$$

Todavia, ao utilizar conceitos emprestados da área vizinha de Recuperação de Informação (RI), é possível também analisar a qualidade de um algoritmo do ponto de vista da consulta realizada ou, 


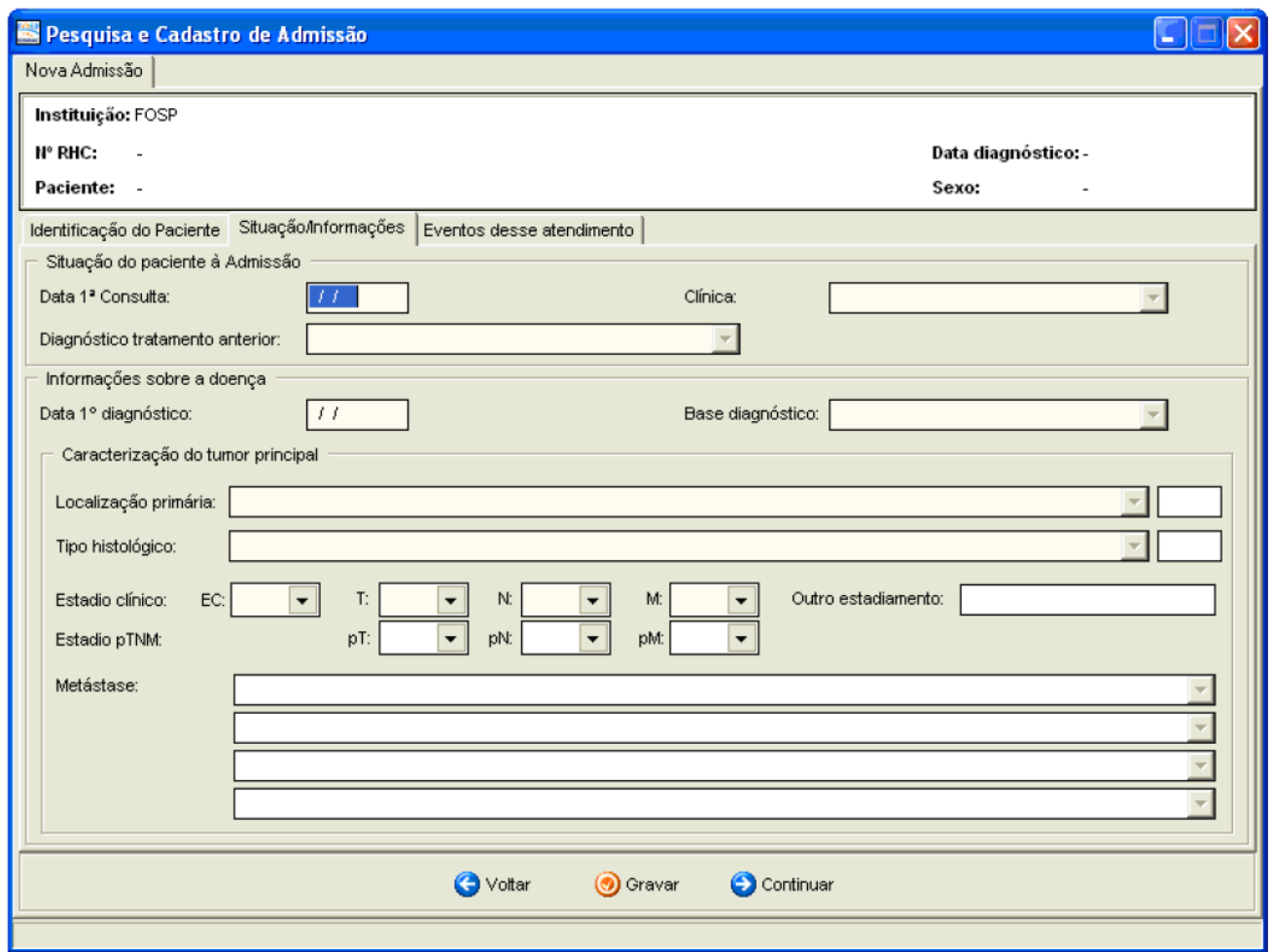

Figura 3.3: Interface de usuário do sistema $R H C$.

em problemas de classificação, do problema de decidir ou não por uma classe para cada documento. A partir dessa análise, um sistema empregado em um vasto universo de documentos - típico em problemas de RI - pode obter alta acurácia classificando todos os documentos como nãopertencentes à classe sob análise, haja vista que essa proporção é naturalmente elevada.

Para contornar esse problema, é comum exibir os resultados também em termos de precisão (em inglês, precision) e cobertura (também referenciada por alguns autores como sensibilidade ou revocação, em uma adaptação direta do inglês recall). A definição desses conceitos é auxiliada por uma tabela de contingência (vide Tabela 3.2), que exibe a semântica das combinações possíveis de resultados recuperados ou não com resultados relevantes ou não.

\begin{tabular}{c|c|c}
\hline & Relevante & Não-relevante \\
\hline Recuperado & verdadeiro positivo $(\mathrm{tp})$ & falso positivo $(\mathrm{fp})$ \\
Não-recuperado & falso negativo $(\mathrm{fn})$ & verdadeiro negativo $(\mathrm{tn})$ \\
\hline
\end{tabular}

Tabela 3.2: Tabela de contingência.

A partir da tabela de contingência, é possível definir precisão e cobertura por meio das Equações 3.2 e 3.3. A precisão é definida como a fração relevante dos documentos recuperados, enquanto que a cobertura, como a fração recuperada dos documentos relevantes (Manning e Schütze, 1999).

$$
\begin{aligned}
P & =\frac{t p}{t p+f p} \\
C & =\frac{t p}{t p+f n}
\end{aligned}
$$

Nessa linha de pensamento, a acurácia passa a ser compreendida como a fração de acertos do 
universo de documentos e é expressa nesses moldes na Equação 3.4.

$$
A=\frac{\text { acertos }}{\text { total de documentos }}=\frac{t p+t n}{t p+f p+f n+t n}
$$

\subsubsection{Medida-F}

A introdução das medidas de precisão e cobertura, embora solucione o problema de expressão dos resultados no contexto de RI, adiciona outro, de menor impacto, mas desconfortável: a falta de uma medida única para qualificar os experimentos. Dependendo do contexto de trabalho, é aceitável uma pequena queda na precisão com a garantia de uma melhor cobertura nos resultados. Embora o peso relativo dessas medidas seja dependente de contexto, é possível expressá-las em conjunto através de um índice conhecido como medida-F.

A medida-F é definida por Manning et al. (2008) como a média harmônica entre a precisão e a cobertura e pode ser expressa por meio da Equação 3.5.

$$
F=\frac{1}{\alpha \frac{1}{P}+(1-\alpha) \frac{1}{C}}=\frac{\left(\beta^{2}+1\right) P C}{\beta^{2} P+C}
$$

Aqui, $\alpha$ é o fator que determina o peso entre precisão e cobertura, que se relaciona com $\beta$ por meio da Equação 3.6.

$$
\beta^{2}=\frac{1-\alpha}{\alpha}
$$

No caso em que precisão e cobertura recebem o mesmo peso, a medida-F é denominada $F_{1}$, haja vista que $\beta=1(\alpha=0,5)$. A expressão pode, então, ser simplificada como a exibida na Equação 3.7.

$$
F_{\beta=1}=\frac{2 P C}{P+C}
$$

Como o presente trabalho prioriza a tarefa de recuperação de informações, foi considerada uma importância duas vezes superior para a medida de cobertura em relação à medida de precisão. Em termos matemáticos, foi utilizado $\beta=2$ e $\alpha=0,2$. Para facilitar a comparação com outros trabalhos, entretanto, a medida- $F_{2}$ será apresentada em conjunto com a medida- $F_{1}$.

\subsubsection{Validação Cruzada}

A obtenção das medidas de avaliação é comumente realizada por meio de validação cruzada. Nessa técnica, os dados disponíveis são divididos em dois conjuntos, um para treinamento e outro para teste. O algoritmo do classificador utiliza os dados do conjunto de treinamento para criar seu modelo e, em seguida, aplicá-lo no conjunto de teste, onde as métricas de eficiência são avaliadas.

De acordo com Duda et al. (2001), há várias heurísticas para a seleção da porção $\gamma(0<\gamma<1)$ do corpus a ser utilizada para o subconjunto de teste. Como o número de parâmetros a serem aprendidos é superior ao número de parâmetros avaliados, costuma-se adotar $\gamma<0,5$ e um valor tradicionalmente utilizado é $\gamma=0,1$. Ainda segundo o autor, classificadores com um número maior de graus de liberdade demandam um maior conjunto de treinamento, isto é, um valor $\gamma$ inferior. Por outro lado, se o número de parâmetros livres no classificador é pequeno, a eficiência calculada é insensível ao valor de $\gamma$ (Duda et al., 2001). 
Uma variação da técnica de validação cruzada é o método $k$-fold de validação cruzada ( $k$-fold cross validation). A metodologia consiste em dividir o corpus de estudo em $k$ partes de mesmo tamanho, separar uma delas para teste e treinar o algoritmo nas partes restantes. Em seguida, um subconjunto diferente é separado para teste e treina-se novamente nas seções restantes. O processo é repetido $k$ vezes e a eficiência final é calculada como a média das eficiências individuais. No limite em que $k$ corresponde ao número de instâncias da base de estudo, a técnica é conhecida como leave-one-out.

No presente trabalho, todos os resultados apresentados foram obtidos por meio do método $k$-fold de validação cruzada, com $k=10$, valor comumente empregado na literatura.

\subsubsection{Média micro e macro}

As medidas de avaliação, quando calculadas para um conjunto de classificadores de duas classes $c$ e $\bar{c}$, podem ser agrupadas em uma única medida de duas formas distintas (Manning et al., 2008). Na média macro, obtém-se a média aritmética simples entre os valores encontrados para cada uma das classes. Na média micro, por sua vez, utiliza-se a média aritmética ponderada pelo número de documentos de cada classe.

Como as métricas de precisão, cobertura e medida-F desprezam os verdadeiros negativos $(t n)$, a média micro costuma aproximar-se dos valores encontrados para as classes mais representativas do corpus, enquanto que a média macro reflete melhor o comportamento encontrado nas classes com poucos exemplos. Quando calculada pela média micro, o valor da acurácia é igual ao da cobertura.

Os resultados apresentados no presente trabalho, exceto quando mencionado, refletem a escolha pela média micro como índice representativo da eficiência do classificador desenvolvido.

\subsection{Métodos}

\subsubsection{Caracterização da pesquisa}

De acordo com a metodologia científica aplicada em ciência da computação (Wazlawick, 2008), a realização da presente pesquisa tem caráter (a) exploratório, (b) descritivo e (c) não-experimental. Essa classificação é justificada pelo fato de que o trabalho implica (a) na exploração de um problema com a finalidade de familiarização com sua natureza, (b) na observação e descrição dos resultados da aplicação de técnicas clássicas e (c) na utilização de dados previamente coletados para fins de avaliação, sem interferência nos processos humanos já existentes.

\subsubsection{Procedimentos}

Em um primeiro momento, foram realizadas análises estatísticas sobre as bases disponíveis, com o objetivo de obter uma visão geral sobre os dados existentes no que diz respeito a (1) número de documentos por paciente, (2) número de tokens por sentença, (3) número de caracteres por sentença, (4) incidência de letras maiúsculas, (5) incidência de dígitos numéricos e (6) distribuição dos dados nos eixos da classificação alvo. Esse estudo visa compreender a estrutura textual dos laudos, a dimensão do problema e a comparabilidade com outros trabalhos.

Em seguida, foi preciso determinar um mínimo para a acurácia dos algoritmos com o intuito de estabelecer um limite inferior para a qualidade dos resultados a serem encontrados. A taxa 
basal (baseline) compreende a utilização de uma estratégia ingênua e encontrada com pouco esforço (Manning e Schütze, 1999). No domínio da oncologia, corresponde a atribuir a classe mais frequente da base de treinamento (por exemplo, câncer de mama) aos dados sob verificação. Uma vez que os dados não são uniformes, qualquer algoritmo de classificação deve superar esses resultados para ser considerado útil e válido.

Após a determinação do limite inferior para o algoritmo, o presente trabalho buscou o treinamento de um classificador bayesiano multinomial (e suas variações apresentadas na Seção 2.2.3), capaz de classificar laudos de anatomia patológica para a Classificação Internacional de Doenças para Oncologia (Seção 2.1.2). Seu comportamento foi estudado em detalhe para o grupo topográfico da CID-O (Seções 4.3.2 a 4.3.6) quanto ao impacto do tamanho da base de treinamento, tamanho do vocabulário, número mínimo de laudos por paciente, poder discriminante dos tokens e eficiência por classe.

Em um momento subsequente, de acordo com a natureza descritiva da pesquisa, o classificador foi aprimorado com conhecimentos linguísticos (Seção 2.3) - a saber: identificação de sentenças, tokens, segmentos, radical e stopwords - e avaliado quanto a seu ganho de desempenho.

Por último, os resultados encontrados foram analisados e comparados quanto aos índices apresentados na Seção 3.2, isto é, precisão, cobertura, acurácia e medida-F, obtidos por validação cruzada. A obtenção desses valores fez uso de um subconjunto dos corpora apresentados na Seção 3.1, denominado padrão-ouro. O presente trabalho atinge seus objetivos se os resultados encontrados no padrão-ouro forem suficientemente superiores ao limite inferior (baseline).

\subsection{Aspectos Tecnológicos}

Com o intuito de facilitar o desenvolvimento do presente trabalho e assegurar o enfoque científico da pesquisa, foram utilizados e adaptados componentes de software já existentes para as tarefas de classificação textual e processamento de linguagem natural.

Para o primeiro intento, foi adotada a proeminente suíte de aprendizagem automática e mineração de dados Weka² (Hall et al., 2009), mantida pela Universidade de Waikato da Nova Zelândia. A suíte foi estendida com um módulo de stemming fornecido pelo projeto PTStemmer ${ }^{3}$. O algoritmo utilizado foi a versão modificada do Porter Stemmer (Porter, 1980) para português brasileiro.

Já para a tarefa de processamento de linguagem natural, dada a necessidade de processamento de texto em português, foi adotada a suíte de PLN embarcada no corretor gramatical CoGrOO ${ }^{4}$ (CoGrOO, 2011) e adaptada da biblioteca OpenNLP (APACHE, 2011), mantida pela Apache Software Foundation.

\footnotetext{
${ }^{2}$ Versão 3.6.4, disponível em http://www.cs.waikato.ac.nz/ml/weka/downloading.html.

${ }^{3}$ Versão 2.0, disponível em https://code.google.com/p/ptstemmer/downloads/list.

${ }^{4}$ Versão 4.0, disponível em http://cogroo.org/download/current.html.
} 


\section{Capítulo 4}

\section{Resultados}

O presente capítulo apresenta os resultados encontrados ao aplicar os métodos descritos no Capítulo 3 sobre os materiais de estudo apresentados no mesmo texto. Todos os resultados apresentados foram obtidos através de validação cruzada, o que lhes garante, portanto, evidência estatística de significância.

\subsection{Análise dos Dados}

A análise computacional dos laudos de anatomia patológica revelou os seguintes padrões textuais, obtidos pela média dos dados disponíveis para análise:

- 3,773 documentos por paciente.

- 7,487 tokens por sentença.

- 46,427 caracteres por sentença.

- 21,929\% dos caracteres textuais são maiúsculos.

- 3,027\% dos caracteres são dígitos numéricos.

Os valores encontrados revelam o predomínio de sentenças curtas e com elevada incidência de letras maiúsculas. Isso se deve, respectivamente, à natureza científica do texto sob análise cujo objetivo é transmitir rapidamente uma informação - e ao uso de artifícios textuais para representação de elementos de estrutura - como o uso de maiúsculas em títulos e subtítulos.

Haja vista que o conteúdo dos textos segue a estrutura descrita nos procedimentos operacionais padrão (POPs) do departamento de Anatomia Patológica, os desvios ortográficos e gramaticais, quando presentes, são mínimos. Além disso, observa-se que os textos são bem escritos e refletem os padrões da norma culta da língua, o que viabiliza o uso de modelos linguísticos já existentes.

\subsubsection{Distribuição dos dados}

Os dados disponíveis foram analisados com relação a sua distribuição nos diferentes eixos da Classificação Internacional de Doenças para Oncologia, conforme detalhado na Seção 2.1.2. O eixo topográfico foi analisado em seus três níveis de detalhamento, denominados grupo, categoria e 
conceito. O eixo das morfologias, por sua vez, foi considerado somente em seus dois níveis de detalhe: grupo e conceito ${ }^{1}$.

O número de classes existente em cada nível pode ser visualizado na Tabela 4.1. Para facilitar a análise nas seções seguintes, quando necessário, o comportamento do classificador será detalhado somente para o grupo topográfico.

\begin{tabular}{c|cc}
\hline Nível & Topografia & Morfologia \\
\hline Grupo & 18 & 49 \\
Categoria & 70 & N/A \\
Conceito & 331 & 895 \\
\hline
\end{tabular}

Tabela 4.1: Número de classes possiveis em diferentes configurações.

Ao se considerar os variados níveis de refinamento, foram selecionadas quantidades diferentes de pacientes, haja vista que, em níveis mais granulares, é possível que um mesmo paciente receba duas classificações distintas. Esses casos foram descartados do estudo e geraram pequena redução da amostra para os classificadores de conceitos, como pode ser visto na tabela 4.2.

\begin{tabular}{c|cc}
\hline Nível & Topografia & Morfologia \\
\hline Grupo & 19578 & 19272 \\
Categoria & 19469 & N/A \\
Conceito & 18983 & 19019 \\
\hline
\end{tabular}

Tabela 4.2: Número de pacientes em diferentes configurações.

Além disso, a distribuição dos pacientes nas diferentes classes não é homogênea. Como visto na Seção 2.2.3, o desbalanceamento natural dos dados é informação essencial para o classificador bayesiano e compõe sua probabilidade a priori. Para o grupo topográfico, a Figura 4.1 exibe o número de pacientes classificados em diferentes grupos de topografia. O significado dos diferentes grupos pode ser consultado no Apêndice A.

\subsection{Classificador basal}

Com o intuito de garantir a comparabilidade dos resultados encontrados, foram estabelecidos de forma prática limites inferiores para a eficiência do classificador. O limite inferior ou taxa basal (baseline) está relacionado à atribuição da classe mais frequente do corpus ao texto sob análise, conforme detalhado na Seção 3.3.

\subsubsection{Limite inferior}

O algoritmo ingênuo construído para a definição do limite inferior (ou baseline) de um algoritmo de classificação é responsável por atribuir a todo documento da base de validação a classe mais frequente encontrada no conjunto de treinamento. Essa classe está representada para os diferentes níveis hierárquicos e para os dois eixos (topografia e morfologia) da Classificação Internacional de Doenças para a Oncologia (CID-O) na Tabela 4.3.

\footnotetext{
${ }^{1}$ Nesse caso, a categoria não se aplica, informação presente nas tabelas sob o acrônimo "N/A".
} 


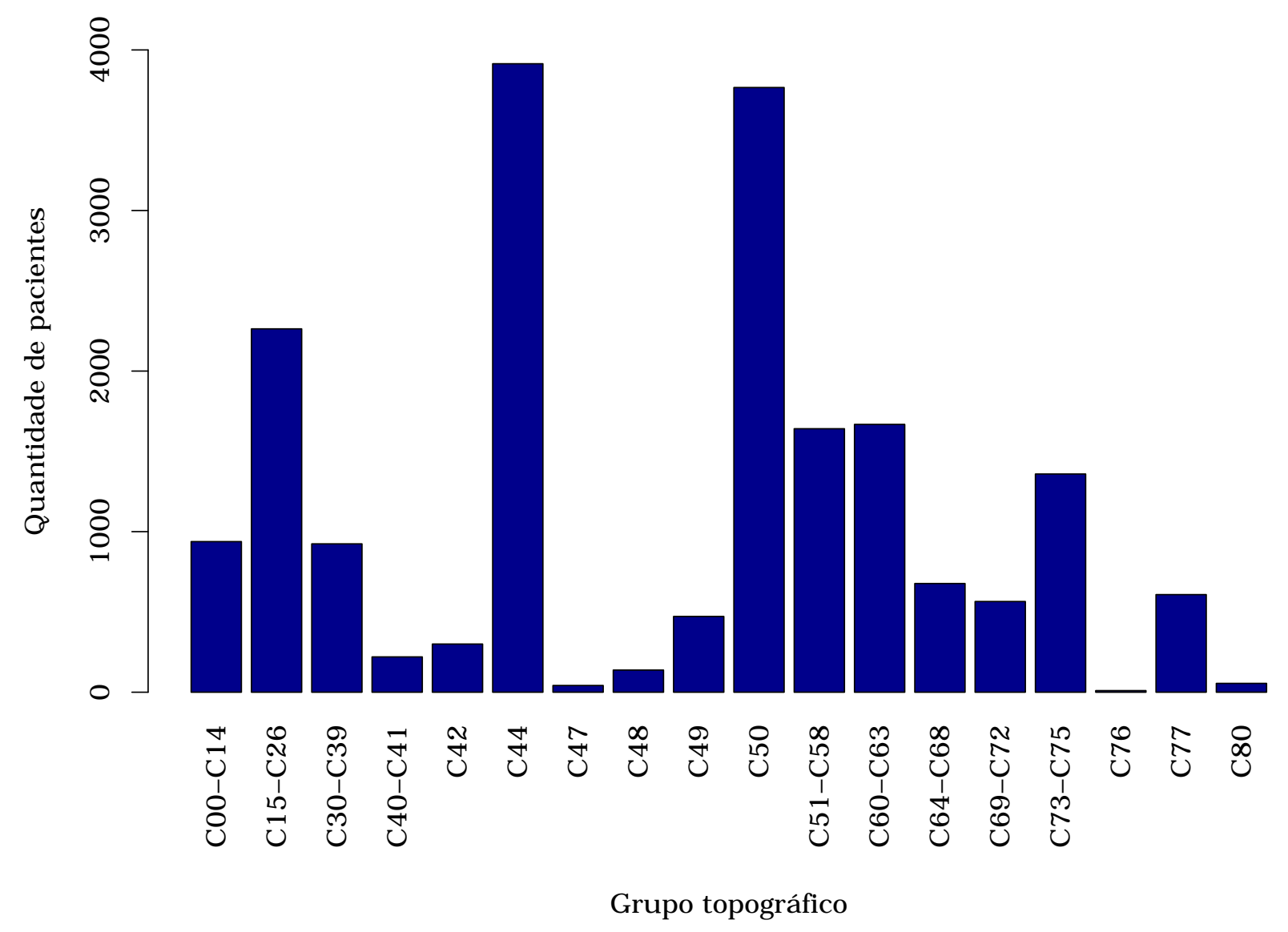

Figura 4.1: Distribuição de pacientes por grupo de topografia.

\begin{tabular}{c|cc}
\hline Nível & Topografia & Morfologia \\
\hline Grupo & C44 & $814-838$ \\
Categoria & C44 & N/A \\
Conceito & C61.9 & M-8500/3 \\
\hline
\end{tabular}

Tabela 4.3: Classe sugerida por diferentes classificadores basais. 
A análise da tabela revela que, para o eixo topográfico, a categoria $\mathrm{C} 44$ : pele repete-se para o grupo, não ao acaso um grupo de única categoria. No nível mais refinado, o conceito C61.9: próstata é o mais frequente. Já no eixo morfológico da CID-O, o conceito M-8500/3: Carcinoma ductal infiltrante, SOE não pertence ao grupo de conceitos mais genérico 814-838: Adenomas e adenocarcinomas.

Ao aplicar cada uma das classes supracitadas aos documentos do conjunto de validação, foram obtidas as métricas de eficiência exibidas na Tabela 4.4, que correspondem aos limites inferiores de um algoritmo de classificação. Reflexo da estratégia utilizada e do desbalanceamento entre as classes, os índices de cobertura $(\mathrm{C})$ foram muito superiores aos índices de precisão $(\mathrm{P})$ para todos os cenários considerados. Em consequência, foram obtidos altos índices de cobertura (superior a 19\% para os níveis de hierarquia mais altos) e medida- $F_{2}$ superior a $11 \%$ para grupos e categorias de conceitos, em ambos os eixos da classificação. Os índices inferiores encontrados a nível de conceito estão relacionados não só a uma distribuição mais homogênea dessas classes, como também a uma eventual não-confiabilidade das informações disponíveis nesse nível de granularidade, hipótese a ser explorada na Seção 4.3 .

\begin{tabular}{c|cccc|cccc}
\hline Nível & \multicolumn{4}{|c|}{ Topografia } & \multicolumn{4}{c}{ Morfologia } \\
& $\mathrm{P}$ & $\mathrm{C}$ & $F_{1}$ & $F_{2}$ & $\mathrm{P}$ & $\mathrm{C}$ & $F_{1}$ & $F_{2}$ \\
\hline Grupo & 4,004 & 20,010 & 6,673 & 11,120 & 3,997 & 19,992 & 6,661 & 11,104 \\
Categoria & 4,049 & 20,122 & 6,742 & 11,217 & \multicolumn{4}{c}{$\mathrm{N} / \mathrm{A}$} \\
Conceito & 0,580 & 7,619 & 1,079 & 2,224 & 1,713 & 13,089 & 3,030 & 5,623 \\
\hline
\end{tabular}

Tabela 4.4: Eficiência (em porcentual) de diferentes classificadores basais.

Convém ressaltar que o classificador basal encontrado, embora pouco eficiente, apresenta elevado desempenho computacional, pois sua simplicidade reflete em um baixo consumo de processamento e memória. Entretanto, sua taxa de acerto é diretamente decorrente da natureza desbalanceada dos dados e do elevado número de classes, condição nem sempre verdadeira em outros cenários.

\subsection{Classificador Bayesiano}

\subsubsection{Resultados iniciais}

A utilização do classificador bayesiano descrito na Seção 2.2.3 produziu resultados bastante superiores ao limite inferior previamente estipulado, conforme exibido na Tabela 4.5. Os maiores valores encontrados situam-se para o problema de escolha do grupo topográfico de um paciente, em que a medida- $F_{2}$ encontrada superou $73 \%$. Para a granularidade imediatamente superior, quando o número de classes a ser distinguidas é elevado de 18 para 70, os valores exibidos sofrem pequena queda e a medida- $F_{2}$ torna-se pouco inferior a $70 \%$. Entretanto, quando o grau de especificidade é novamente aumentado e o classificador passa a distinguir entre 331 conceitos, os resultados sofrem queda significativa, com medida- $F_{2}$ em torno de $40 \%$. Mesmo assim, os valores situam-se muito acima da taxa basal especificada, o que revela o potencial da técnica utilizada.

No eixo morfológico, as medidas encontradas são inferiores ao eixo topográfico - mas ainda superiores à taxa basal - para todos os graus de detalhamento. Para distinguir entre 49 grupos de morfologia, o classificador treinado obtém medida- $F_{2}$ de $60,877 \%$, superior à medida encontrada 


\begin{tabular}{c|cccc|cccc}
\hline Nível & \multicolumn{4}{|c|}{ Topografia } & \multicolumn{4}{c}{ Morfologia } \\
& $\mathrm{P}$ & $\mathrm{C}$ & $F_{1}$ & $F_{2}$ & $\mathrm{P}$ & $\mathrm{C}$ & $F_{1}$ & $F_{2}$ \\
\hline Grupo & 78,459 & 73,456 & 75,053 & 73,855 & 68,235 & 60,749 & 62,302 & 60,877 \\
Categoria & 72,279 & 67,950 & 68,957 & 68,029 & \multicolumn{4}{c}{ N/A } \\
Conceito & 42,433 & 41,806 & 39,681 & 40,415 & 46,819 & 41,832 & 41,467 & 40,892 \\
\hline
\end{tabular}

Tabela 4.5: Eficiência (em porcentual) por micro-averaging de diferentes classificadores bayesianos.

para diferenciar entre 895 morfologias: 40,892\%. Todavia, tal resultado é altamente dependente do desbalanceamento da probabilidade a priori das classes de saída, haja vista que, quando calculada por macro-averaging (média aritmética simples entre classes), a medida- $F_{2}$ registrada na Tabela 4.6 é de $25,543 \%$ para o grupo e de $2,677 \%$ para o conceito morfológico.

\begin{tabular}{c|cccc|cccc}
\hline Nível & \multicolumn{4}{|c|}{ Topografia } & \multicolumn{4}{c}{ Morfologia } \\
& $\mathrm{P}$ & $\mathrm{C}$ & $F_{1}$ & $F_{2}$ & $\mathrm{P}$ & $\mathrm{C}$ & $F_{1}$ & $F_{2}$ \\
\hline Grupo & 53,093 & 56,935 & 53,196 & 54,757 & 27,934 & 27,076 & 24,347 & 25,543 \\
Categoria & 29,819 & 29,769 & 28,319 & 28,835 & \multicolumn{4}{c}{$\mathrm{N} / \mathrm{A}$} \\
Conceito & 8,111 & 7,809 & 6,985 & 7,287 & 3,255 & 3,014 & 2,497 & 2,677 \\
\hline
\end{tabular}

Tabela 4.6: Eficiência (em porcentual) por macro-averaging de diferentes classificadores bayesianos.

Uma maior participação da probabilidade a priori de cada classe é também encontrada no eixo topográfico, em especial para os níveis de categoria e conceito. Enquanto no nível mais elevado a medida- $F_{2}$ calculada por macro-averaging é de $54,757 \%$ e difere da medida obtida por microaveraging de $73,855 \%$, no nível de conceito essa diferença é mais significativa, uma vez que a medida- $F_{2}$ não ponderada por classe é de apenas $7,287 \%$, enquanto que a mesma medida calculada por micro-averaging alcança 40,415\%.

\subsubsection{Tamanho da base de treinamento}

Com o intuito de avaliar a hipótese de insuficiência de dados de treinamento para o bom desempenho do classificador, foi analisado o comportamento do algoritmo em função do tamanho da base de treinamento. O gráfico presente na Figura 4.2 apresenta no eixo das ordenadas o valor das medidas de avaliação - a saber: precisão, cobertura e medida- $F_{2}$ - do classificador bayesiano de grupos topográficos para cada quantidade de pacientes utilizada para treinamento, exibidas no eixo das abscissas.

A análise do gráfico revela que o desempenho do classificador satura sem utilizar todos os dados disponíveis para treinamento, o que invalida a hipótese de insuficiência de material de entrada. $\mathrm{O}$ classificador atinge $95 \%$ de sua eficiência máxima a partir de 1120 pacientes e supera 99\% para bases de treinamento com mais de 2179 instâncias.

Desse modo, é possível afirmar que o mero aumento do tamanho do corpus não levará a uma melhoria significativa do classificador e que os dados disponíveis são suficientes para o problema em questão.

Ainda com base no gráfico, é razoável supor que o aumento da dimensionalidade do problema sem prejuízo significativo do poder de classificação é possível. Ao reproduzir a análise para o classificador de categorias de topografia, foi obtido o gráfico presente na Figura 4.3. 


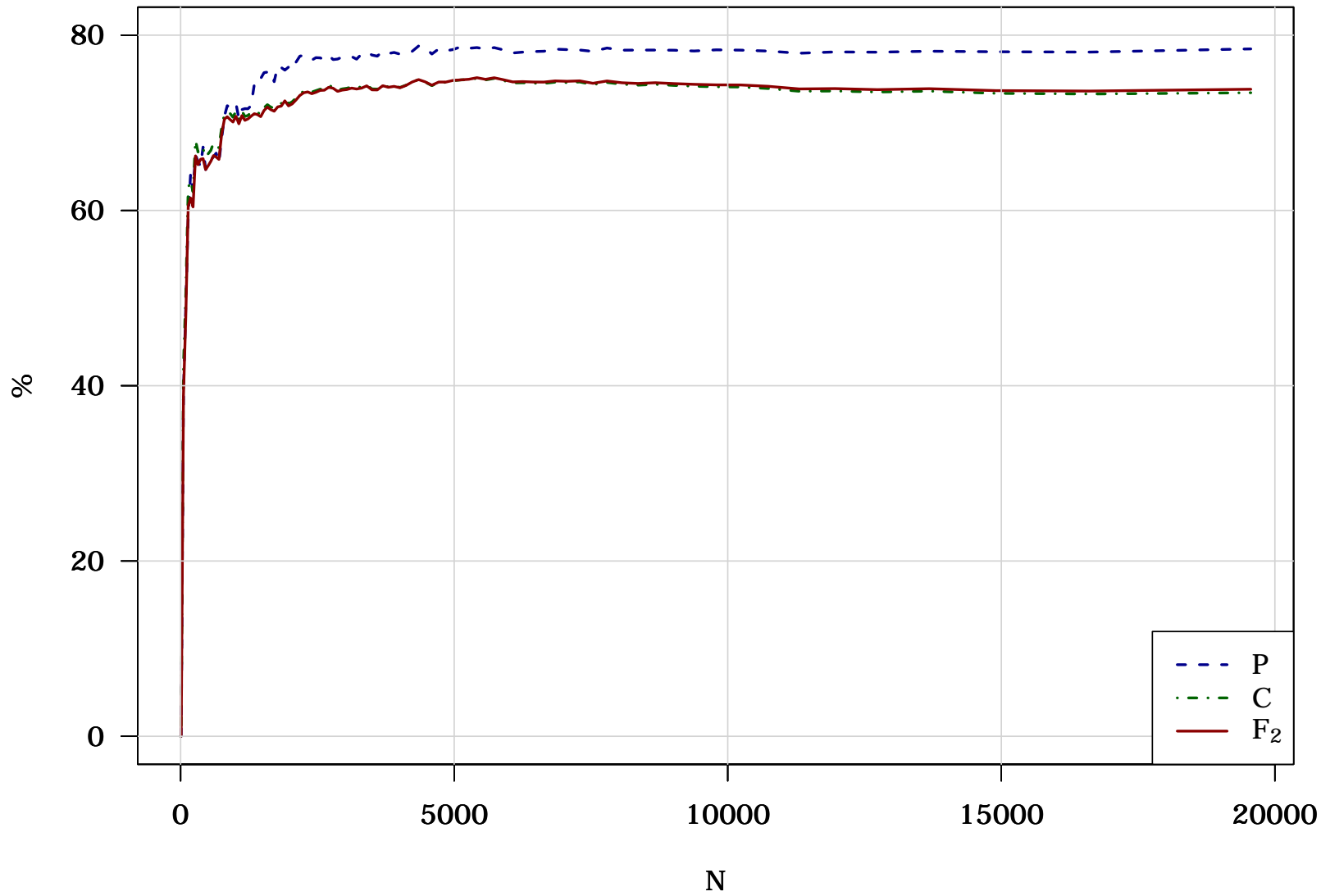

Figura 4.2: Avaliação do classificador de grupos de topografia em função do número de pacientes utilizado para treinamento. 


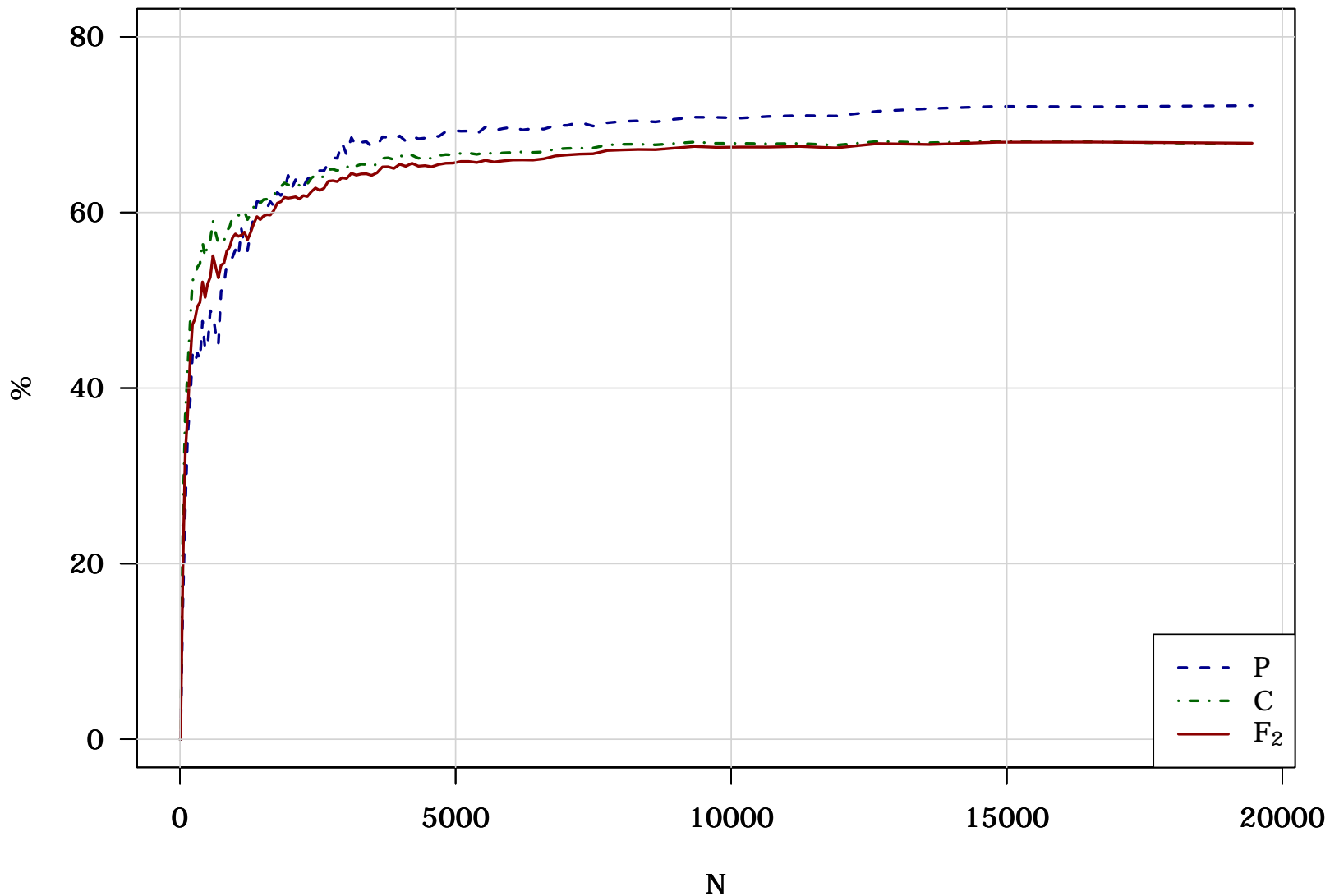

Figura 4.3: Avaliação do classificador de categorias de topografia em função do número de pacientes utilizado para treinamento. 
Ao comparar com o gráfico previamente obtido, é possível observar que o aumento da dimensionalidade do problema de 18 para 70 classes de decisão provoca um deslocamento da saturação das medidas de avaliação para valores maiores do eixo das abscissas. Entretanto, a saturação a $95 \%$ ainda ocorre para valores a partir de 3574 pacientes e a $99 \%$ para mais de 8965 pacientes. Resultados similares foram encontrados para o eixo morfológico e demonstram a suficiência dos dados para todos os cenários considerados.

\subsubsection{Tamanho do vocabulário}

O número de palavras utilizadas no vocabulário de treinamento constitui uma importante variável a ser balanceada. Embora um vocabulário maior tenda a produzir resultados melhores, a velocidade do classificador pode ser gravemente afetada (Baeza-Yates e Ribeiro-Neto, 2011). Por esse motivo, foi avaliada a eficiência do classificador quanto a precisão, cobertura e medida- $F_{2}$ em função do número de palavras presentes no vocabulário, variação representada graficamente na Figura 4.4. Em cada iteração, são descartadas as palavras com menor frequência no corpus de entrada até o número máximo ser atingido, uma técnica de seleção de características simples e eficiente conhecida como "frequência de documentos de um termo" (Baeza-Yates e Ribeiro-Neto, 2011).

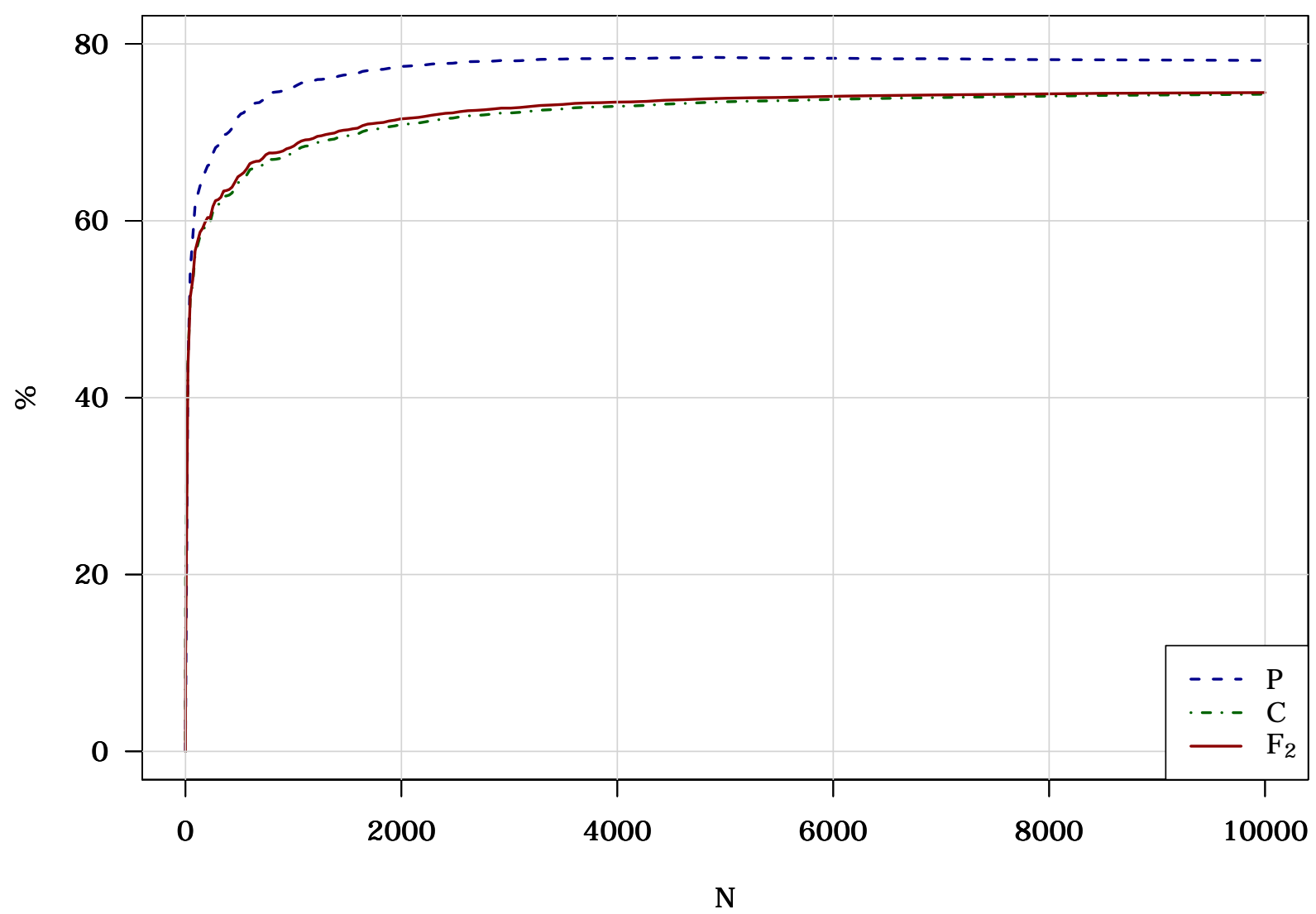

Figura 4.4: Avaliação do classificador de grupo de topografias em função do número de palavras utilizadas para treinamento.

O gráfico revela que a eficiência atinge $95 \%$ de seu máximo com cerca de 1690 palavras e $99 \%$ com 4800 palavras. Conforme previsto pela Lei de Zipf, o aumento do tamanho do vocabulário acima desses valores contribui muito pouco para uma maior eficiência do classificador, mas pode comprometer sua velocidade de execução. Para o presente trabalho, foram selecionadas as 5000 
palavras mais frequentes do corpus para constituir o vocabulário do classificador.

\subsubsection{Número mínimo de laudos por paciente}

Em acordo com o esperado intuitivamente, verificou-se que o número mínimo de laudos por paciente segue uma distribuição exponencial, como pode ser visualizado na Figura 4.5. No gráfico, é possível perceber que a grande maioria dos pacientes possui um número pequeno de laudos, enquanto que um número reduzido de pacientes apresenta maior quantidade de documentos.

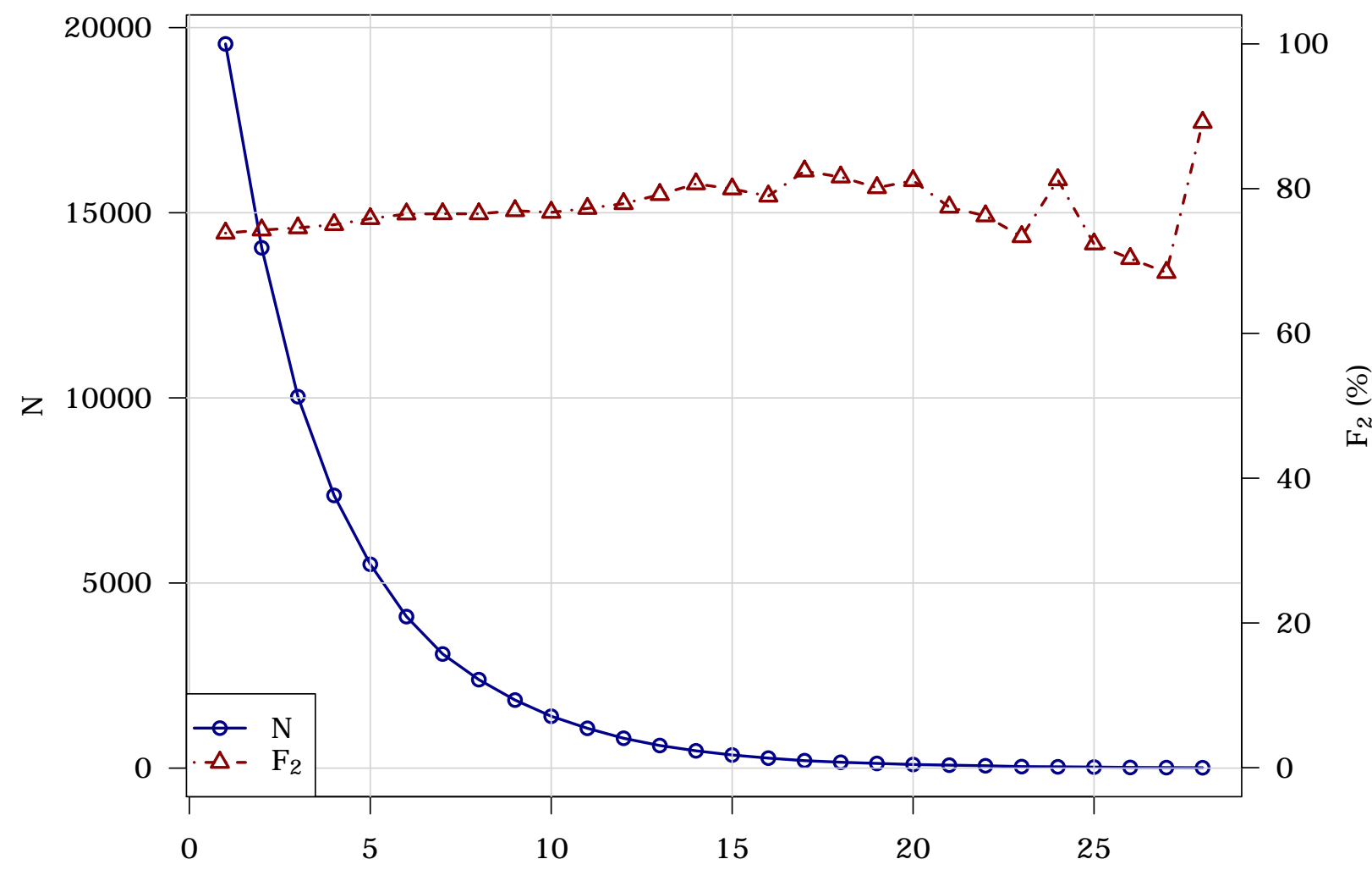

Número mínimo de laudos por paciente

Figura 4.5: Variação do tamanho da amostra e medida- $F_{2}$ em função do número mínimo de laudos por paciente.

Ao limitar a amostra do classificador para pacientes com um número mínimo de laudos, observouse que a eficiência aumenta, como pode ser percebido na Figura 4.5. Para uma amostra em que todos os pacientes possuem ao menos 15 documentos, por exemplo, a medida- $F_{2}$ obtida com o classificador de grupos de topografia subiu de cerca de $74 \%$ para $80 \%$, embora o número de casos tenha sido reduzido de 19560 para 355 pacientes. Resultados similares foram encontrados para os demais níveis de classificação. Devido ao ganho linear em eficiência com a redução exponencial da base de treinamento, a base de estudo considerada utiliza todos os pacientes com ao menos um laudo de anatomia patológica registrado.

A hipótese de uma discordância entre os laudos de um mesmo paciente afetar negativamente a eficiência do classificador foi avaliada com a exclusão de pacientes dotados de mais de um laudo. Esse experimento gerou uma queda significativa na qualidade avaliada do classificador e foi descontinuado. 


\subsubsection{Poder discriminante dos tokens}

Além da probabilidade a priori de um conjunto de laudos pertencer a uma dada classe, o classificador bayesiano também considera a probabilidade a posteriori de um dado token pertencer a cada uma das classes de estudo. Para avaliar a relevância desse critério na classificação de um paciente, foram obtidos os coeficientes para cada combinação de palavra do vocabulário e os 18 grupos topográficos. Um trecho dos valores encontrados pode ser visualizado na Figura 4.6, na qual os coeficientes em cada linha foram destacados em uma escala de cor que varia do vermelho (menor valor) ao verde (maior valor) para facilidade de leitura.

\begin{tabular}{l|l|l|l|l|l|l|l|l|l|l|l|l|l|l|l|l|l|l|l|l|l|l|l|l|l|l}
$\mathrm{C} 00-\mathrm{C} 14$ & $\mathrm{C} 15-\mathrm{C} 26$ & $\mathrm{C} 30-\mathrm{C} 39$ & $\mathrm{C} 40-\mathrm{C} 41$ & $\mathrm{C} 42$ & $\mathrm{C} 44$ & $\mathrm{C} 47$ & $\mathrm{C} 48$ & $\mathrm{C} 49$ & $\mathrm{C} 50$ & $\mathrm{C} 51-\mathrm{C} 58$ & $\mathrm{C} 60-\mathrm{C} 63$ & $\mathrm{C} 64-\mathrm{C} 68$ & $\mathrm{C} 69-\mathrm{C} 72$ & $\mathrm{C} 73-\mathrm{C} 75$ & $\mathrm{C} 76$ & $\mathrm{C} 77$ & $\mathrm{C} 80$
\end{tabular}

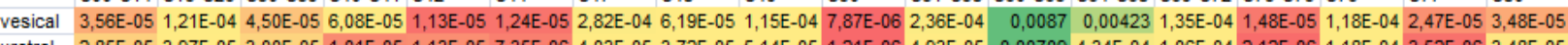
uretral 2,85E-05 3,97E-05 3,00E-05 1,01E-05 1,13E-05 7,35E-06 4,03E-05 3,72E-05 5,14E-05 1,21E-06 4,93E-05 0,00709 4,34E-04 1,06E-04 2,12E-06 1,18E-04 3,52E-06 3,48E-05

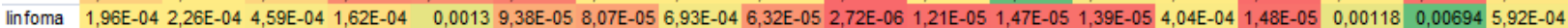
$\begin{array}{lllllllllllllllllll}\text { linfoma } & 1,96 E-04 & 2,26 E-04 & 4,59 E-04 & 1,62 E-04 & 0,0013 & 9,38 E-05 & 8,07 E-05 & 6,93 E-04 & 6,32 E-05 & 2,72 E-06 & 1,21 E-05 & 1,47 E-05 & 1,39 E-05 & 4,04 E-04 & 1,48 E-05 & 0,00118 & 0,00694 & 5,92 E-04 \\ \text { óptico } & 1,60 \mathrm{E}-05 & 8,82 \mathrm{E}-07 & 4,71 \mathrm{E}-05 & 1,01 \mathrm{E}-05 & 3,38 \mathrm{E}-05 & 3,50 \mathrm{E}-05 & 1,21 \mathrm{E}-04 & 1,24 \mathrm{E}-05 & 1,15 \mathrm{E}-04 & 1,21 \mathrm{E}-06 & 8,65 \mathrm{E}-07 & 1,22 \mathrm{E}-06 & 2,32 \mathrm{E}-06 & 0,00588 & 2,12 \mathrm{E}-06 & 1,18 \mathrm{E}-04 & 3,52 \mathrm{E}-06 & 3,48 \mathrm{E}-05\end{array}$

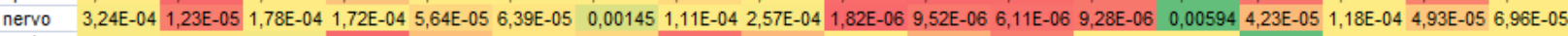

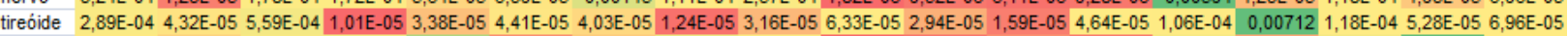

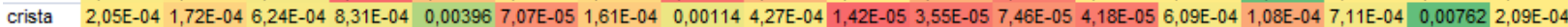

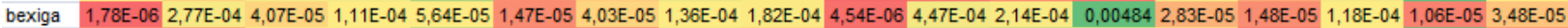

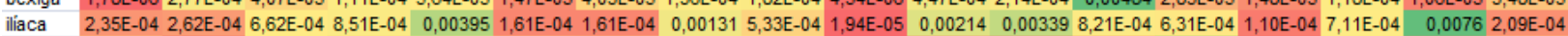

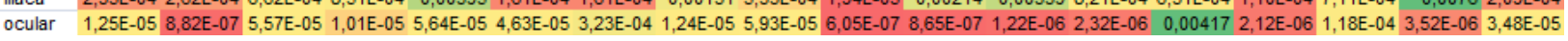

Figura 4.6: Mapa de calor do grupo topográfico.

Um índice denominado fator discriminante e expresso pela Equação 4.1 foi elaborado pelo autor e utilizado para ordenar os tokens com maior poder de decisão na classificação final. O índice varia de 0,5 , quando a probabilidade da palavra a ser gerada em cada uma das classes é a mesma e vale $50 \%$, a 2,0 , quando a palavra possui probabilidade máxima (100\%) de ser gerada em uma classe $c_{i}$ e mínima $(0 \%)$ de ser gerada em uma classe diferente $c_{j}$. Assim como a métrica de informação mútua, o fator apresentado é uma medida da entropia relativa entre as distribuições das classes (Baeza-Yates e Ribeiro-Neto, 2011).

$$
D=\left[\max _{c \in \mathbb{C}} \hat{P}(t \mid c)\right]^{2}+\left[1-\min _{c \in \mathbb{C}} \hat{P}(t \mid c)\right]^{2}
$$

Com base no fator discriminante, foram elencadas as palavras com maior poder de decisão no grupo topográfico, presentes na Tabela 4.7.

\begin{tabular}{c|c|c|c}
\hline Token & $\arg \max _{c \in \mathbb{C}} \hat{P}(t \mid c)$ & $\arg \min _{c \in \mathbb{C}} \hat{P}(t \mid c)$ & $D$ \\
\hline vesical & $\mathrm{C} 60-\mathrm{C} 63$ & $\mathrm{C} 50$ & 1,000059912 \\
uretral & $\mathrm{C} 60-\mathrm{C} 63$ & $\mathrm{C} 50$ & 1,000047880 \\
linfoma & $\mathrm{C} 77$ & $\mathrm{C} 50$ & 1,000042662 \\
óptico & $\mathrm{C} 69-\mathrm{C} 72$ & $\mathrm{C} 50$ & 1,000032853 \\
nervo & $\mathrm{C} 69-\mathrm{C} 72$ & $\mathrm{C} 50$ & 1,000031621 \\
tireóide & $\mathrm{C} 73-\mathrm{C} 75$ & $\mathrm{C} 40-\mathrm{C} 41$ & 1,000030501 \\
crista & $\mathrm{C} 77$ & $\mathrm{C} 50$ & 1,000029548 \\
bexiga & $\mathrm{C} 64-\mathrm{C} 68$ & $\mathrm{C} 00-\mathrm{C} 14$ & 1,000019895 \\
ilíaca & $\mathrm{C} 77$ & $\mathrm{C} 50$ & 1,000019040 \\
ocular & $\mathrm{C} 69-\mathrm{C} 72$ & $\mathrm{C} 50$ & 1,000016205 \\
\hline
\end{tabular}

Tabela 4.7: Lista de tokens com maior poder discriminante para grupo de topografia.

A análise da tabela revela o comportamento verossímil do classificador, haja vista que as palavras destacadas possuem relação semântica com as classes em que a probabilidade é máxima. Por exemplo, o termo "tireóide" possui probabilidade máxima para o grupo topográfico C73-C75: 
Tireóide e outras glândulas endócrinas e mínima para o grupo C40-C41: Ossos, articulações e cartilagens articulares. O significado das demais classes pode ser visualizado no Apêndice A.

Ainda, é possível observar que elementos de frases nominais, como "nervo" e "óptico" na expressão "nervo óptico", possuem probabilidade máxima em um mesmo grupo topográfico; nesse caso, C69-C72: Olho, cérebro e outras partes do sistema nervoso central. O efeito de utilizar frases nominais detectadas automaticamente por meio de técnicas de PLN como características do classificador bayesiano será analisado na Seção 4.5.4 adiante.

\subsubsection{Eficiência por classe}

A matriz de confusão apresentada na Tabela 4.8 revela que, para o grupo topográfico da CID-O, o erro mais frequente apresentado pelo classificador bayesiano ocorre na classificação incorreta de C50: Mama como C51-C58: Órgãos genitais femininos. Tal comportamento é responsável por 8,552\% (444/5192) das instâncias incorretamente classificadas. Em uma análise amostral, verificou-se que, em cerca de $70 \%$ dos casos, a classe correta é a segunda mais provável no índice calculado pelo classificador.

\begin{tabular}{|r||r|r|r|r|r|r|r|r|r|r|r|r|r|r|r|r|r|r|}
\hline & $\mathrm{a}$ & $\mathrm{b}$ & $\mathrm{c}$ & $\mathrm{d}$ & $\mathrm{e}$ & $\mathrm{f}$ & $\mathrm{g}$ & $\mathrm{h}$ & $\mathrm{i}$ & $\mathrm{j}$ & $\mathrm{k}$ & $\mathrm{l}$ & $\mathrm{m}$ & $\mathrm{r}$ & $\mathrm{o}$ & $\mathrm{p}$ & $\mathrm{q}$ & $\mathrm{r}$ \\
\hline \hline $\mathrm{a}=\mathrm{C} 00-\mathrm{C} 14$ & 610 & 3 & 101 & 9 & 32 & 37 & 0 & 0 & 10 & 2 & 11 & 3 & 14 & 7 & 22 & 0 & 42 & 35 \\
$\mathrm{~b}=\mathrm{C} 15-\mathrm{C} 26$ & 20 & 1495 & 123 & 9 & 102 & 30 & 0 & 66 & 23 & 9 & 141 & 8 & 122 & 14 & 17 & 0 & 59 & 25 \\
$\mathrm{c}=\mathrm{C} 30-\mathrm{C} 39$ & 156 & 19 & 397 & 10 & 62 & 17 & 0 & 4 & 17 & 3 & 10 & 3 & 65 & 9 & 14 & 0 & 96 & 42 \\
$\mathrm{~d}=\mathrm{C} 40-\mathrm{C} 41$ & 15 & 1 & 9 & 121 & 15 & 7 & 0 & 1 & 24 & 0 & 5 & 0 & 4 & 2 & 1 & 0 & 13 & 2 \\
$\mathrm{e}=\mathrm{C} 42$ & 3 & 10 & 5 & 14 & 137 & 15 & 0 & 1 & 1 & 0 & 13 & 1 & 18 & 4 & 1 & 0 & 76 & 1 \\
$\mathrm{f}=\mathrm{C} 44$ & 118 & 27 & 19 & 13 & 19 & 3420 & 1 & 4 & 62 & 18 & 55 & 7 & 39 & 14 & 23 & 0 & 37 & 38 \\
$\mathrm{~g}=\mathrm{C} 47$ & 1 & 0 & 4 & 2 & 0 & 8 & 1 & 4 & 15 & 0 & 2 & 0 & 0 & 2 & 1 & 0 & 1 & 1 \\
$\mathrm{~h}=\mathrm{C} 48$ & 0 & 7 & 2 & 0 & 7 & 2 & 2 & 63 & 20 & 0 & 8 & 0 & 6 & 0 & 1 & 0 & 19 & 1 \\
$\mathrm{i}=\mathrm{C} 49$ & 20 & 4 & 10 & 32 & 4 & 25 & 0 & 18 & 302 & 1 & 11 & 0 & 11 & 5 & 3 & 0 & 22 & 4 \\
$\mathrm{j}=\mathrm{C} 50$ & 19 & 28 & 36 & 10 & 37 & 61 & 0 & 3 & 19 & 2950 & $\mathbf{4 4 4}$ & 1 & 83 & 13 & 30 & 0 & 9 & 23 \\
$\mathrm{k}=\mathrm{C} 51-\mathrm{C} 58$ & 22 & 100 & 20 & 3 & 25 & 20 & 0 & 52 & 25 & 7 & 1220 & 0 & 84 & 7 & 9 & 0 & 11 & 36 \\
$\mathrm{l}=\mathrm{C} 60-\mathrm{C} 63$ & 26 & 63 & 30 & 9 & 33 & 75 & 2 & 38 & 40 & 1 & 8 & 1211 & 57 & 14 & 25 & 0 & 18 & 18 \\
$\mathrm{~m}=\mathrm{C} 64-\mathrm{C} 68$ & 4 & 27 & 14 & 6 & 11 & 6 & 0 & 48 & 12 & 1 & 42 & 8 & 449 & 5 & 31 & 0 & 8 & 5 \\
$\mathrm{n}=\mathrm{C} 69-\mathrm{C} 72$ & 13 & 14 & 8 & 6 & 19 & 36 & 1 & 0 & 8 & 0 & 23 & 1 & 7 & 384 & 3 & 0 & 36 & 6 \\
$\mathrm{O}=\mathrm{C} 73-\mathrm{C} 75$ & 36 & 10 & 16 & 4 & 23 & 26 & 0 & 26 & 8 & 6 & 54 & 2 & 24 & 6 & 1098 & 0 & 8 & 12 \\
$\mathrm{p}=\mathrm{C} 76$ & 0 & 0 & 2 & 0 & 2 & 0 & 0 & 0 & 3 & 0 & 0 & 0 & 1 & 0 & 0 & 0 & 2 & 0 \\
$\mathrm{q}=\mathrm{C} 77$ & 4 & 7 & 11 & 1 & 40 & 5 & 0 & 6 & 2 & 2 & 15 & 0 & 13 & 3 & 5 & 0 & 494 & 0 \\
$\mathrm{r}=\mathrm{C} 80$ & 6 & 1 & 6 & 0 & 5 & 4 & 0 & 1 & 4 & 1 & 2 & 0 & 3 & 1 & 0 & 0 & 5 & 16 \\
\hline
\end{tabular}

Tabela 4.8: Matriz de confusão para grupo de topografia. Os valores para cada par de classes indicam o número de pacientes classificados como tal. A classe correta está representada nas linhas e a classe escolhida pelo classificador, nas colunas.

No grupo C51-C58: Órgãos genitais femininos citado, a categoria mais expressiva é C53: Colo do útero, o que pode revelar um comportamento específico do domínio de estudo, haja vista que o diagnóstico de câncer de mama é normalmente acompanhado por um exame preventivo de câncer de colo de útero. Além disso, C53: Colo do útero possui probabilidade $a$ priori elevada, motivo por si só suficiente para justificar o erro do classificador.

Entretanto, a hipótese simplificadora adotada no início, ao considerar uma única topografia para todos os laudos anatomopatológicos de um mesmo paciente, pode aqui se revelar falha. Como não há dados disponíveis para cada um dos documentos, a classificação do paciente no Registro Hospitalar 
de Câncer é utilizada para todas as instâncias, o que nem sempre é uma assunção verossímil. Em um trabalho subsequente, a utilização de um classificador multialvo pode trazer melhorias nesse ponto.

O comportamento apresentado anteriormente reflete em uma menor precisão - e, consequentemente, menor medida- $F_{2}$ - para o grupo C51-C58: Órgãos genitais femininos, como expresso na Tabela 4.9. A tabela apresenta as medidas de precisão, cobertura e medida- $F_{2}$ em cada um dos grupos topográficos considerados.

\begin{tabular}{c|c|c|c|l}
\hline $\mathrm{P}$ & $\mathrm{C}$ & $F_{2}$ & Classe & Descrição \\
\hline 0,901 & 0,874 & 0,879 & $\mathrm{C} 44$ & Pele \\
0,855 & 0,808 & 0,817 & C73-C75 & Tireóide e outras glândulas endócrinas \\
0,983 & 0,783 & 0,816 & $\mathrm{C} 50$ & Mama \\
0,973 & 0,726 & 0,765 & $\mathrm{C} 60-\mathrm{C} 63$ & Órgãos genitais masculinos \\
0,517 & 0,813 & 0,729 & $\mathrm{C} 77$ & Linfonodos \\
0,591 & 0,743 & 0,707 & $\mathrm{C} 51-\mathrm{C} 58$ & Orgãos genitais femininos \\
0,784 & 0,680 & 0,699 & C69-C72 & Olho, cérebro e outras partes do sistema nervoso central \\
0,568 & 0,661 & 0,640 & C15-C26 & Órgãos digestivos \\
0,568 & 0,650 & 0,632 & C00-C14 & Lábio, cavidade oral e faringe \\
0,508 & 0,640 & 0,608 & C49 & Tecido conjuntivo, subcutâneo e outros tecidos moles \\
0,449 & 0,663 & 0,605 & C64-C68 & Trato urinário \\
0,486 & 0,550 & 0,536 & C40-C41 & Ossos, articulações e cartilagens articulares \\
0,488 & 0,430 & 0,440 & C30-C39 & Aparelho respiratório e órgãos intratorácicos \\
0,239 & 0,457 & 0,386 & C42 & Sistemas hematopoiético e reticuloendotelial \\
0,188 & 0,457 & 0,355 & C48 & Retroperitônio e peritônio \\
0,060 & 0,291 & 0,164 & C80 & Localização primária desconhecida \\
0,143 & 0,024 & 0,029 & C47 & Nervos periféricos e sistema nervoso autômato \\
0,000 & 0,000 & 0,000 & C76 & Outras localizações e localizações mal definidas \\
\hline
\end{tabular}

Tabela 4.9: Eficiência (valor absoluto) por classe para grupo de topografia, ordenada pela medida- $F_{2}$.

Por outro lado, a tabela também revela excelente precisão de 98,3\% para o grupo C50: Mama e de 97,3\% para o grupo C60-C63: Órgaos genitais masculinos. No que diz respeito à medida de cobertura, os melhores resultados são encontrados para o grupo C44: Pele, o que reflete também em uma melhor medida- $F_{2}$. Valores nulos foram encontrados para o grupo C76: Outras localizações e localizações mal definidas, haja vista que, dos dez exemplos presentes na base, nenhum foi corretamente identificado.

\subsubsection{Resultados finais}

Os resultados apresentados nessa seção revelaram que a base de treinamento disponível é superior em todos os aspectos analisados ao mínimo necessário para atingir eficiência próxima à máxima. Desse modo, embora valores menores possam ser utilizados em ambientes em que o desempenho computacional seja um fator crítico, serão utilizados no presente trabalho todos os dados disponíveis. Essa assunção garante a possibilidade de análises futuras em que um maior refinamento da classificação seja desejável.

Por esse motivo e levando em conta o pequeno ganho em eficiência ao se restringir o número mínimo de laudos por paciente, serão utilizados na amostra todos os pacientes com ao menos um laudo registrado nos sistemas. 
No que diz respeito ao tamanho do vocabulário construído pelo classificador, serão utilizados, conforme apresentado na subseção correspondente, os 5000 tokens mais frequentes.

\subsection{Técnicas de Suavização}

\subsubsection{Suavização de Laplace}

O desempenho do classificador obtido até então pode ser resumido por meio da Tabela 4.10. Nela, são exibidas as eficiências porcentuais de classificadores treinados com Suavização de Laplace, a técnica mais simples para eliminar o problema de probabilidades nulas para dados não vistos na base de treinamento.

\begin{tabular}{c|cccc|cccc}
\hline Nível & \multicolumn{4}{|c|}{ Topografia } & \multicolumn{4}{c}{ Morfologia } \\
& $\mathrm{P}$ & $\mathrm{C}$ & $F_{1}$ & $F_{2}$ & $\mathrm{P}$ & $\mathrm{C}$ & $F_{1}$ & $F_{2}$ \\
\hline Grupo & 78,459 & 73,456 & 75,053 & 73,855 & 68,235 & 60,749 & 62,302 & 60,877 \\
Categoria & 72,279 & 67,950 & 68,957 & 68,029 & \multicolumn{4}{c}{$\mathrm{N} / \mathrm{A}$} \\
Conceito & 42,433 & 41,806 & 39,681 & 40,415 & 46,819 & 41,832 & 41,467 & 40,892 \\
\hline
\end{tabular}

Tabela 4.10: Eficiência (em porcentual) de diferentes classificadores bayesianos com o uso de suavização de Laplace.

\subsubsection{Add $-\alpha$}

A adoção da suavização $a d d-\alpha$ - técnica em que um valor $\alpha, 0<\alpha \leq 1$, é adicionado em cada contagem de frequência de termos — produziu os resultados apresentados na Tabela 4.11. Para o presente trabalho, foi adotado $\alpha=0,5$.

\begin{tabular}{c|cccc|cccc}
\hline Nível & \multicolumn{4}{|c|}{ Topografia } & \multicolumn{4}{c}{ Morfologia } \\
& $\mathrm{P}$ & $\mathrm{C}$ & $F_{1}$ & $F_{2}$ & $\mathrm{P}$ & $\mathrm{C}$ & $F_{1}$ & $F_{2}$ \\
\hline Grupo & 78,928 & 73,451 & 75,304 & 73,952 & 68,813 & 60,172 & 62,256 & 60,490 \\
Categoria & 73,180 & 67,631 & 69,284 & 67,995 & \multicolumn{4}{c}{$\mathrm{N} / \mathrm{A}$} \\
Conceito & 43,239 & 40,820 & 39,941 & 40,063 & 49,151 & 39,705 & 40,673 & 39,197 \\
\hline
\end{tabular}

Tabela 4.11: Eficiência (em porcentual) de diferentes classificadores bayesianos com o uso de suavização add- $\alpha$.

A tabela revela que a suavização $a d d-\alpha$ tende a produzir melhores resultados de precisão em detrimento das medidas de cobertura. Esse fato está relacionado à menor crença na uniformidade, que, ao refletir melhor o comportamento real encontrado, reduz o erro decorrente da contagem de termos desconhecidos.

\subsubsection{Good-Turing}

A Tabela 4.12 apresenta os resultados obtidos para um classificador bayesiano suavizado por Good-Turing. A técnica baseia-se na intuição de que, uma vez vistos muitos termos uma única vez na base de treinamento, é muito provável que termos inéditos sejam igualmente prováveis.

Os resultados encontrados demonstram, assim como para a técnica de suavização $a d d-\alpha$, um ganho de precisão, contraposto a uma redução significativa de cobertura. Haja vista que a medida 


\begin{tabular}{c|cccc|cccc}
\hline Nível & \multicolumn{4}{|c|}{ Topografia } & \multicolumn{4}{c}{ Morfologia } \\
& $\mathrm{P}$ & $\mathrm{C}$ & $F_{1}$ & $F_{2}$ & $\mathrm{P}$ & $\mathrm{C}$ & $F_{1}$ & $F_{2}$ \\
\hline Grupo & 77,135 & 66,570 & 69,320 & 67,146 & 70,918 & 45,790 & 48,354 & 45,995 \\
Categoria & 77,642 & 56,522 & 62,936 & 58,359 & \multicolumn{4}{c}{$\mathrm{N} / \mathrm{A}$} \\
Conceito & 47,802 & 32,901 & 36,506 & 33,761 & 51,860 & 30,953 & 34,617 & 31,498 \\
\hline
\end{tabular}

Tabela 4.12: Eficiência (em porcentual) de diferentes classificadores bayesianos com o uso de suavização Good-Turing.

$F_{2}$ privilegia o segundo índice, seu valor também é reduzido consideravelmente. A queda de eficiência está relacionada ao fato de os laudos serem padronizados, o que reduz a chance de ocorrência de termos inéditos na base de teste, premissa adotada pela suavização.

\subsubsection{Resultados finais}

Além de gerar resultados mais confiáveis, a adoção de uma técnica de suavização para suprimir probabilidades nulas em termos desconhecidos produz um classificador com maior eficiência. Dada a flexibilidade de ajuste do fator $\alpha$, foi escolhida a suavização add- $\alpha$ como referência para as análises das seções futuras.

\subsection{Processamento de Linguagem Natural}

Os resultados apresentados nas seções anteriores utilizam versões simplificadas de técnicas de processamento de linguagem natural, de forma com que o impacto de técnicas mais sofisticadas possa ser analisado em separado. Em termos concretos, a identificação de sentenças é ignorada, a detecção de tokens é baseada unicamente em caracteres vazios (espaço, tabulação, nova linha, retorno de carro e alimentação de formulário), nenhuma palavra é excluída como stopword e os termos são utilizados como características do classificador sem etapas adicionais de normalização.

A seção presente apresenta e discute os resultados obtidos através da utilização de técnicas mais sofisticadas, problema central do presente trabalho.

\subsubsection{Stopwords}

Com o intuito de reduzir o tamanho do léxico utilizado pelo classificador, foram excluídas as 36 palavras mais frequentes do corpus sob estudo, consideradas stopwords conforme explicitado na Seção 2.3.2. Para efeito de comparação, a lista utilizada é exibida ao lado da lista compilada por Sardinha (2004) na Tabela 4.13.

A análise da tabela revela, conforme esperado, uma maior predominância de termos médicos no corpus em estudo, cuja frequência é superior às palavras mais comuns do domínio jornalístico. Tal fato está diretamente relacionado ao uso de modelos para confecção dos laudos, em que um conjunto de palavras fixo é utilizado em todos os documentos. Em todo caso, a ordem relativa das palavras mais frequentes da língua portuguesa, salvo raras exceções, é preservada no corpus médico, o que sugere boa adequação linguística dos textos em estudo. No classificador elaborado, a utilização de uma lista de exclusão de palavras gerou uma melhoria nos resultados de eficiência encontrados, conforme visto na Tabela 4.14 . 


\begin{tabular}{|c|c|c|}
\hline Posição & Banco de Português & Anatomia Patológica \\
\hline 1 & de & de \\
\hline 2 & $\mathrm{a}$ & $\mathrm{e}$ \\
\hline 3 & o & $\mathrm{a}$ \\
\hline 4 & $\mathrm{e}$ & material \\
\hline 5 & que & exame \\
\hline 6 & do & $\mathrm{cm}$ \\
\hline 7 & da & o \\
\hline 8 & $\mathrm{em}$ & em \\
\hline 9 & para & do \\
\hline 10 & no & espécime \\
\hline 11 & é & foi \\
\hline 12 & com & histológico \\
\hline 13 & os & com \\
\hline 14 & um & por \\
\hline 15 & na & medindo \\
\hline 16 & não & submetido \\
\hline 17 & uma & totalmente \\
\hline 18 & se & tecido \\
\hline 19 & por & células \\
\hline 20 & dos & da \\
\hline 21 & as & mede \\
\hline 22 & mais & não \\
\hline 23 & ao & que \\
\hline 24 & são & margem \\
\hline 25 & como & fragmentos \\
\hline 26 & foi & para \\
\hline 27 & das & pele \\
\hline 28 & à & superfície \\
\hline 29 & mas & congelação \\
\hline 30 & ele & recebido \\
\hline
\end{tabular}

Tabela 4.13: Comparação entre lista de palavras do Banco de Português (Sardinha, 2004) e do dominio em estudo.

\begin{tabular}{c|cccc|cccc}
\hline Nível & \multicolumn{4}{|c|}{ Topografia } & \multicolumn{4}{c}{ Morfologia } \\
& $\mathrm{P}$ & $\mathrm{C}$ & $F_{1}$ & $F_{2}$ & $\mathrm{P}$ & $\mathrm{C}$ & $F_{1}$ & $F_{2}$ \\
\hline Grupo & 79,102 & 73,931 & 75,667 & 74,395 & 69,450 & 60,827 & 62,923 & 61,155 \\
Categoria & 73,409 & 68,238 & 69,765 & 68,561 & \multicolumn{4}{c}{$\mathrm{N} / \mathrm{A}$} \\
Conceito & 43,481 & 41,427 & 40,307 & 40,560 & 49,594 & 40,442 & 41,333 & 39,904 \\
\hline
\end{tabular}

Tabela 4.14: Eficiência (em porcentual) de diferentes classificadores bayesianos com o uso de stopwords. 


\subsubsection{Detecção de sentenças e itemização}

A utilização de uma ferramenta especialista em detecção de sentenças e itemização, em conunto com o uso de stopwords, produziu os resultados de classificação apresentados na Tabela 4.15. A análise da tabela revela pouca ou nenhuma melhoria em relação aos valores obtidos na seção 4.4, de acordo com o esperado. Um exemplo do processamento realizado está presente na Figura 4.7.

\begin{tabular}{c|cccc|cccc}
\hline Nível & \multicolumn{4}{|c|}{ Topografia } & \multicolumn{4}{c}{ Morfologia } \\
& $\mathrm{P}$ & $\mathrm{C}$ & $F_{1}$ & $F_{2}$ & $\mathrm{P}$ & $\mathrm{C}$ & $F_{1}$ & $F_{2}$ \\
\hline Grupo & 79,081 & 73,865 & 75,622 & 74,337 & 69,353 & 60,671 & 62,773 & 61,002 \\
Categoria & 73,469 & 68,192 & 69,728 & 68,512 & \multicolumn{4}{c}{$\mathrm{N} / \mathrm{A}$} \\
Conceito & 43,761 & 41,527 & 40,533 & 40,718 & 49,390 & 40,184 & 41,112 & 39,654 \\
\hline
\end{tabular}

Tabela 4.15: Eficiência (em porcentual) de diferentes classificadores bayesianos com o uso de detector de sentenças e itemizador.

\section{Entrada:}

Carcinoma de mama sem amplificação do gene HER-2/neu pesquisada através de FISH. Razão HER2/cr17 igual a 1,4 .

Saída:

[Carcinoma] [de] [mama] [sem] [amplificação] [de] [o] [gene] [HER-2/neu] [pesquisada] [através] [de] [FISH] [.]

[Razão] [HER2/cr17] [igual] [a] [1,4] [.]

Figura 4.7: Exemplo de texto antes e após processamento por detector de sentenças e itemização.

\subsubsection{Detecção de radicais}

Ainda com objetivo de redução do tamanho do vocabulário, foi analisado o impacto da utilização de stemmer e lemmatizer para deteç̧ão do radical de cada token. Os resultados encontrados estão presentes nas Tabelas 4.16 e 4.17. Exemplos dos processamentos realizados podem ser vistos nas Figuras 4.8 e 4.9. Convém observar que, embora a saída do detector de lemas seja mais compreensível, alguns radicais não foram localizados e a forma original foi mantida.

Em termos gerais, os melhores resultados com detecção de radicais foram exibidos com o uso de stemmer. Esse fato pode estar relacionado à necessidade de adaptação de um dicionário médico à ferramenta de detecção de lemas, enquanto que o primeiro opera por regras gerais ao idioma. A análise das tabelas revela ainda uma melhora na eficiência do classificador de topografia em nível de conceito e grupo com o uso da ferramenta.

\begin{tabular}{c|cccc|cccc}
\hline Nível & \multicolumn{4}{|c|}{ Topografia } & \multicolumn{4}{c}{ Morfologia } \\
& $\mathrm{P}$ & $\mathrm{C}$ & $F_{1}$ & $F_{2}$ & $\mathrm{P}$ & $\mathrm{C}$ & $F_{1}$ & $F_{2}$ \\
\hline Grupo & 79,141 & 73,978 & 75,698 & 74,431 & 69,098 & 60,557 & 62,588 & 60,864 \\
Categoria & 73,265 & 68,202 & 69,619 & 68,473 & \multicolumn{4}{c}{$\mathrm{N} / \mathrm{A}$} \\
Conceito & 43,393 & 41,727 & 40,472 & 40,801 & 48,965 & 40,411 & 41,146 & 39,828 \\
\hline
\end{tabular}

Tabela 4.16: Eficiência (em porcentual) de diferentes classificadores bayesianos com o uso de stemmer. 


\begin{tabular}{c|cccc|cccc}
\hline Nível & \multicolumn{4}{|c|}{ Topografia } & \multicolumn{4}{c}{ Morfologia } \\
& $\mathrm{P}$ & $\mathrm{C}$ & $F_{1}$ & $F_{2}$ & $\mathrm{P}$ & $\mathrm{C}$ & $F_{1}$ & $F_{2}$ \\
\hline Grupo & 79,020 & 73,865 & 75,610 & 74,337 & 69,107 & 60,604 & 62,557 & 60,876 \\
Categoria & 73,165 & 68,063 & 69,539 & 68,361 & \multicolumn{4}{c}{$\mathrm{N} / \mathrm{A}$} \\
Conceito & 43,342 & 41,474 & 40,299 & 40,581 & 49,560 & 40,347 & 41,276 & 39,827 \\
\hline
\end{tabular}

Tabela 4.17: Eficiência (em porcentual) de diferentes classificadores bayesianos com o uso de lemmatizer.

\section{Entrada:}

Recebemos para revisão 01 bloco e 01 lâmina identificados como M10-20990, provenientes do Serviço de Anatomia Patológica de Santos, acompanhados do respectivo laudo anátomo-patológico. Aqui, foram identificados como A-1032588.

\section{Saída:}

[receb] [par] [revisã] [01] [bloc] [e] [01] [lâmin] [identific] [com] [m10-20990] [,] [provenient] [de] [o] [servic] [de] [anatom] [patológ] [de] [sant] [,] [acompanh] [de] [o] [respect] [laud] [anátomo-patológ] [.]

[aqu] [,] [for] [identific] [com] [a-1032588] [.]

Figura 4.8: Exemplo de texto antes e após processamento por stemmer.

\section{Entrada:}

Recebemos para revisão 01 bloco e 01 lâmina identificados como M10-20990, provenientes do

Serviço de Anatomia Patológica de Santos, acompanhados do respectivo laudo anátomo-patológico. Aqui, foram identificados como A-1032588.

\section{Saída:}

[receber] [para] [revisão] [01] [bloco] [e] [01] [lâmina] [identificar] [como] [M10-20990] [,] [proveniente] [de] [o] [serviço] [de] [Anatomia] [Patológica] [de] [Santos] [,] [acompanhar] [de] [o] [respectivo] [laudo] [anátomo-patológico] [.] [aqui] [,] [ir] [identificar] [como] [A-1032588] [.]

Figura 4.9: Exemplo de texto antes e após processamento por detector de lemas. 


\subsubsection{Detecção de segmentos}

Ao utilizar um detector de segmentos, é possível remover tokens não interessantes à classificação e utilizar expressões com significado completo como característica em um classificador bayesiano. Os resultados do uso de um detector de segmentos — aliado à suavização $a d d-\alpha(\alpha=0,5)$, remoção de stopwords, detecção de segmentos e lemas e itemização — na tarefa de classificação pode ser visto na Tabela 4.18. Um exemplo do processamento realizado está presente na Figura 4.10.

\begin{tabular}{c|cccc|cccc}
\hline Nível & \multicolumn{4}{|c|}{ Topografia } & \multicolumn{4}{c}{ Morfologia } \\
& $\mathrm{P}$ & $\mathrm{C}$ & $F_{1}$ & $F_{2}$ & $\mathrm{P}$ & $\mathrm{C}$ & $F_{1}$ & $F_{2}$ \\
\hline Grupo & 77,811 & 72,198 & 74,067 & 72,699 & 68,071 & 59,731 & 61,584 & 59,980 \\
Categoria & 71,709 & 66,387 & 67,925 & 66,690 & \multicolumn{4}{c}{$\mathrm{N} / \mathrm{A}$} \\
Conceito & 41,808 & 39,956 & 38,856 & 39,078 & 47,930 & 39,511 & 40,429 & 39,017 \\
\hline
\end{tabular}

Tabela 4.18: Eficiência (em porcentual) de diferentes classificadores bayesianos com o uso de detector de segmentos.

\section{Entrada:}

O quadro morfológico associado ao estudo imunoistoquímico é compatível com Carcinoma ductal invasivo, com perfil molecular a ser definido após exame de FISH.

\section{Saída:}

[o quadro morfológico] [associar] [a] [o estudo imunoistoquímico] [ser] [compatível] [com] [carcinoma ductal invasivo] [com] [perfil molecular] [a] [ser definir] [após] [exame] [de] [FISH]

Figura 4.10: Exemplo de texto antes e após processamento por detector de segmentos.

Os valores apresentados são inferiores aos anteriormente apresentados na seção 4.4, o que pode estar relacionado a uma baixa acurácia dos modelos linguísticos utilizados - originalmente treinados em textos de jornais - quando aplicados ao domínio médico. Ao fazerem um trabalho amplo e atualizado de revisão bibliográfica sobre o assunto, Barrett e Weber-Jahnke (2011) relatam decréscimo médio de $10 \%$ nas taxas de acurácia observadas.

Por outro lado, a utilização de um detector de segmentos garante maior poder de expressividade ao classificador, especialmente se adaptado para um modelo baseado em regras. Essa maior expressividade pode ser vista na Tabela 4.19, que revela as expressões com maior poder de decisão para o grupo topográfico no CID-O.

\begin{tabular}{c|c|c|c}
\hline Chunk & $\arg \max _{c \in \mathbb{C}} \hat{P}(t \mid c)$ & $\arg \min _{c \in \mathbb{C}} \hat{P}(t \mid c)$ & $D$ \\
\hline tireóide & $\mathrm{C} 73-\mathrm{C} 75$ & $\mathrm{C} 40-\mathrm{C} 41$ & 1,000049738 \\
linfoma & $\mathrm{C} 77$ & $\mathrm{C} 50$ & 1,000037854 \\
nervo óptico & $\mathrm{C} 69-\mathrm{C} 72$ & $\mathrm{C} 50$ & 1,000036597 \\
margem vesical & $\mathrm{C} 60-\mathrm{C} 63$ & $\mathrm{C} 50$ & 1,000031935 \\
lobo esquerdo & $\mathrm{C} 73-\mathrm{C} 75$ & $\mathrm{C} 40-\mathrm{C} 41$ & 1,000022883 \\
microbiologia & $\mathrm{C} 51-\mathrm{C} 58$ & $\mathrm{C} 60-\mathrm{C} 63$ & 1,000021195 \\
tecido ósseo trabeculado & $\mathrm{C} 77$ & $\mathrm{C} 50$ & 1,000020879 \\
vesícula seminal & $\mathrm{C} 60-\mathrm{C} 63$ & $\mathrm{C} 50$ & 1,000018667 \\
porção posterior & $\mathrm{C} 60-\mathrm{C} 63$ & $\mathrm{C} 50$ & 1,000017610 \\
prostatectomia radical & $\mathrm{C} 60-\mathrm{C} 63$ & $\mathrm{C} 50$ & 1,000014548 \\
\hline
\end{tabular}

Tabela 4.19: Lista de segmentos com maior poder discriminante para grupo de topografia. 
Bastante similar à Tabela 4.7 anteriormente apresentada, aqui os termos relacionados surgem unidos em um mesmo conceito. Por exemplo, os tokens "nervo" e "óptico" são agora representados em um mesmo chunk "nervo óptico" e possuem, do mesmo modo, probabilidade máxima para o grupo topográfico C69-C72: Olho, cérebro e outras partes do sistema nervoso central.

Ainda, a semântica é preservada. A presença da expressão "prostatectomia radical" é um forte fator determinante para a classificação do caso sob análise com o grupo C60-C63: Órgãos genitais masculinos e, ao mesmo tempo, sua exclusão do grupo C50: Mama.

\subsection{Discussão}

Para facilitar a comparação dos resultados encontrados em diferentes tarefas de classificação a partir da utilização dos métodos propostos, foram organizadas na Tabela 4.20 as medidas de eficiência $F_{2}$ encontradas. Linhas horizontais separam os grupos de estudo, dentro dos quais as características exploradas são cumulativas. O melhor resultado de um grupo de estudo é promovido ao grupo de estudo seguinte.

\begin{tabular}{c|ccc|cc}
\hline Método & \multicolumn{3}{|c|}{ Topografia } & \multicolumn{2}{c}{ Morfologia } \\
& Grupo & Categoria & Conceito & Grupo & Conceito \\
\hline Limite inferior & 11,120 & 11,217 & 2,224 & 11,104 & 5,623 \\
\hline Suavização de Laplace & 73,855 & 68,029 & 40,415 & 60,877 & $\mathbf{4 0 , 8 9 2}$ \\
Suavização add- $\alpha$ & 73,952 & 67,995 & 40,063 & 60,490 & 39,197 \\
Suavização Good-Turing & 67,146 & 58,359 & 33,761 & 45,995 & 31,498 \\
\hline Stopwords & 74,395 & $\mathbf{6 8 , 5 6 1}$ & 40,560 & $\mathbf{6 1 , 1 5 5}$ & 39,904 \\
Detecção de sentenças e itemização & 74,337 & 68,512 & 40,718 & 61,002 & 39,654 \\
Stemmer & $\mathbf{7 4 , 4 3 1}$ & 68,473 & $\mathbf{4 0 , 8 0 1}$ & 60,864 & 39,828 \\
Detecção de lemas & 74,337 & 68,361 & 40,581 & 60,876 & 39,827 \\
Deteç̧ão de segmentos & 72,699 & 66,690 & 39,078 & 59,980 & 39,017 \\
\hline
\end{tabular}

Tabela 4.20: Resultados (em porcentual) encontrados para medida- $F_{2}$ em diferentes configurações.

Ao contrário do esperado, a utilização de técnicas simples de processamento de linguagem natural, como uso de stopwords, detecção de sentenças, itemização, detecção de radicais e detecção de lemas, trouxe melhores resultados ao classificador de topografia e morfologia em todos os níveis. Uma análise mais refinada revela ainda um ganho de precisão em praticamente todos os cenários contemplados com as técnicas de processamento de linguagem natural. Esse fato revela a importância do uso dessas técnicas para melhoria da qualidade dos resultados individuais.

Embora permita a construção de modelos mais refinados, a utilização de técnicas mais sofisticadas de PLN, como a deteç̧ão de segmentos, trouxe uma piora nos resultados de classificação encontrados. Baseado na saída de um etiquetador morfossintático (ferramenta responsável por identificar a classe gramatical de cada palavra), o detector de segmentos é, portanto, indiretamente dependente de uma boa cobertura do dicionário utilizado. Além disso, a predominância de sentenças curtas no domínio estudado oferece pouco contexto para a identificação de segmentos, o que pode contribuir para uma baixa eficiência da ferramenta.

A criação ou utilização de um dicionário especialista, em conjunto com o retreinamento de modelos linguísticos no domínio médico pode aprimorar também a eficiência da tarefa de classificação. 
Oleynik et al. (2010) relatam uma variação de 75,3\% para 91,5\% na acurácia de um etiquetador morfológico aplicado no domínio médico quando treinado, respectivamente, em um corpus jornalístico e em um corpus médico.

Embora não avaliada nesse estudo, a eficiência em classes pouco representativas do corpus poderia ser aprimorada por meio de uma melhor seleção de características. A utilização de métricas como $t f . i d f$, informação mútua, ganho de informação e chi-quadrado (Baeza-Yates e Ribeiro-Neto, 2011) ou então um limiar de frequência de termos $t f$ definido por classe pode trazer ganhos nesses casos, sem prejuízo das medidas de eficiências globais avaliadas. Em especial, a utilização de um detector de segmentos provoca uma explosão combinatória do número de termos presentes no vocabulário, para o qual o limiar de frequência utilizado pode ser inapropriado.

$\mathrm{Na}$ avaliação do classificador, deve-se considerar também que mesmo humanos nem sempre concordam quanto à classificação de um documento, seja por falta de informação e contexto, seja por falha. Em um artigo escrito pelo diretor do departamento de Anatomia Patológica do A.C. Camargo Cancer Center, Soares (2012) apresenta os diversos erros que permeiam os laudos e os divide em erros pré-analíticos, analíticos e pós-analíticos. O autor afirma que, em casos difíceis, "a interpretação entre dois patologistas pode ser discordante, ainda que ambas sejam viáveis e plausíveis" e que diversos trabalhos científicos mostram "altos níveis de discrepância entre diagnósticos interobservadores e mesmo intraobservador", com resultados que alcançam apenas 50\% de concordância (Soares, 2012). Existe ainda o cenário em que um diagnóstico preliminar é rapidamente realizado para atender à necessidade médica, mas um teste posterior guia o resultado para uma direção diametralmente oposta (Soares, 2012). Nesse caso, é razoável supor que uma estratégia computacional, treinada em dados gerados por humanos, não seja capaz de superar a qualidade da classificação por eles gerada.

Por outro lado, a utilização de laudos com estrutura textual padronizada, como os preconizados pelo Colégio Americano de Patologistas (CAP), é um fator favorável à qualidade da classificação realizada, haja vista que possibilita a rápida identificação de padrões que explicitem a classe alvo.

Em todo caso, os resultados encontrados reforçam aqueles já existentes na literatura. Embora a comparabilidade entre os trabalhos não seja fácil devido a corpora e classificação alvo distintos, a medida- $F_{1}$ de $75,698 \%$ aqui relatada para distinção entre 18 grupos topográficos e $69,765 \%$ entre 70 categorias topográficas aproxima-se do valor de 71,5\% reportado por Jouhet et al. (2012) para decisão entre 26 classes de topografia. No eixo morfológico, enquanto o presente trabalho obteve medida- $F_{1}$ de $62,923 \%$ para 49 grupos de morfologia, Jouhet et al. (2012) relata 85,4\% para um problema menor, com 18 classes. Ainda, o tamanho da base de estudo aqui utilizada alcança 19578 pacientes para o grupo topográfico, quase quatro vezes superior ao corpus de 5121 documentos utilizados no trabalho de Jouhet et al. (2012). 


\section{Capítulo 5}

\section{Conclusões}

\subsection{Considerações Finais}

A realização do presente trabalho revelou a viabilidade de uso de um classificador bayesiano para a tarefa de classificação de laudos de anatomia patológica na Classificação Internacional de Doenças para Oncologia. Como detalhado no Capítulo 4, foi possível atingir o objetivo geral do projeto (descrito na Seção 1.3.1) ao obter-se automaticamente dados estruturados sobre um paciente com eficiência avaliada pela medida- $F_{2}$ acima de $74 \%$ para o problema de 18 grupos de topografia e de $61 \%$ para o contexto de 49 grupos de morfologia.

A disponibilidade dessas informações de forma automatizada facilita o trabalho das equipes de Registros Hospitalares de Câncer ao reduzir o escopo de busca de conceitos estruturados àqueles priorizados pela ferramenta, de forma a gradualmente substituir a tarefa de classificação pela tarefa de correção. De modo análogo, a possibilidade de obtenção de dados estruturados por meio de uma ferramenta computacional, mesmo que sujeita a incertezas, acelera sua disponibilidade ao reduzir o tempo de uma classificação humana para o tempo necessário para execução do algoritmo.

Dentre os objetivos específicos apresentados na Seção 1.3.2, o limite inferior do algoritmo foi determinado por meio de uma estratégia ingênua na Seção 4.2.1 para os diversos níveis de granularidade propostos. Os valores obtidos em medida- $F_{2}$ de $11,120 \%$ para o grupo topográfico e 11,104\% para o grupo morfológico guiaram com sucesso a realização da pesquisa através da busca e seleção de algoritmos com resultados superiores.

Nas Seções 4.3 e 4.4, um classificador bayesiano foi treinado e sua eficiência basal de $73,855 \%$ para o grupo topográfico e 60,877\% para o grupo morfológico mostrou-se bastante similar às obtidas por técnicas de suavização. A Suavização Good-Turing, por outro lado, apresentou eficiência inferior, com $67,146 \%$ para o grupo de topografias e 45,995\% para o grupo de morfologias, o que pode demonstrar uma não adequação da técnica em textos semiestruturados.

Ainda na Seção 4.3, verificou-se que os dados disponíveis são suficientes em quantidade para o nível de detalhamento exigido, mas que a eficiência é maximizada para os pacientes com número maior de laudos. Melhores resultados foram também encontrados para classes mais significativas no conjunto de entrada, o que reflete a importância da probabilidade a priori, decorrente do desbalanceamento dos dados de treinamento, para o bom desempenho do classificador.

Técnicas de processamento de linguagem natural foram aplicadas na Seção 4.5 e mostraram-se positivas para refinar o espaço de características, embora a adaptação dos modelos para o domínio médico mostre-se necessária para melhores resultados. A eficiência para o eixo topográfico alcançou 
um máximo global de 74,431\% com o uso de stemmer e, para o eixo das morfologias, um máximo local de 61,155\% com o uso de stopwords. Os resultados reforçam a utilização de técnicas simples não somente para redução do tempo de processamento, como também para uma melhor eficiência.

\subsection{Contribuições}

A realização do presente trabalho, além de viabilizar melhorias para a prática hospitalar, trouxe contribuições científicas importantes para a área de estudo.

No âmbito hospitalar e em especial no âmbito do A.C. Camargo Cancer Center, fornecedor dos dados da presente pesquisa, a utilização dos resultados é imediata para a coleta de estatísticas e descoberta de conhecimento. Considerando a simplicidade do modelo adotado, regras diretas podem ser inferidas para a construção de consultas estruturadas. Ainda, por meio da construção de uma interface de programação, a presente ferramenta pode ser incorporada em outros sistemas de recuperação de informação e facilitar a tarefa de integração de bancos de dados.

Os resultados apresentados revelaram não somente novos potenciais de uso, mas também dificuldades encontradas nas bases de dados originais, como a inexistência de informações estruturadas sobre a pertinência ou não de um exame ao diagnóstico principal do paciente.

O trabalho possibilita, além disso, a disponibilização de dados estruturados sobre câncer em um menor período de tempo, o que atende às necessidades de pesquisa clínica e de gestão das instituições de saúde. Por último, a inclusão do software nos processos de Registros Hospitalares de Câncer (RHCs) pode acelerar a codificação de casos e facilitar o trabalho dos profissionais de saúde.

No meio científico, a revisão de literatura realizada revelou que os resultados encontrados são inéditos no domínio médico em português brasileiro, o que possibilita o uso da presente pesquisa como baseline e referência para futuros trabalhos. As conclusões encontradas no cenário brasileiro reforçam aquelas encontradas em trabalhos similares recentes apresentados em outros idiomas. Além disso, o trabalho contribui com os primeiros resultados da utilização de técnicas de processamento de linguagem natural para a classificação de textos médicos em terminologias de domínio.

\subsection{Trabalhos Futuros}

Além de suas contribuições científicas diretas, o presente trabalho revelou também oportunidades para o desenvolvimento de pesquisas futuras. Diante dos resultados e da experiência de trabalho no domínio alcançados, os potenciais científicos podem ser organizados em áreas distintas.

Em trabalhos de cunho epidemiológico, novos estudos devem ser realizados sobre o material utilizado para a pesquisa. A confiabilidade dos dados estruturados disponíveis pode ser avaliada por meio da reanotação por diferentes especialistas e a medida do fator $\kappa(k a p p a)$ de discordância entre eles, que revelará o quanto a concordância entre profissionais supera a chance de concordância ao acaso para diferentes níveis de granularidade de classificação. Esse fator é essencial para a determinação do limite superior de um algoritmo computacional, haja vista que informações externas ao laudo de anatomia patológica podem ter sido utilizadas na classificação dos dados originais.

Ainda, o melhor conhecimento dos laudos de anatomia patológica e dos processos que envolvem a sua redação poderá revelar características que orientem uma melhor seleção dos dados. Devido à 
natureza semiestruturada da informação, técnicas de processamento de linguagem natural podem se fazer necessárias para a detecção automatizada dessas características. Por exemplo, diferentes tipos de laudos podem ser utilizados de formas distintas, bem como seções específicas do documento podem ser mais relevantes do que outras ou mesmo outros documentos do PEP podem ser relevantes para a classificação.

Trabalhos em níveis introdutórios de computação podem ainda explorar o impacto da construção e utilização de modelos de PLN específicos do domínio médico, assim como a simples agregação de dicionários a modelos já existentes.

Por sua vez, trabalhos avançados podem estudar a utilização de outras técnicas, sejam elas conhecidas ou inéditas. Máquinas de suporte vetorial (SVM) para o mecanismo de classificação e métricas $t f . i d f$ ou $t f . i c f$ para a seleção de características revelam-se promissoras em trabalhos relacionados mencionados em revisão bibliográfica (especialmente para classes pouco representativas) e podem ser estudadas em novas pesquisas de mestrado. A deteç̧ão de morfemas (componentes formadores de uma palavra) pode ser interessante em estudos de classificação e recuperação de informação entre idiomas, aplicável em qualquer nível acadêmico. Trabalhos de doutorado podem explorar a modificação de algoritmos existentes para a criação de técnicas inéditas. A avaliação do problema como uma tarefa de mapeamento multiclasse - bastante frequente em literatura, mas fora do escopo do presente trabalho - revelou-se promissora para a correta modelagem dos dados, em especial ao considerar a realização de exames diversos para a deteç̧ão de metástases. Dada a complexidade da análise decorrente e o potencial uso de ontologias de domínio para a completa abordagem do problema, uma pesquisa em nível de doutorado mostra-se adequada também nesse sentido.

Por último, considerando a ausência de dados públicos do domínio disponíveis em português brasileiro, a completa anonimização e disponibilização dos dados utilizados, após aprovação ética das entidades responsáveis, pode acelerar e facilitar o desenvolvimento de novas pesquisas em nível nacional e mundial. 
CONCLUSÕES 


\section{Apêndice A}

\section{Classificação Internacional de Doenças para Oncologia}

Para facilitar a leitura do presente documento, esse apêndice descreve os significados dos códigos utilizados na Classificação Internacional de Doenças para Oncologia (CID-O) em seus eixos topográfico e morfológico e nos menores níveis de granularidade. A lista completa com os 331 conceitos de topografia e 895 conceitos de morfologia pode ser consultada em Percy et al. (2000).

\begin{tabular}{c|l}
\hline Classe & Descrição \\
\hline C00-C14 & Lábio, cavidade oral e faringe \\
C15-C26 & Órgãos digestivos \\
C30-C39 & Aparelho respiratório e órgãos intratorácicos \\
C40-C41 & Ossos, articulações e cartilagens articulares \\
C42 & Sistemas hematopoiético e reticuloendotelial \\
C44 & Pele \\
C47 & Nervos periféricos e sistema nervoso autômato \\
C48 & Retroperitônio e peritônio \\
C49 & Tecido conjuntivo, subcutâneo e outros tecidos moles \\
C50 & Mama \\
C51-C58 & Órgãos genitais femininos \\
C60-C63 & Orgãos genitais masculinos \\
C64-C68 & Trato urinário \\
C69-C72 & Olho, cérebro e outras partes do sistema nervoso central \\
C73-C75 & Tireóide e outras glândulas endócrinas \\
C76 & Outras localizações e localizações mal definidas \\
C77 & Linfonodos \\
C80 & Localização primária desconhecida \\
\hline
\end{tabular}

Tabela A.1: Grupos de topografia na Classificação Internacional de Doenças para Oncologia. 


\begin{tabular}{c|l}
\hline Classe & Descrição \\
\hline 800 & Neoplasias, SOE \\
$801-804$ & Neoplasias epiteliais, SOE \\
$805-808$ & Neoplasias de células escamosas \\
$809-811$ & Neoplasias basocelulares \\
$812-813$ & Papilomas e carcinomas de células transicionais \\
$814-838$ & Adenomas e adenocarcinomas \\
$839-842$ & Neoplasias dos anexos e apêndices cutâneos \\
843 & Neoplasias mucoepidermóides \\
$844-849$ & Neoplasias císticas, mucinosas e serosas \\
$850-854$ & Neoplasias ductais e lobulares \\
855 & Neoplasias de células acinosas \\
$856-857$ & Neoplasias epiteliais complexas \\
858 & Neoplasias epiteliais tímicas \\
$859-867$ & Neoplasias epiteliais, SOE \\
$868-871$ & Paragangliomas e tumores glômicos \\
$872-879$ & Nevos e melanomas \\
880 & Tumores e sarcomas de partes moles, SOE \\
$881-883$ & Neoplasias fibromatosas \\
884 & Neoplasias mixomatosas \\
$885-888$ & Neoplasias lipomatosas \\
$889-892$ & Neoplasias miomatosas \\
$893-899$ & Neoplasias complexas mistas e do estroma \\
$900-903$ & Neoplasias fibroepiteliais \\
904 & Neoplasias sinoviais \\
905 & Neoplasias mesoteliais \\
$906-909$ & Neoplasias de células germinativas \\
910 & Neoplasias trofoblásticas \\
911 & Mesonefromas \\
$912-916$ & Tumores de vasos sanguíneos \\
917 & Tumores de vasos linfáticos \\
$918-924$ & Neoplasias ósseas e condromatosas \\
925 & Tumores de células gigantes \\
926 & Tumores ósseos diversos \\
$927-934$ & Tumores odontogênicos \\
$935-937$ & Tumores diversos \\
$938-948$ & Gliomas \\
$949-952$ & Neoplasias neuroepiteliais \\
953 & Meningiomas \\
$954-957$ & Tumores da bainha nervosa \\
958 & Tumores de células granulares e sarcoma alveolar de partes moles \\
$959-972$ & Linfomas de Hodgkin e não-Hodgkin \\
973 & Tumores de plasmócitos \\
974 & Tumores de mastócitos \\
975 & Neoplasias de histiócitos e células linfóides acessórias \\
976 & Doenças imunoproliferativas \\
$980-994$ & Leucemias \\
$995-996$ & Alterações mielo proliferativas crônicas \\
997 & Outras alteracões hematológicas \\
\hline 99 & Síndromes mielodisplásicas \\
\hline &
\end{tabular}

Tabela A.2: Grupos de morfologia na Classificação Internacional de Doenças para Oncologia. 


\section{Referências Bibliográficas}

Abney (1991) Steven Abney. Parsing by chunks. Principle-based parsing, páginas 257-278. Citado na pág. 17

A.C. Camargo (2012) Hospital A.C. Camargo. Manual de Laudos Padronizados para Uso na Rotina Diagnóstica, 2012. Citado na pág. 22

Alpaydin (2004) Ethem Alpaydin. Introduction to machine learning. The MIT Press. Citado na pág. 9

APACHE (2011) Apache Software Foundation APACHE. OpenNLP. http://opennlp.sourceforge. net, 2011. Último acesso em 23/10/2011. Citado na pág. 14, 27

Aronson (2001) Alan R. Aronson. Effective mapping of biomedical text to the UMLS Metathesaurus: the MetaMap program. Em Proceedings of the AMIA Symposium, página 17. American Medical Informatics Association. Citado na pág. 18, 19

Baeza-Yates e Ribeiro-Neto (2011) Ricardo Baeza-Yates e Berthier Ribeiro-Neto. Modern information retrieval. Addison-Wesley Professional. Citado na pág. 36, 38, 48

Barrett e Weber-Jahnke (2011) Neil Barrett e Jens Weber-Jahnke. A token centric partof-speech tagger for biomedical text. Em Artificial Intelligence in Medicine, páginas 317-326. Springer. Citado na pág. 46

Bayes e Price (1763) Thomas Bayes e Richard Price. An essay towards solving a problem in the doctrine of chances. by the late rev. mr. bayes, frs communicated by mr. price, in a letter to john canton, amfrs. Philosophical Transactions, 53:370. Citado na pág. 10

Bulegon (2011) Hugo Bulegon. Identificação de diagnósticos contidos em narrativas clínicas e mapeamento para a classificação internacional de doenças. Dissertação de Mestrado, Programa de Pós-Graduação em Tecnologia em Saúde, Pontifícia Universidade Católica do Paraná, Brasil. Citado na pág. 19

Chen e Goodman (1996) Stanley F. Chen e Joshua Goodman. An empirical study of smoothing techniques for language modeling. Em Proceedings of the 34th annual meeting on Association for Computational Linguistics, páginas 310-318. Association for Computational Linguistics. Citado na pág. 11,12

CoGrOO (2011) Time de desenvolvimento CoGrOO. CoGrOO: Corretor Gramatical acoplável ao OpenOffice.org. CCSL IME/USP, BrOffice.org, São Paulo, Brasil, 2011. URL http://cogroo. sourceforge.net. Citado na pág. 16, 27

Cuminale (2011) Natalia Cuminale. Hospital dedicado ao câncer mira classe AAA. http://veja. abril.com.br/noticia/saude/hospital-dedicado-ao-cancer-mira-publico-classe-aaa, Abril 2011. Último acesso em $02 / 06 / 2011$. Citado na pág. 1

Duda et al. (2001) Richard O. Duda, Peter E. Hart e David G. Stork. Pattern classification. Wiley, segunda ed. Citado na pág. 9, 10, 25 
Filocomo (2010) Fábio Filocomo. Seleção de atributos para detecção de status tumoral em pacientes do Hospital A.C. Camargo. Relatório técnico, Faculdade de Medicina de Ribeirão Preto, Universidade de São Paulo, Brasil. Citado na pág. 1

Friedman et al. (1994) Carol Friedman, Philip O. Alderson, John H. M. Austin, James J. Cimino e Stephen B. Johnson. A general natural-language text processor for clinical radiology. Journal of the American Medical Informatics Association, 1(2):161. Citado na pág. 18

Friedman et al. (2004) Carol Friedman, Lyudmila Shagina, Yves Lussier e George Hripcsak. Automated encoding of clinical documents based on natural language processing. Journal of the American Medical Informatics Association, 11(5):392. Citado na pág. 18, 19

Hall et al. (2009) Mark Hall, Eibe Frank, Geoffrey Holmes, Bernhard Pfahringer, Peter Reutemann e Ian H. Witten. The weka data mining software: an update. ACM SIGKDD Explorations Newsletter, 11(1):10-18. Citado na pág. 27

Hayes e Weinstein (1990) Philip J. Hayes e Steven P. Weinstein. CONSTRUE/TIS: a system for content-based indexing of a database of news stories. Em Second Annual Conference on Innovative Applications of Artificial Intelligence, volume 97. Citado na pág. 8

Hripcsak et al. (1995) George Hripcsak, Carol Friedman, Philip O. Alderson, William DuMouchel, Stephen B. Johnson e Paul D. Clayton. Unlocking clinical data from narrative reports: a study of natural language processing. Annals of Internal Medicine, 122(9):681. Citado na pág. 18, 19

Hull (1996) David A. Hull. Stemming algorithms: A case study for detailed evaluation. Journal of the American Society for Information Science, 47(1):70-84. Citado na pág. 15

Jacobs e Rau (1990) Paul S. Jacobs e Lisa F. Rau. Scisor: Extracting information from on-line news. Communications of the ACM, 33(11):88-97. Citado na pág. 8

Jouhet et al. (2012) Vianney Jouhet, Georges Defossez, Anita Burgun, Pierre Le Beux, P Levillain, Pierre Ingrand, Vincent Claveau et al. Automated classification of free-text pathology reports for registration of incident cases of cancer. Methods of Information in Medicine, 51(3):242. Citado na pág. 19,48

Kučera e Francis (1967) Henry Kučera e Winthrop Nelson Francis. Computational analysis of present-day American English. Dartmouth Publishing Group. Citado na pág. 13

Manning e Schütze (1999) Christopher D. Manning e Hinrich Schütze. Foundations of Statistical Natural Language Processing. The MIT Press, primeira ed. Citado na pág. 11, 13, 14, 15, 16, 24, 27

Manning et al. (2008) Christopher D. Manning, Prabhakar Raghavan e Hinrich Schütze. An Introduction to Information Retrieval. Cambridge University Press. Citado na pág. 8, 9, 10, 11, 12, $13,15,16,25,26$

Maron e Kuhns (1960) Melvin Earl Maron e John Lary Kuhns. On relevance, probabilistic indexing and information retrieval. Journal of the ACM (JACM), 7(3):216-244. Citado na pág. 10

Oleynik et al. (2010) Michel Oleynik, Percy Nohama, Pindaro Secco Cancian e Stefan Schulz. Performance analysis of a POS Tagger applied to discharge summaries in Portuguese. Studies in Health Technology and Informatics, 160:959-963. Citado na pág. 14, 19, 48

Pacheco (2009) Edson José Pacheco. MorphoMap: Mapeamento automático de narrativas clínicas para uma terminologia médica. Tese de Doutorado, Programa de Pós-Graduação em Engenharia Elétrica e Informática Industrial, Universidade Tecnológica Federal do Paraná, Brasil. Citado na pág. 2,19 
Palmer e Hearst (1994) David D. Palmer e Marti A. Hearst. Adaptive sentence boundary disambiguation. Em Proceedings of the fourth conference on Applied natural language processing, páginas 78-83. Association for Computational Linguistics. Citado na pág. 14

Palmer e Hearst (1997) David D. Palmer e Marti A. Hearst. Adaptive multilingual sentence boundary disambiguation. Computational Linguistics, 23(2):241-267. Citado na pág. 14

Pearl (1985) Judea Pearl. Bayesian Networks: A Model of Self-Activated: Memory for Evidential Reasoning. Computer Science Department, University of California. Citado na pág. 10

Percy et al. (2000) Constance Percy, Valerie Van Holten e Calum Munir, editors. Classificação Internacional de Doenças para Oncologia. Edusp, terceira ed. Citado na pág. xi, 1, 5, 6, 7, 53

Porter (1980) Martin F. Porter. An algorithm for suffix stripping. Program: electronic library and information systems, 14(3):130-137. Citado na pág. xiii, 16, 27

Porter (2011) Martin F. Porter. Snowball. http://snowball.tartarus.org, 2011. Último acesso em 23/10/2011. Citado na pág. 16

Reynar e Ratnaparkhi (1997) Jeffrey C. Reynar e Adwait Ratnaparkhi. A maximum entropy approach to identifying sentence boundaries. Em Proceedings of the fifth conference on Applied natural language processing, páginas 16-19. Association for Computational Linguistics. Citado na pág. 14

Riley (1989) Michael D. Riley. Some applications of tree-based modelling to speech and language. Em Proceedings of the workshop on Speech and Natural Language, páginas 339-352. Association for Computational Linguistics. Citado na pág. 14

Russell e Norvig (2010) Stuart J. Russell e Peter Norvig. Artificial intelligence: a modern approach. Prentice hall. Citado na pág. 9

Salton (1989) Gerard M. Salton. Automatic text processing: the transformation. Citado na pág. 15

Sardinha (2004) Tony Berber Sardinha. Lingüistica de corpus. Manole. Citado na pág. xiii, 16, 17, 42,43

Shortliffe e Cimino (2006) Edward H. Shortliffe e James J. Cimino. Biomedical Informatics. Springer, terceira ed. Citado na pág. 5, 14

Silva (2013) William Daniel Colen de Moura Silva. Aprimorando o corretor gramatical cogroo. Dissertação de Mestrado, Instituto de Matemática e Estatística, Universidade de São Paulo, Brasil. Citado na pág. 17, 19

Soares (2012) Fernando Soares. Patologia cirúrgica: a tentativa de se aproximar da perfeição. Oncoß̉ - Oncologia para todas as especialidades, (11):20-23. Citado na pág. 48

Sobin e Wittekind (2004) Leslie H. Sobin e Christian Wittekind, editors. TNM: Classificação de tumores malignos. Instituto Nacional do Câncer - INCA, sexta ed. Citado na pág. 1, 21

Veras e Martins (1994) Claudia Maria T. Veras e Mônica S. Martins. A confiabilidade dos dados nos formulários de Autorização de Internação Hospitalar (AIH), Rio de Janeiro, Brasil. Cadernos de Saúde Pública, 10(3):339-355. Citado na pág. 2

Wazlawick (2008) Raul Sidnei Wazlawick. Metodologia de pesquisa para ciência da computação. Elsevier. Citado na pág. 26

WHO (2004) World Health Organization WHO, editor. International statistical classification of diseases and related health problems: tenth revision. World Health Organization - WHO, second ed. Citado na pág. 5,6 
Wilcox e Hripcsak (2003) Adam B. Wilcox e George Hripcsak. The role of domain knowledge in automating medical text report classification. Journal of the American Medical Informatics Association, 10(4):330-338. Citado na pág. 18

Wilcox e Hripcsak (1999) Adam B. Wilcox e George Hripcsak. Classification algorithms applied to narrative reports. Em Proceedings of the AMIA Symposium, página 455. American Medical Informatics Association. Citado na pág. 18 


\section{Índice Remissivo}

acurácia, 23

add-one, 11

aprendizagem automática

Good-Turing, 11

não-supervisionada, 9

Laplace, 11

supervisionada, 9

topografia, 6

Classificação Internacional de Doenças, 5

Classificação Internacional de Doenças para Oncologia, 6

classificadores

baseado em regras, 8

bayesiano, 10

cobertura, 23

cross-validation, 25

detecção de sentenças, 14

Digital Clinics, 1

haplologia, 13

itemização, 13

Lei de Zipf, 12

lemmatizer, 15

macro-averaging, 26

medida-F, 25

MedLEE, 18

MetaMap, 17

micro-averaging, 26

morfologia, 6

MorphoMap, 18

Porter Stemmer, 16

precisão, 23

processamento de linguagem natural, 13

Registro Hospitalar de Câncer, 1

sacola de segmentos, 17

segmentador, 17

Sistema Integrado de Gestão Hospitalar, 1

stemmer, 15

stopwords, 16

suavização

add-alpha, 11 